\title{
Effects of schedule segmentation on pausing and escape in the transitions between favorable and unfavorable schedules of reinforcement
}

Tammy R. Wade

West Virginia University

Follow this and additional works at: https://researchrepository.wvu.edu/etd

\section{Recommended Citation \\ Wade, Tammy R., "Effects of schedule segmentation on pausing and escape in the transitions between favorable and unfavorable schedules of reinforcement" (2004). Graduate Theses, Dissertations, and Problem Reports. 2093.}

https://researchrepository.wvu.edu/etd/2093

This Dissertation is protected by copyright and/or related rights. It has been brought to you by the The Research Repository @ WVU with permission from the rights-holder(s). You are free to use this Dissertation in any way that is permitted by the copyright and related rights legislation that applies to your use. For other uses you must obtain permission from the rights-holder(s) directly, unless additional rights are indicated by a Creative Commons license in the record and/ or on the work itself. This Dissertation has been accepted for inclusion in WVU Graduate Theses, Dissertations, and Problem Reports collection by an authorized administrator of The Research Repository @ WVU.

For more information, please contact researchrepository@mail.wvu.edu. 
Effects of Schedule Segmentation on Pausing and Escape in the Transitions between Favorable and Unfavorable Schedules of Reinforcement

\author{
Tammy R. Wade
}

\author{
Dissertation submitted to the \\ Eberly College of Arts and Sciences \\ at West Virginia University \\ in partial fulfillment of the requirements \\ for the degree of \\ Doctor of Philosophy \\ in \\ Psychology
}

Michael Perone, Ph.D., Chair

Philip Chase, Ph.D.

Christy Foran, Ph.D.

B. Kent Parker, Ph.D.

Matthew Scullin, Ph.D.

Department of Psychology

Morgantown, West Virginia

2004

Keywords: chained schedule, escape, fixed-interval schedule, fixed-ratio schedule, multiple schedule, pause, pigeon 


\begin{abstract}
Effects of Schedule Segmentation on Pausing and Escape in the Transitions between Favorable and Unfavorable Schedules of Reinforcement
\end{abstract}

Tammy R. Wade

Simple schedules of reinforcement typically are preferred to chained schedules of equal duration. In the current study, pigeons served in six experiments designed to test whether the juxtaposition of simple and chained schedules would engender the disruption in behavior typically observed in the transition from favorable to unfavorable conditions of reinforcement. In one set of experiments, a multiple schedule was employed in which a simple schedule alternated irregularly with a chained schedule. Whether fixed-ratio or fixed-interval schedules were employed, only half the subjects paused for an extended duration in the simple-to-chain transition, and this occurred only when the first segment of the chained schedule was short. When the option to turn off the stimuli correlated with the schedule in effect (escape) was available at the start of each component, escape occurred infrequently and inconsistently across pigeons. In another set of experiments, a (rich) schedule ending in a large reinforcer was juxtaposed with a (lean) schedule ending in a small reinforcer. In addition, either the rich or lean schedule was segmented across conditions. Inconsistent results were obtained when fixed-ratio schedules were employed; however, when fixed-interval schedules were employed, pausing was extended in the rich-to-lean transition and this effect was attenuated by segmenting the rich schedule and enhanced by segmenting the lean schedule. When the option to escape was available, escape was more frequent (or constituted a larger percentage of the session) in the rich-to-lean transition when simple schedules operated. Segmenting the lean schedule had inconsistent effects on escape. The fact that the predicted results were obtained only when fixedinterval schedules differed in reinforcer magnitude and schedule segmentation is attributed to two factors. First, perhaps it was only in this experiment that the difference in favorability across schedules was sufficient to produce noticeable disruptions in behavior. Second, response patterns suggest that the pigeons failed to respond differentially across the simple and chained fixed-ratio schedules. The results of the present study together with previous findings suggest the potential for basic research to contribute to the identification and manipulation of variables that control problem behavior in institutional settings and in everyday situations. 


\section{Acknowledgments}

First and foremost I would like to thank Michael Perone, my advisor and chair of my dissertation committee, for being the greatest teacher and mentor a student could have. I am very lucky that it was his lab I chose to work in so many years ago. I will never forget the lessons, regarding $\mathrm{EAB}$ or life in general, that I have learned from him.

In addition to Michael Perone, I would like to thank Philip Chase, Christy Foran, Kent Parker, and Matthew Scullin, for serving on my dissertation committee. I truly appreciate the helpful and thought-provoking comments that I received from all of you.

I would like to thank my family for their support throughout my graduate career. Specifically, I thank my sister Michelle for sitting with my dogs when my days were long. I also would like to thank Chad Galuska for his patience and unwavering faith in me during the ups and downs of graduate school. He continues to inspire me on a daily basis and I look forward to our future together.

Finally, there are a few people that I would like to thank for a variety of reasons. I would like to thank Oliver Wirth for allowing me to work with him at the National Institute of Occupational Safety and Health throughout the previous academic year; this was an invaluable experience that I hope will prepare me for working in a multidisciplinary environment. I also thank Harold Lobo for helping me conduct daily sessions for my dissertation, as well as the rest of the current Perone-lab members, Jeff Everly and Jessica Long, for making me feel indispensable! Finally, I would like to thank Leo Carlin, the creator of all of the programs that I modified in running my dissertation. I also would like to thank him for being a critical reason for why I chose to become a behavior analyst. 


\section{Table of Contents}

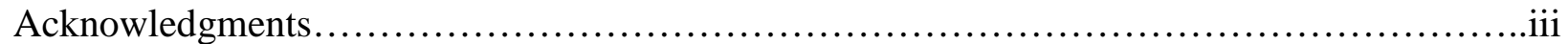

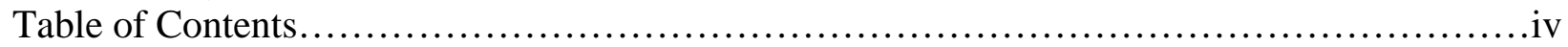

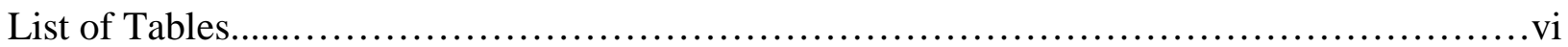

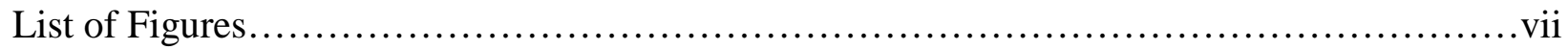

General Introduction.................................................................

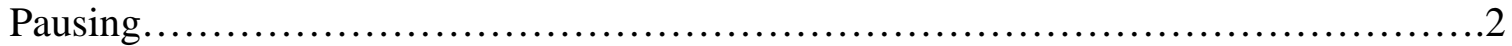

Segmentation...................................................................... 5

Statement of the Problem......................................................8

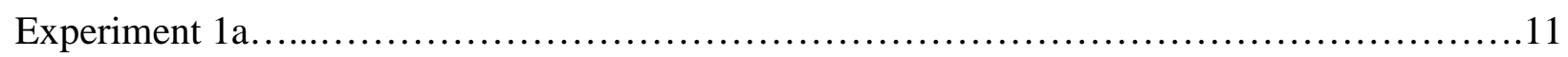

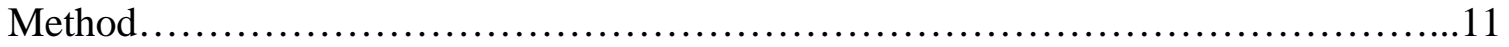

Subjects....................................................................... 11

Apparatus......................................................................

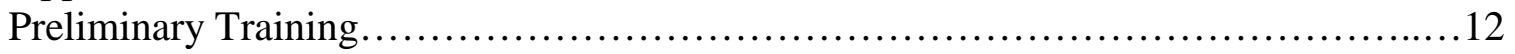

Experimental Conditions.......................................................13

Results and Discussion..........................................................

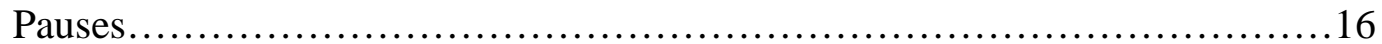

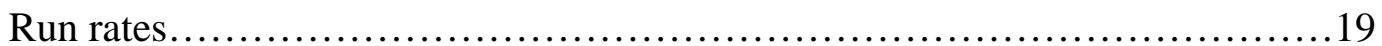

Experiment 1b..................................................................23

Method....................................................................24

Subjects and Apparatus.......................................................... 24

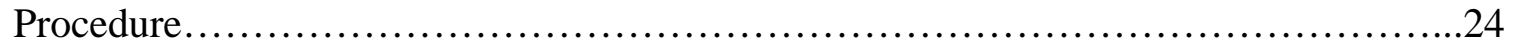

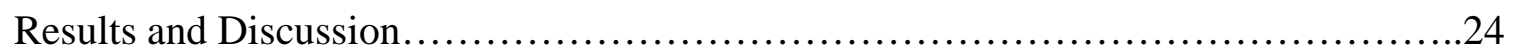

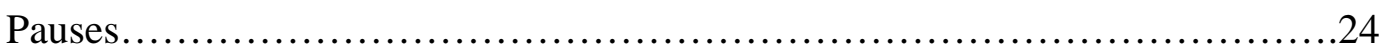

Response rates....................................................27

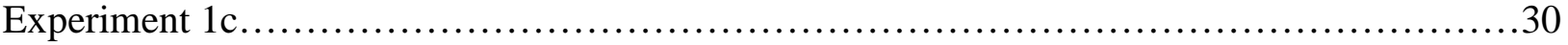

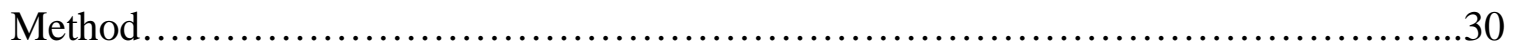

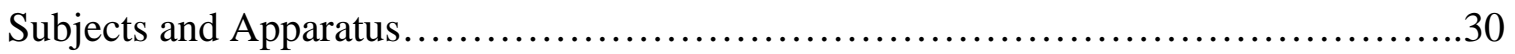

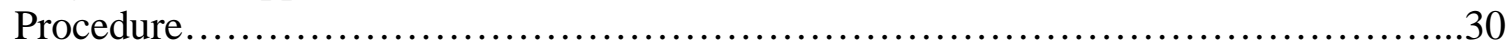

Results and Discussion..................................................... 31

Escape............................................................... 31

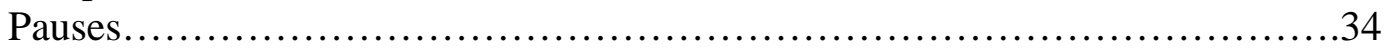

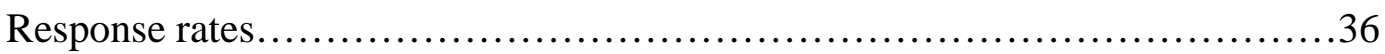

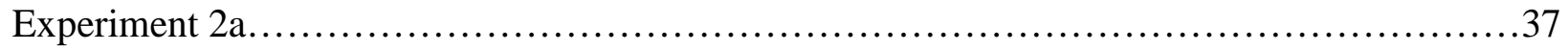

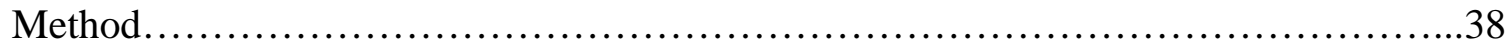

Subjects and Apparatus.........................................................

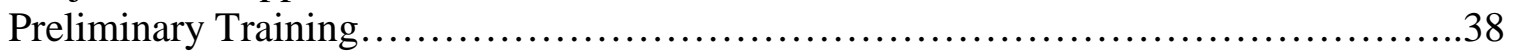

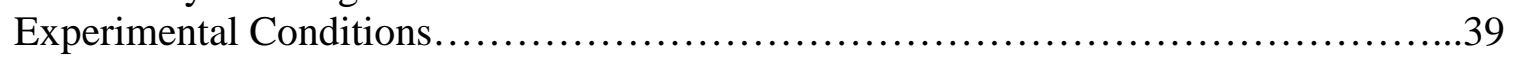

Results and Discussion....................................................... 41

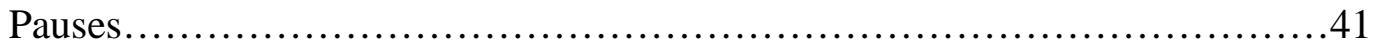

Run rates............................................................ 44

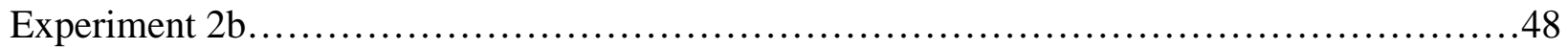

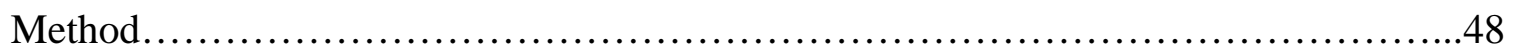

Subjects and Apparatus......................................................48

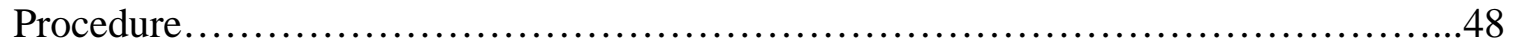

Results and Discussion........................................................ 49 
Table of Contents Continued

Pauses.................................................................... 50

Response rates...................................................... 52

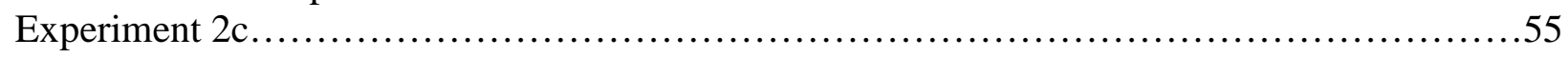

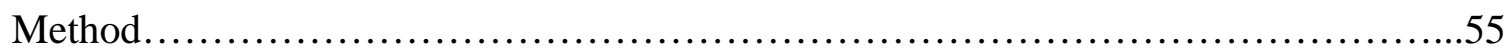

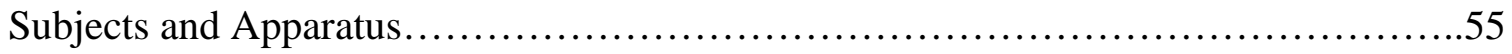

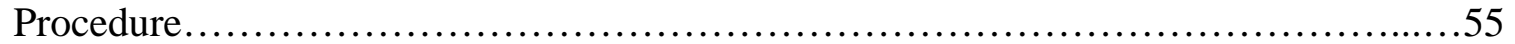

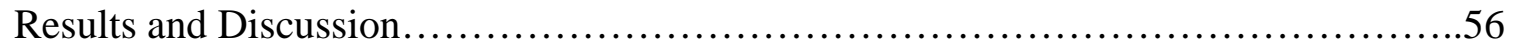

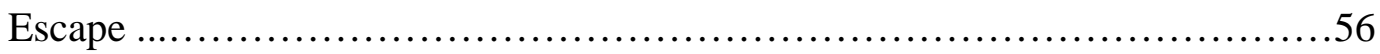

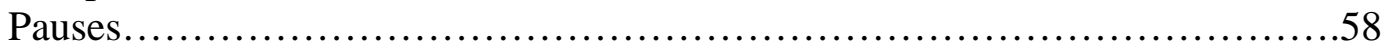

Response rates....................................................60

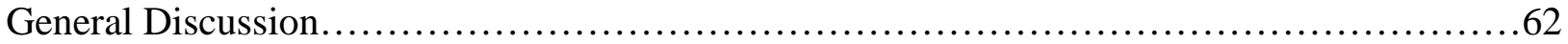

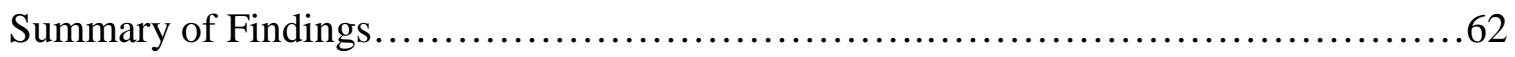

Relative Favorability of the Components........................................64

FR versus FI Schedules......................................................65

Escape..................................................................67

Applied Significance.........................................................68

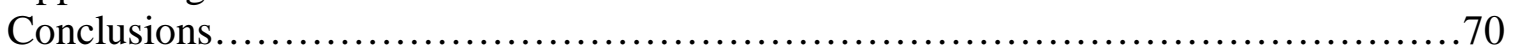

References.................................................................... 72 


\section{List of Tables}

Table 1. Keycolors used in Experiments 1a, 1b, and 1c................................13

Table 2. Order and number of sessions conducted in the conditions of Experiments $1 \mathrm{a}, 1 \mathrm{~b}$, and

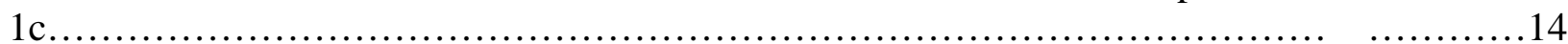

Table 3. Second-segment pauses in Experiment 1a........................................19

Table 4. First-segment run rates in Experiment 1a.......................................21

Table 5. Second-segment run rates in Experiment 1a.....................................22

Table 6. Second-segment pauses in Experiment 1b.........................................26

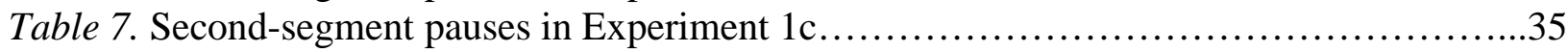

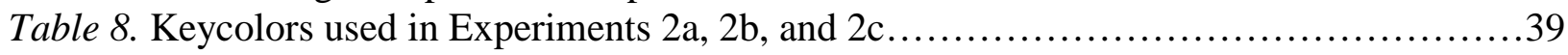

Table 9. Order and number of sessions conducted in the conditions of Experiments 2a, $2 \mathrm{~b}$, and

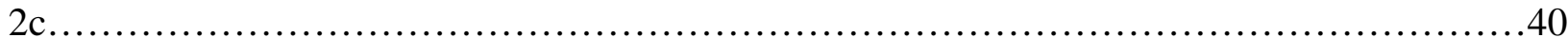

Table 10. Second-segment pauses in Experiment 2a......................................43

Table 11. First-segment run rates in Experiment 2a........................................46

Table 12. Second-segment run rates in Experiment 2a...................................47

Table 13. Pauses in Experiment 2b expressed as the percentage of the total pause time..........51

Table 14. Second-segment pauses in Experiment 2b...................................52

Table 15. Second-segment pauses in Experiment 1c.....................................60 


\section{List of Figures}

Figure 1. Pauses in the transitions between simple and chained schedules in Experiment 1a.....17

Figure 2. Run rate in the transitions between simple and chained schedules in Experiment 1a...20

Figure 3. Pauses in the transitions between simple and chained schedules in Experiment 1b.....25

Figure 4. Response rate across tenths of the interval in Experiment 1b......................28

Figure 5. Frequency of escape in the transitions between simple and chained schedules in

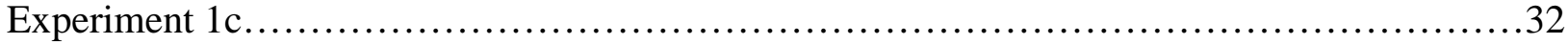

Figure 6. Percent of the session in timeout in the transitions between simple and chained schedules in Experiment 1c.......................................................33

Figure 7. Pauses in the transitions between simple and chained schedules in Experiment 1c.....34

Figure 8. Response rate across tenths of the interval in Experiment 1c......................36

Figure 9. Pauses in the transitions between rich and lean schedules in Experiment 2a..........41

Figure 10. Run rate in the transitions between rich and lean schedules in Experiment 2a........44

Figure 11. Pauses in the transitions between rich and lean schedules in Experiment 2b.........49

Figure 12. Response rate across tenths of the interval in Experiment $2 b \ldots \ldots \ldots \ldots \ldots \ldots \ldots \ldots . . . .53$

Figure 13. Frequency of escape in the transitions between rich and lean schedules in Experiment

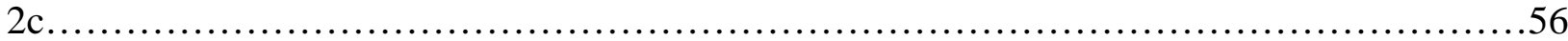

Figure 14. Percent of the session in timeout in the transitions between simple and chained schedules in Experiment 2c......................................................58

Figure 15. Pauses in the transitions between rich and lean schedules in Experiment 2c..........59

Figure 16. Response rate across tenths of the interval in Experiment 2c.....................61 


\section{General Introduction}

Schedules of positive reinforcement are characterized by an absence of responding immediately following the delivery of a reinforcer and extending beyond the time necessary to consume the reinforcer. These pauses in responding are more pronounced on schedules in which reinforcement is delivered following a fixed number of responses (fixed-ratio, or FR, schedules) or following a response that occurs after a fixed amount of time has elapsed (fixed-interval, or FI, schedules) (Ferster \& Skinner, 1957).

Recent research has investigated the effects of the context in which pausing occurs. This context includes both past conditions of reinforcement (prior to pausing) and upcoming conditions (before pausing gives way to responding). Experiments have manipulated schedule parameters such as the magnitude of the reinforcer and the ratio or interval size. This work has shown that pausing is a function of both past and upcoming conditions (when upcoming conditions are signaled), and that a large increase in the duration of pausing occurs when the subject is in a transition from favorable conditions (e.g., a large reinforcer magnitude) to unfavorable conditions (e.g., a small reinforcer magnitude) (Bejarano, Williams, \& Perone, 2003; Carlin, 1998; Courtney, 1994; Perone \& Courtney, 1992; Wade-Galuska, Perone, \& Wirth, 2004). Research also has shown that, in addition to pausing for extended periods of time, subjects will escape from this transition when given the opportunity to do so (Carlin, 1998; Courtney, 1994; Perone, 2003).

The present study was designed to investigate the behavioral effects of transitions from favorable to unfavorable conditions, with favorability operationalized in terms of schedule segmentation. In the first experiment, schedules that are segmented alternated with unsegmented, or simple, schedules. A segmented, or chained, schedule consists of two or more schedules (i.e., segments) that are linked in succession by some exteroceptive stimulus change (Lattal, 1991). On such a schedule, completing the response requirement in the first segment produces the second segment and its correlated stimulus; completing the requirement in the second segment produces reinforcement. For example, in the case of a chained FR 50 FR 50 schedule, completion of the first 50 responses would result in a stimulus change accompanying the initiation of the second segment of the schedule. Completion of the 50 responses required by the second segment would result in reinforcement. A comparable simple FR schedule (in which the 
total response requirement is held constant) would be an FR 100 schedule; on this schedule, the emission of 100 responses would result in reinforcement.

Research has shown that when given a choice between simple and chained schedules (for which the time before a response can be reinforced is held constant across both types), preference for the simple schedule is reliably observed (Duncan \& Fantino, 1972; Fantino, 1969b; Fantino, 1983; Leung, 1989, 1993). Therefore, the simple and chained schedules constitute relatively favorable and unfavorable conditions, respectively, that can be juxtaposed to study transitions between conditions of reinforcement.

The following sections review research on the various contexts in which pausing has been investigated, as well as research that has examined choice between simple versus chained schedules of positive reinforcement. The final section discusses the methods used in the current study to assess pausing and escape in the transitions between chained and simple schedules as well as the combined effects of segmentation and reinforcer magnitude on these same measures. By doing so, the ways in which more complex contexts differentially affect behavior in transitions between favorable and unfavorable circumstances were examined.

Pausing

In an earlier investigation of the effects of context on pausing, Perone and Courtney (1992) separated the effects of past and upcoming conditions of reinforcement. Pigeons pecked a response key that occasionally resulted in the delivery of either a small or a large reinforcer (different durations of access to mixed grain). Food was delivered according to an FR schedule. In one phase mixed-schedule conditions operated in which the key color remained the same regardless of the magnitude of the reinforcer that was programmed to follow completion of the ratio. The behavior of the pigeon could be affected by the magnitude of the reinforcer previously delivered (i.e., past conditions), but not by the upcoming reinforcer magnitude. In another phase, a multiple schedule operated in which the response key was lit one color when the ratio was going to end in a small reinforcer and another color when the ratio was going to end in a large reinforcer. In this case, the pigeon's behavior could be affected not only by the magnitude of the past reinforcer, but also by the magnitude of the upcoming reinforcer.

Perone and Courtney's (1992) procedure allowed examination of pauses in four transitions: (a) a ratio ending in a small reinforcer followed by another ratio ending in a small reinforcer (unfavorable-unfavorable), (b) a ratio ending in a small reinforcer followed by a ratio 
ending in a large reinforcer (unfavorable-favorable), (c) a ratio ending in a large reinforcer followed by a ratio ending in a small reinforcer (favorable-unfavorable), and (d) a ratio ending in a large reinforcer followed by another ratio ending in a large reinforcer (favorable-favorable).

On the mixed schedule, pausing was directly related to past conditions: Pauses were longer after a large reinforcer than after a small one. The upcoming reinforcer magnitude had no effect. On the multiple schedule in which discriminative stimuli were correlated with the magnitude of the upcoming reinforcer, pausing was a joint function of past and upcoming conditions. The magnitude of the past reinforcer had little effect on the duration of pausing when the stimulus signaled that the upcoming reinforcer was large. Under these circumstances, pauses were short. However, the magnitude of the past reinforcer did affect pausing when the stimulus signaled that the next reinforcer was small, with extended pausing when the past reinforcer had been large.

Baron, Mikorski, and Schlund (1992, Experiment 2) examined the relation between reinforcer magnitude and pausing on progressive-ratio (PR) schedules. On a PR schedule each reinforcer is followed by an increase in the number of responses required to complete the next ratio. For instance, if a PR schedule has a step size of 2 responses (i.e., a PR-2 schedule), the first ratio would require 2 responses, the next ratio would require 4 responses, the next 6 , and so on, until the ratio becomes so large that the subject ceases to respond. In a procedure modeled after that used by Perone and Courtney (1992), rats pressed a response lever that resulted in the availability of a 30\% milk concentration according to a PR-2 schedule. Sometimes the completion of a ratio would end in 1 delivery of milk (i.e., a small reinforcer) and sometimes in 3 consecutive deliveries (i.e., a large reinforcer). As in Perone and Courtney's study, pauses were examined in mixed-schedule conditions (i.e., stimulus conditions were constant regardless of the magnitude of the upcoming reinforcer) and in multiple-schedule conditions (i.e., constant and blinking cue lights were correlated with the magnitude of the upcoming reinforcer).

Under mixed-schedule conditions, pausing increased as the size of the ratio increased and pause durations were longer after a large reinforcer than after a small one. In multiple-schedule conditions, when a stimulus signaled that the upcoming reinforcer was small, the duration of pausing was affected by the magnitude of the past reinforcer. Under these circumstances, pauses were longer when the past reinforcer was large. When a stimulus signaled that the upcoming reinforcer was large, pauses were short regardless of the magnitude of the past reinforcer. These 
results are consistent with the observations of Perone and Courtney (1992); pausing was affected by both past and upcoming conditions. In addition, pauses increased in the context of both the continuously increasing ratio requirements of the PR schedule, and in the transition from favorable to unfavorable reinforcer magnitudes.

Courtney (1994) extended the previous findings on reinforcer magnitude to FI schedules of reinforcement in which a response is reinforced after a fixed amount of time has elapsed. In addition, Courtney studied reinforcement rate by manipulating the duration of the interval in the FI schedules and the response requirement of FR schedules. Regardless of the type of schedule (ratio or interval) and the manipulated schedule parameters (magnitude or rate), pausing was a joint function of both past and upcoming conditions when upcoming conditions were signaled. Past conditions of reinforcement had little effect on the duration of pausing when the stimulus signaled that upcoming conditions of reinforcement were favorable (pauses were short regardless of past conditions). However, past conditions of reinforcement did affect pausing when the stimulus signaled that the next reinforcer was unfavorable; pauses were longer when the past reinforcer had been favorable.

Baron and Herpolsheimer (1999) recently replicated a portion of Courtney’s (1994) work. Rats were exposed to multiple FR schedules in which the size of the ratio was either small or large (i.e., reinforcement rate was either high or low). While the smaller ratio was held constant, the size of the larger ratio increased across conditions. The results showed that as the size of the ratio increased, overall pause durations increased. This is consistent with the results obtained by Baron, Mikorski, and Schlund (1992) with PR schedules. As with the results of previous studies, pauses were not affected by past conditions when a stimulus signaled that the upcoming reinforcement rate was high, or favorable. When a stimulus signaled that the upcoming reinforcement rate was low, or unfavorable, pausing was extended, especially when the past reinforcement rate was favorable.

Most recently, Wade-Galuska, Perone, and Wirth (2004) manipulated the effort required for a rat to press a lever to complete an FR schedule. The force was either high (an unfavorable requirement) or low (a favorable requirement). Again, the results were consistent with the previously cited research; rats paused for extended periods of time in the transition from the favorable force requirement to the unfavorable force requirement relative to the other transitions. In a couple of cases, this effect intensified as the high-force requirement was increased. 
Research on pausing consistently has shown that pauses on FR and FI schedules of positive reinforcement are affected by the interaction of both past and upcoming conditions of reinforcement. Pauses were longest in the transition from favorable to unfavorable conditions, regardless of whether favorability was operationalized in terms of the magnitude of the food reinforcer, FR size, FI duration, or response effort. These extended pauses are of interest because they are counterproductive; that is, an absence of responding for extended periods of time results in an increase in the delay to reinforcement, as well as a decrease in the overall rate of reinforcement.

The results of research on the contextual variables that affect pausing have been interpreted as showing that in some contexts, responding on schedules of positive reinforcement can be aversive. Parallels have been noted between patterns of pausing across the various transitions (e.g., favorable to favorable, favorable to unfavorable, etc.) and the tendency to escape from the transition. Some studies have arranged an explicit escape response; by emitting this response, all stimuli correlated with the schedule are turned off for some period of time. When such an opportunity is provided, more escape responses are made during the transition from favorable to unfavorable conditions during which pauses typically are longest (Carlin, 1998; Courtney, 1994; Perone, 2003). Therefore, it has been suggested that pausing is itself a form of escape from prevailing schedule conditions. Cohen and Campagnoni (1989) observed that during the postreinforcement period of FI schedules (with values ranging from $30 \mathrm{~s}$ to 390 s), pigeons remained in the back of the chamber (facing away from the reinforcer dispenser) for a period of time proportional to the time between reinforcers. In one experiment, a time-out (characterized by explicit stimulus changes) was produced when the pigeon retreated to the rear of the chamber. In instances when such a time-out could be produced, pigeons spent more time in the back of the chamber. In another experiment, a keypeck produced a time-out (during which the food key was inoperative). Keypecks, like retreat, were more frequent as the duration of time between reinforcers increased (i.e., as the FI value increased). The authors concluded that retreat to the rear of the chamber during the postreinforcement period was functionally similar to timeout, or escape, produced by keypecks.

\section{Segmentation}

When given the opportunity to choose between a simple schedule and a chained schedule that is equal in duration, nonhumans and humans consistently have preferred the simple schedule 
(Duncan \& Fantino, 1972; Fantino, 1983; Leung, 1989, 1993). Likewise, when given the opportunity to choose between two chained schedules of equal duration, but differing in the number of segments, the schedule with the fewer segments has been preferred, albeit to a lesser degree than a chained schedule with only two segments (Duncan \& Fantino, 1972; Leung, 1987).

Duncan and Fantino (1972) studied choice with pigeons on a concurrent-chains procedure. This procedure arranges two chained schedules that operate simultaneously (i.e., concurrently). During the first segment of the chained schedules (the initial link), two response keys are available. Completion of the designated response requirement on one of these keys leads to the second segment of the schedule (the terminal link). Completing the terminal link schedule leads to reinforcement. The relative distribution of responses across the two keys in the initial link serves as an index of the reinforcing efficacy of the two terminal-link schedules. Based on this measure, it would be concluded that a particular terminal link was preferred if the proportion of initial-link responses was greater on the key granting access to that terminal link. In Duncan and Fantino’s experiment, an independent variable-interval (VI) schedule operated on each of two keys (the initial link). After an average of $60 \mathrm{~s}$, the first peck on either key resulted in access to a terminal link. When access to the left terminal link was provided (i.e., following completion of the VI schedule on the left key), pecks were reinforced according to an FI schedule. When access to the right terminal link was provided (i.e., following completion of the VI schedule on the right key), pecks were reinforced according to a chained FI FI schedule. The total duration of the chained schedule in the right terminal link was equal to that of the simple FI schedule in the left terminal link. The relative distribution of pecks across the two keys in the initial link revealed that the pigeons preferred the simple FI schedule. In a second experiment, the left terminal link consisted of a two-component chained schedule and the right terminal link consisted of a three-component chained schedule. Under these circumstances, pigeons preferred the two-component schedule. In both experiments, preference became more extreme when the total terminal link (i.e., schedule) duration was increased.

The results of Duncan and Fantino’s (1972) study have been replicated with humans (Leung, 1989, 1993) and monkeys (Takahashi, 1993) as subjects, with schedules that require a variable number of responses or a variable amount of time before a response can be reinforced (Leung \& Winton, 1985; Schneider, 1972), and with schedules that do not require responding for 
reinforcement (on these response-independent schedules, stimuli that normally function as reinforcers, such as food, are delivered after designated periods of time; Leung \& Winton, 1986).

Segmentation of a schedule of positive reinforcement has been referred to as increasing the "psychological distance to reward” (Fantino, 1969b). The notion of psychological distance implies that the segmentation of a schedule causes that schedule to function as if it were longer than the unsegmented schedule, even though both are equal in duration. In studies of choice, preference typically is observed for a schedule in which the time to reinforcement is short relative to the time to reinforcement in an alternative schedule (Fantino, 1969a; Belke, Pierce, \& Powell, 1989; Mazur, 2000). If segmentation increases the psychological distance to reward, the unsegmented schedule should be preferred because the reinforcer it arranges would function as if it were more proximate to the choice response.

More specific explanations for the effect of schedule segmentation include those based on conditioned reinforcement in the simple schedule, a discriminable period of nonreinforcement in the first segment of the chained schedule, and an additional work requirement in the first segment of the chained schedule. Duncan and Fantino (1972) discussed the possibility that conditioned reinforcement is responsible for preference for the unsegmented schedule. That is, the stimulus associated with the FI schedule is directly paired with food at the end of the interval. Therefore, this stimulus acquires conditioned reinforcing properties and is preferred over the chained schedule, in which the stimulus associated with the first segment of the schedule is further removed from food. This also is supported by the results of a study conducted by Leung and Winton (1988) which concluded that the closer the stimulus change in a chained schedule was to the reinforcer (i.e., the shorter the second segment was), the less a comparable simple schedule was preferred. In this case, because the stimulus change occurred closer to the reinforcer, the stimulus correlated with the first segment signaled a reduction in the subsequent delay to reinforcement, and also was less removed from food than when the change occurred earlier in the schedule.

Another possible explanation involves the aversiveness of the discriminable period of nonreinforcement during the first segment of the chained schedule. Leung (1994) exposed pigeons to a chained fixed-time fixed-time (chain FT FT) schedule of food reinforcement. According to this schedule, one food delivery was arranged independently of responding after the second of two fixed periods (each associated with a distinct stimulus) had elapsed. Pecks to a 
response key produced a blackout, during which the stimuli associated with the reinforcement schedule were turned off. Pigeons escaped (i.e., produced a blackout) from the first segment of the chained schedule. Furthermore, escape responses increased as the total duration of the chained schedule increased.

Preference for the simple schedule, or for the chained schedule with fewer components, may be due to the response requirement during the first segment when reinforcement is unavailable (Moore \& Fantino, 1975). Moore and Fantino (1975) used a concurrent-chains procedure to assess preference for a tandem FT FT schedule versus a tandem FR FI schedule. In a tandem schedule, the same exteroceptive stimulus is associated with each segment of the schedule. The authors were interested in determining if a preference for the tandem FT FT schedule would develop as a result of the requirement to respond during a period of nonreinforcement (i.e., during the FR segment of the chained FR FI schedule). [Previous studies (e.g., Neuringer, 1969) showed that pigeons were indifferent between FI and FT schedules with equal reinforcement rates.] Under these circumstances, pigeons preferred the tandem FT FT schedule. In addition, when the tandem schedules were replaced with chained schedules (all else remaining equal), the same preferences were obtained. These results suggest that the work requirement in the first segment of a chained schedule may play a role in pigeons' preference for the unsegmented schedule.

The results of other studies (Fantino, 1983; Leung \& Winton, 1985) suggest that the additional work requirement does not play a significant role in the effect of schedule segmentation. For instance, Fantino (1983) found that pigeons were indifferent between an FI schedule and a tandem FI FI schedule of equal duration, but preferred an FI schedule to a chained FI FI schedule. Again, a tandem schedule operates like a chained schedule, but no stimulus change occurs upon entry into the second segment of the schedule. Therefore, while both the tandem and chained schedules required additional work relative to the FI schedule, only the chained schedule required this work during a discriminable period of nonreinforcement. These results suggest that the stimulus change in a chained schedule, and not additional work, is responsible for the development of preference for the unsegmented schedule.

\section{Statement of the Problem}

The present research is directed toward extending the generality of the finding that transitions from favorable to unfavorable conditions of reinforcement are aversive. This 
aversiveness can be demonstrated by the extent to which animals will pause or escape (as well as engage in other types of emotional or disruptive behavior) during this type of transition.

The goal of Experiment 1a was two-fold. First it attempted to extend these general findings by examining pausing and escape in shifts between chained and simple FR schedules of reinforcement, both of which required the same total amount of work. Second, it attempted to further elucidate the variables that produce such profound disruptions in behavior as a result of their juxtaposition. Previous research supports the classification of chained schedules as less favorable than simple schedules. Therefore, it was expected that, in the context of a twocomponent multiple schedule in which one component was a chained FR FR schedule and the other a simple FR schedule, the transition from a simple to a chained schedule would result in extended pausing relative to pausing in the other transitions. Across conditions, the chained schedule was segmented at different points throughout the course of the response requirement. It was expected that the favorability of the chained schedule would increase when the schedule was segmented close to the reinforcer. As a result of this change, the duration of pausing in the transition from a simple to a chained schedule was expected to be longest when, on an FR 100 schedule, the first segment required 25 responses and shortest when it required 75 responses. Supporting this prediction is research showing that preference for the simple schedule is inversely related to duration of the initial component of the chained schedule (Leung \& Winton, 1986, 1988). Put another way, research suggests that chained schedules become less favorable when the initial segment is short.

In Experiment 1b, a two-component multiple schedule operated in which one component was a simple FI schedule and the other a chained FI FI schedule. The location of the stimulus change, or the duration of the first segment, varied across conditions as in Experiment 1a. For example, in one condition a simple FI 60-s schedule operated in one component. In the other component, an FI 20-s schedule operated in the first segment of a chained FI FI schedule and an FI 40-s schedule operated in the second segment. It was predicted, as in Experiment 1a, that extended pausing would occur in the transition from the simple FI schedule to the chained FI FI schedule relative to the other transitions and that this effect would be greatest when first segment of the chained FI FI schedule was shortest.

In Experiment 1c the condition that produced the longest pauses in Experiment 1b was reinstated. The pigeons were given the opportunity to peck a key to produce a timeout (i.e., to 
escape) from the prevailing schedule conditions. It was expected that escape would be directly related to the degree of pausing observed in the previous experiment and, if so, the interpretation that pausing itself is a form of escape from an aversive shift in schedule conditions would be supported.

The daily environments of organisms are likely to involve numerous shifts between schedule conditions that vary along many dimensions. Bejarano, Williams, and Perone (2003) investigated such a possibility when they exposed a man with mental retardation to a multiple schedule in which an FR 10 schedule operated in one component and an FR 60 schedule in the other. In addition to manipulating the ratio requirement, reinforcer magnitude (monetary earning) was adjusted across the two schedules such that the completion of the FR 10 schedule earned the subject 25 cents (the favorable condition), while the completion of the FR 60 schedule earned the subject 1 cent (the unfavorable condition). The results showed, as previous studies have shown, that the subject paused longest in the transition from the favorable to unfavorable conditions of reinforcement.

Experiments 2a through 2c examined pausing and escape in the transitions between schedule components that differed in more than one respect. In Experiment 2a, the typical procedure employed by Perone and Courtney (1992) was arranged. This procedure consisted of a two-component multiple schedule in which one component (an FR schedule) ended in a small reinforcer (hereafter, the lean component) and the other in a large (hereafter, the rich component), so that pausing could be measured in the transitions from a lean component to another lean component, a lean to a rich component, an so on. In addition, either the lean component or the rich component was segmented across two sets of conditions. As in Experiment 1a, segmentation occurred at different points in the ratio.

It was predicted that pausing during the transition from a rich to a lean component would decrease relative to baseline when the rich component was segmented early in the ratio. These changes were expected as the result of making the rich component less favorable (i.e., via segmentation) and in turn, by decreasing the disparity in favorability across the two components. As the stimulus change occurred closer to the reinforcer, the rich component was expected to increase in favorability relative to the lean component. As the result of increasing the difference in favorability across the components, pausing in the transition from a rich to a lean component was expected to increase, approaching baseline levels. 
When the lean component was segmented early in the ratio, pausing in the rich-to-lean transition was expected to increase as the result of further decreasing the favorability of the lean component relative to the rich component. Across conditions (i.e., as the stimulus change occurs closer to the reinforcer), this pause was expected to decrease, again approaching baseline levels.

In Experiment 2b, the procedure by Perone and Courtney (1992) was employed again, but with FI schedules leading to either the small or large reinforcer. Across conditions, either the lean component or the rich component was chained. Unlike Experiment 1b, the duration of the first segment of the chained FI FI schedule was not varied. It was predicted that extended pausing would occur in rich-to-lean transition, and that this effect would be attenuated when the rich component was chained and greater when the lean component was chained.

In Experiment 2c the condition that produced the longest pauses in Experiment 2b was reinstated. As in Experiment 1b, the pigeons were given the opportunity to peck a key to escape from the prevailing schedule conditions. Again, it was expected that escape would be directly related to the degree of pausing observed in the previous experiment.

\section{EXPERIMENT 1a}

Experiment 1a examined the effects of segmenting FR schedules on pausing. A twocomponent multiple schedule operated in which one component consisted of a simple FR schedule and the other a chained FR FR schedule. Reinforcer magnitude remained constant across both components. Because previous research has shown a simple schedule to be more favorable than a chained schedule, extended pausing was expected in the transition from a simple to a chained schedule. Furthermore, the favorability of the chained schedule was expected to increase when the schedule was segmented close to the reinforcer, resulting in a corresponding decrease in the duration of simple-to-chain pauses. Segmentation of the chained schedule early in the completion of the response requirement was expected to decrease the favorability of the schedule and result in an increase in simple-to-chain pause durations.

\section{Method}

\section{Subjects}

Four male White Carneau pigeons, all with experience on a variety of schedules, served as subjects. Pigeons 2V9, 3V, and 437 were maintained at $80 \%( \pm 2 \%)$ of their free-feeding weights and Pigeon 426 was maintained at 85\% ( $\pm 2 \%)$ of his free-feeding weight. These target weights were maintained by grain deliveries during the experimental sessions and, if necessary, 
by supplemental feedings following each session. Water and health grit were freely available in the home cage, which was kept in a temperature-controlled room with a 12:12 hr light/dark cycle.

\section{Apparatus}

Sessions were conducted in three identical sound-attenuating chambers. Each chamber was $37 \mathrm{~cm}$ high, $30 \mathrm{~cm}$ wide, and $32 \mathrm{~cm}$ deep. General illumination was provided by a 28-v houselight (No. 1829) located behind a translucent screen in the lower left corner of the front panel. Noise from a ventilation fan on the side of the chamber helped to mask extraneous sounds. Three response keys, about $2 \mathrm{~cm}$ in diameter, were arranged in a row on the front panel $24 \mathrm{~cm}$ from the floor and $9 \mathrm{~cm}$ apart, center to center. Only the center key was used, and this key was illuminated from behind by a 28-v bulb (No. 1829) covered with colored caps. Pecks on the center key were reinforced by providing access to grain through a 5-cm x 6-cm rectangular aperture located about $11 \mathrm{~cm}$ below the center key. During the reinforcement period, the houselight and center key were darkened and the aperture was illuminated by a 28-v bulb (No. 1829). Control and recording operations were accomplished with microcomputers connected to the chambers by a commercial interface.

\section{Preliminary Training}

The goals of preliminary training were to establish responding on an FR 100 schedule and to determine the existence of any color biases (e.g., as a result of the pigeons' previous experimental histories) that could obscure the effects of the experimental manipulations. After a 5-min pre-session delay in the darkened chamber (to allow the pigeon to recover from handling), the session began with the illumination of the houselight and center key. Throughout pretraining, a two-component multiple schedule operated. Each component was signaled by a distinct color on the center key and, initially, required 10 responses for reinforcement (i.e., a multiple FR 10 FR 10 schedule). Reinforcement consisted of 4-s access to grain and sessions ended after the delivery of 41 reinforcers.

The components of the multiple schedule alternated irregularly according to a sequence developed by Perone and Courtney (1992) and discussed below. Across sessions, the FR requirement in both components was raised from 10 to either 80 or 100, depending on the pigeon, in steps of 10 . The terminal FR size was the largest ratio requirement that could maintain 
reliable responding with the reinforcement parameters employed in the current experiment. Each FR requirement was in effect for 2 sessions.

Table 1. Key colors correlated with the schedules in each component of Experiments $1 a, 1 b$, and $1 c$.

Manipulated Component

\begin{tabular}{|c|c|c|c|c|}
\hline \multirow[b]{2}{*}{ Pigeon } & \multirow[b]{2}{*}{$\begin{array}{c}\text { Constant } \\
\text { Component }\end{array}$} & \multirow[b]{2}{*}{ Simple FR } & \multicolumn{2}{|c|}{ Chain FR FR } \\
\hline & & & Segment 1 & Segment 2 \\
\hline 2V9 & Green & White & Red & White \\
\hline 426 & Green & Yellow & White & Yellow \\
\hline $3 \mathrm{~V}$ & Blue & White & Yellow & White \\
\hline 437 & Blue & White & Green & White \\
\hline
\end{tabular}

To reduce color bias, the key colors correlated with the components of the multiple schedule were varied on a session-by-session basis. The center key in each chamber was equipped with 3 key colors (for example, white, green, and red) yielding three color combinations (white and green, white and red, green and red). All three combinations were used, across sessions, as the FR requirement was increased. At least 3 sessions were conducted at the terminal FR size, allowing for the presentation of each color combination. Upon completion of this step, if a particular color was accompanied by extended pausing relative to the other colors, this color was correlated with the simple schedule. One of the remaining colors was correlated with each segment of the chained schedule that operated in the other component. If a particular color was accompanied by minimal pausing relative to the other colors, this color was correlated with the first segment of the chained schedule. Table 1 shows the colors chosen for each pigeon. Experimental Conditions

As in pretraining, sessions began after a 5-min pre-session delay. The beginning of the session was signaled by the illumination of the houselight and center key, and a two-component multiple schedule operated. These details of the procedure remained the same throughout the study. During baseline, an FR 80 or FR 100 schedule, depending on the pigeon, operated in both components of the multiple schedule, with each component signaled by a different key color 
(established for each pigeon during pretraining; see Table 1). In the experimental conditions, one component remained a simple FR schedule, while the second component became a chained schedule. Note in Table 1 the change in the key colors when the simple schedule became chained. The stimulus correlated with the first segment of the chained schedule was distinct (i.e., one previously uncorrelated with the simple schedules that operated during baseline). The stimulus correlated with the second segment, however, was the same as that correlated with the simple schedule before it became chained. This procedure ensured that the same stimulus preceded reinforcement regardless of whether the schedule was simple or chained. For example, during baseline, the simple FR schedule in what would be the manipulated component was signaled by a white key light for Pigeon 2V9. When the schedule became chained in subsequent conditions, a red key light accompanied the first segment, while the white key light accompanied the second.

Table 2. The number of sessions completed by each pigeon in each condition of Experiments 1a, 1b, and 1c. The order of conditions is shown in parentheses.

\begin{tabular}{|c|c|c|c|c|c|}
\hline \multirow[b]{2}{*}{$\begin{array}{c}\text { Constant } \\
\text { Component }\end{array}$} & \multirow[b]{2}{*}{$\begin{array}{l}\text { Manipulated } \\
\text { Component }\end{array}$} & \multicolumn{4}{|c|}{ Pigeon } \\
\hline & & 2V9 & 426 & 3V & 437 \\
\hline \multicolumn{6}{|c|}{ Experiment $1 \mathrm{a}$} \\
\hline FR 100 & FR 100 & $21(1)$ & $55(1)$ & -- & -- \\
\hline FR 100 & Chain FR 25 FR 75 & $43(2)$ & $22(3)$ & -- & -- \\
\hline FR 100 & Chain FR 75 FR 25 & $27(3)$ & $42(2)$ & -- & -- \\
\hline FR 100 & FR 100 & $0(4)^{\mathrm{a}}$ & $0(4)^{\mathrm{a}}$ & & \\
\hline FR 80 & FR 80 & - & - & $49(1)$ & $47(1)$ \\
\hline FR 80 & Chain FR 20 FR 60 & -- & -- & $23(2)$ & $26(3)$ \\
\hline FR 80 & Chain FR 60 FR 20 & -- & -- & $26(3)$ & $22(2)$ \\
\hline FR 80 & FR 80 & -- & -- & $23(4)$ & $40(4)$ \\
\hline \multicolumn{6}{|c|}{ Experiment $1 \mathrm{~b}$} \\
\hline FI $60 \mathrm{~s}$ & FI $60 \mathrm{~s}$ & $20(1)$ & $24(1)$ & $20(1)$ & $34(1)$ \\
\hline FI $60 \mathrm{~s}$ & Chain FI $20 \mathrm{~s}$ FI $40 \mathrm{~s}$ & $20(2)$ & $20(3)$ & $27(2)$ & $20(3)$ \\
\hline FI $60 \mathrm{~s}$ & Chain FI $40 \mathrm{~s}$ FI $20 \mathrm{~s}$ & $24(3)$ & $20(2)$ & $21(3)$ & $20(2)$ \\
\hline FI $60 \mathrm{~s}$ & FI $60 \mathrm{~s}$ & $19(4)$ & $14(4)$ & $14(4)$ & $14(4)$ \\
\hline \multicolumn{6}{|c|}{ Experiment 1 c } \\
\hline FI $60 \mathrm{~s}$ & FI $60 \mathrm{~s}$ & $16(1)$ & $15(1)$ & $15(1)$ & $17(1)$ \\
\hline FI $60 \mathrm{~s}$ & Chain FI $20 \mathrm{~s}$ FI $40 \mathrm{~s}$ & $15(2)$ & $14(2)$ & $14(2)$ & $14(2)$ \\
\hline FI $60 \mathrm{~s}$ & FI $60 \mathrm{~s}$ & (3) & $14(3)$ & $14(3)$ & (3) \\
\hline
\end{tabular}

${ }^{\mathrm{a}}$ Experiment 1a was ended before Pigeons 2V9 and 426 experienced a replication of baseline, therefore the number of sessions for this condition is recorded as 0 . 
Table 2 shows a summary of schedules operating in the chained component across conditions. All chained schedules required, in total, the same number of responses as the simple schedule. For example, if the simple schedule required 100 responses (i.e., an FR 100 schedule), the chained schedule also required a total of 100 responses and operated as follows. The chained schedule began with the onset of the first segment accompanied by the appropriate key color. After 25 responses, access to the second segment of the schedule was provided. The onset of the second segment was accompanied by a change in the key color from that correlated with the first segment to that correlated with the second segment. Upon entry into the second segment, 75 responses were required (for a total of 100 responses) for a reinforcer delivery.

The response requirements in the two segments of the chain were varied across conditions. For example, for the two pigeons exposed to a total ratio requirement of 100 responses, the ratio requirement in the first segment was either 25 or 75 responses, depending on the condition. For the pigeons exposed to a total ratio requirement of 80 responses, the ratio requirement in the first segment was either 20 or 60 responses, depending on the condition. Finally, baseline was reinstated for 2 of the 4 pigeons, with a simple FR schedule operating in both components. The baseline condition was replicated for just 2 pigeons because, when it became apparent that the observed changes were not consistent across subjects, the experiment was ended in order to proceed with Experiment 1b. In this experiment (and in all subsequent experiments) the order of conditions was counterbalanced across pigeons.

The overall sequence of components within a session was arranged so that the transitions between schedules were divided equally among the following four types: A simple schedule followed by another simple schedule (simple-to-simple), a simple schedule followed by a chained schedule (simple-to-chain), a chained schedule followed by a simple schedule (chain-tosimple), and a chained schedule followed by another chained schedule (chain-to-chain). As in Perone and Courtney’s (1992) study, sessions lasted until 41 reinforcers had been delivered, allowing for 40 total transitions in each session. The 40 transitions included 10 transitions of each type and no more than four simple or four chained schedules occurred consecutively. A total of 40 sequences meeting these criteria were assembled into 2 sets of 20. One set included sequences with 20 simple schedule components and 21 chained schedule components, with the first component being a chained one. Sequences in the other set included 21 simple schedule components and 20 chained ones, with the first component being a simple one. At the beginning 
of every other session, one of the sets was selected at random; the other set was used in the next session. Once a set was selected, a sequence was drawn at random for that day's session. The procedure used to determine the daily sequence of components was the same for all experiments.

Behavior was judged stable in each condition when the following criteria were met: First, a minimum of 20 sessions had to be completed. Second, beginning with the $16^{\text {th }}$ session of each condition the median pause duration in each of the four transition-types was calculated over a “moving window” of the most recent 10 sessions. The first median was based on the median pauses obtained in sessions 7 through 16; the second median was based on sessions 8 through 17; and so on. When five consecutive medians showed no significant increasing or decreasing trend, as judged by visual inspection, the measure was considered stable. When the pause durations in each of the four transitions met the stability criterion simultaneously, the condition ended.

Results and Discussion

Pauses. Figure 1 shows the median pause duration in each transition calculated over the last 10 sessions of each condition. Accompanying all medians reported in the present study are the interquartile ranges, represented by error bars extending downward to the $25^{\text {th }}$ percentile and upward to the $75^{\text {th }}$ percentile. During baseline, a simple FR schedule operated in both components of the multiple schedule. Pauses were longer in the transition from what would become the chained schedule to the simple schedule for Pigeons 2V9 and 426, while pauses were longer overall in the component consisting of a simple schedule for $3 \mathrm{~V}$ and 437 . The designations of the components as simple and chained were made as the result of the pause durations observed during pretraining and subsequently baseline. The component characterized by longer pauses was designated the component in which a simple schedule would operate, while the component characterized by shorter pauses was designated the component in which a chained schedule would operate. This procedure ensured that any biases for a particular key color observed during baseline would not be in the direction of the predicted effects. 

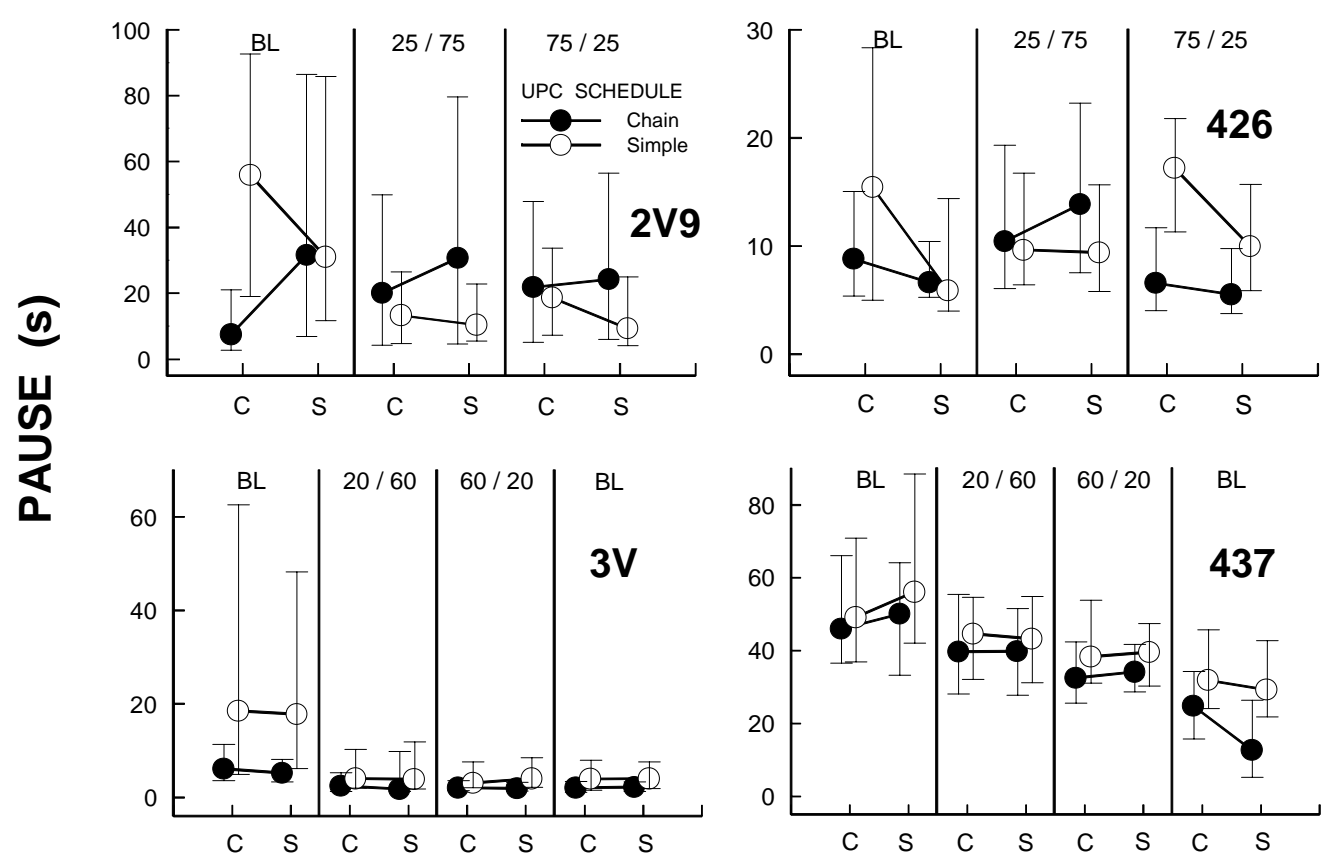

\section{PAST SCHEDULE}

Figure 1. Median pause durations in the transitions between a simple FR schedule and a chained FR FR schedule calculated over the last 10 sessions of each condition in Experiment 1a. Error bars represent the interquartile range. The conditions are portrayed at the top of each panel in each graph: Baseline (BL) (note that a simple schedule operated in both the simple and chained components during baseline), when 25 responses were required in the first segment of the chained schedule and 75 in the second (25/75), and when 75 responses were required in the first segment of the chained schedule and 25 in the second (75/25). The abbreviation "UPC" in the legend stands for "upcoming."

When segmentation of the chained FR FR schedule occurred early in completion of the schedule (after 20 or 25 responses, depending on the pigeon), pauses by 2 pigeons (2V9 and 426) increased during the transition from the simple schedule to the chained schedule relative to those observed in the other transitions. This was consistent with the prediction that pauses would become extended in the simple-to-chain transition. This effect was not observed for 3V and 437. For these pigeons, overall pauses decreased and there was no differentiation with respect to transition. 
When the segmentation of the chained FR FR schedule occurred later in the schedule (after 75 or 60 responses), two types of changes were observed. Pauses by 2V9 decreased in the simple-to-chain transition, remaining only slightly longer than in the other transitions. For 426, the effect observed in the previous condition reverted to the pattern observed during baseline, when a simple FR 100 schedule operated in both components. Pauses in the simple component became longer than in the chained component, and pauses became extended in the transition from a chained schedule to a simple schedule. Only the effect shown by 2V9 was consistent with the prediction that the chained schedule would become more favorable (but remain less favorable than the simple schedule) when segmentation occurred close to the reinforcer.

As with 3V, pauses emitted by 437 remained longer when the upcoming schedule was simple, but were not differentiated across transitions. In addition, overall pause durations decreased across conditions, including the replication of baseline.

Table 3 shows the median pause duration in the second segment of each transition calculated over the last 10 sessions of each condition. In the chained component, this pause was measured as the time between entry into the second segment and the first response toward completion of the schedule in that segment. Second-segment pauses measured during completion of a simple FR schedule (i.e., in the simple-to-simple and chain-to-simple transitions) were calculated as if the simple schedule was a tandem FR FR schedule. A tandem schedule operates like a chained schedule, but with no stimulus change upon entry into the second segment of the schedule. For this reason, a tandem FR FR schedule operates no differently from a simple FR schedule requiring the same total number of responses. Therefore, if a chain FR 25 FR 75 schedule was operating in the chained component, second-segment pauses in the simple schedule were measured as the time between the $25^{\text {th }}$ and $26^{\text {th }}$ response.

Pause durations in the second segment were not differentiated with respect to transition for any of the pigeons. The absence of a difference across simple and chained schedules indicates that behavior was not disrupted by the stimulus change at the onset of the second segment of the schedule. It suggests instead, that once the pigeons started responding in the first segment, they pecked through the stimulus change and until the reinforcer was delivered. For 3V and 437, second-segment pauses were shorter in the condition in which the stimulus change occurred later in the chained schedule. This is likely the result of a high rate of responding at this point in the schedule and will be considered further in the discussion of run rates below. 
Table 3. Median pauses in the second segment of the chained FR FR schedule, calculated over the last 10 sessions of each condition in Experiment 1a. In the transitions leading to a simple FR schedule (chain-simple and simple-simple), pauses preceding what would have been the first response in the second segment of a tandem FR FR schedule were recorded. The interquartile range is shown in parentheses.

\begin{tabular}{|c|c|c|c|c|c|}
\hline \multirow[b]{2}{*}{ Bird } & \multirow[b]{2}{*}{ Condition } & \multicolumn{4}{|c|}{ Transition } \\
\hline & & Chain-Chain & Chain-Simple & Simple-Chain & Simple-Simple \\
\hline \multirow[t]{2}{*}{ 2V9 } & $25 / 75$ & $0.33(0.17-0.52)$ & $0.35(0.19-0.44)$ & $0.35(0.28-0.63)$ & $0.32(0.16-0.40)$ \\
\hline & $75 / 25$ & $0.32(0.22-0.41)$ & $0.30(0.28-0.33)$ & $0.32(0.16-0.43)$ & $0.29(0.26-0.31)$ \\
\hline \multirow[t]{2}{*}{426} & $25 / 75$ & $0.31(0.27-0.35)$ & $0.27(0.23-0.33)$ & $0.31(0.27-0.40)$ & $0.28(0.20-0.32)$ \\
\hline & $75 / 25$ & $0.29(0.26-0.32)$ & $0.30(0.26-0.33)$ & $0.30(0.28-0.33)$ & $0.29(0.26-0.32)$ \\
\hline \multirow[t]{2}{*}{$3 \mathbf{V}$} & $20 / 60$ & $0.28(0.16-0.36)$ & $0.28(0.14-0.44)$ & $0.31(0.18-0.41)$ & $0.26(0.13-0.44)$ \\
\hline & $60 / 20$ & $0.13(0.10-0.19)$ & $0.14(0.11-0.20)$ & $0.12(0.10-0.19)$ & $0.13(0.11-0.19)$ \\
\hline \multirow[t]{2}{*}{437} & $20 / 60$ & $0.37(0.23-0.53)$ & $0.41(0.24-0.57)$ & $0.35(0.19-0.50)$ & $0.46(0.23-0.64)$ \\
\hline & $60 / 20$ & $0.29(0.16-0.58)$ & $0.29(0.16-0.60)$ & $0.26(0.14-0.53)$ & $0.22(0.13-0.57)$ \\
\hline
\end{tabular}

Run rates. Figure 2 shows the median running response rates (run rate) (total number of responses divided by the time between the first and last response in the ratio) in each transition calculated over the last 10 sessions of each condition. In baseline and in the experimental conditions, minimal changes in run rates were observed. For $3 \mathrm{~V}$ and 437, run rates tended to increase across conditions, including the reinstatement of baseline. For 2V9 and 426, run rates increased slightly relative to baseline when a chained schedule operated in one component, but there was no consistent difference in run rates when the segmentation of the chained schedule occurred early versus late in the completion of the ratio requirement. 


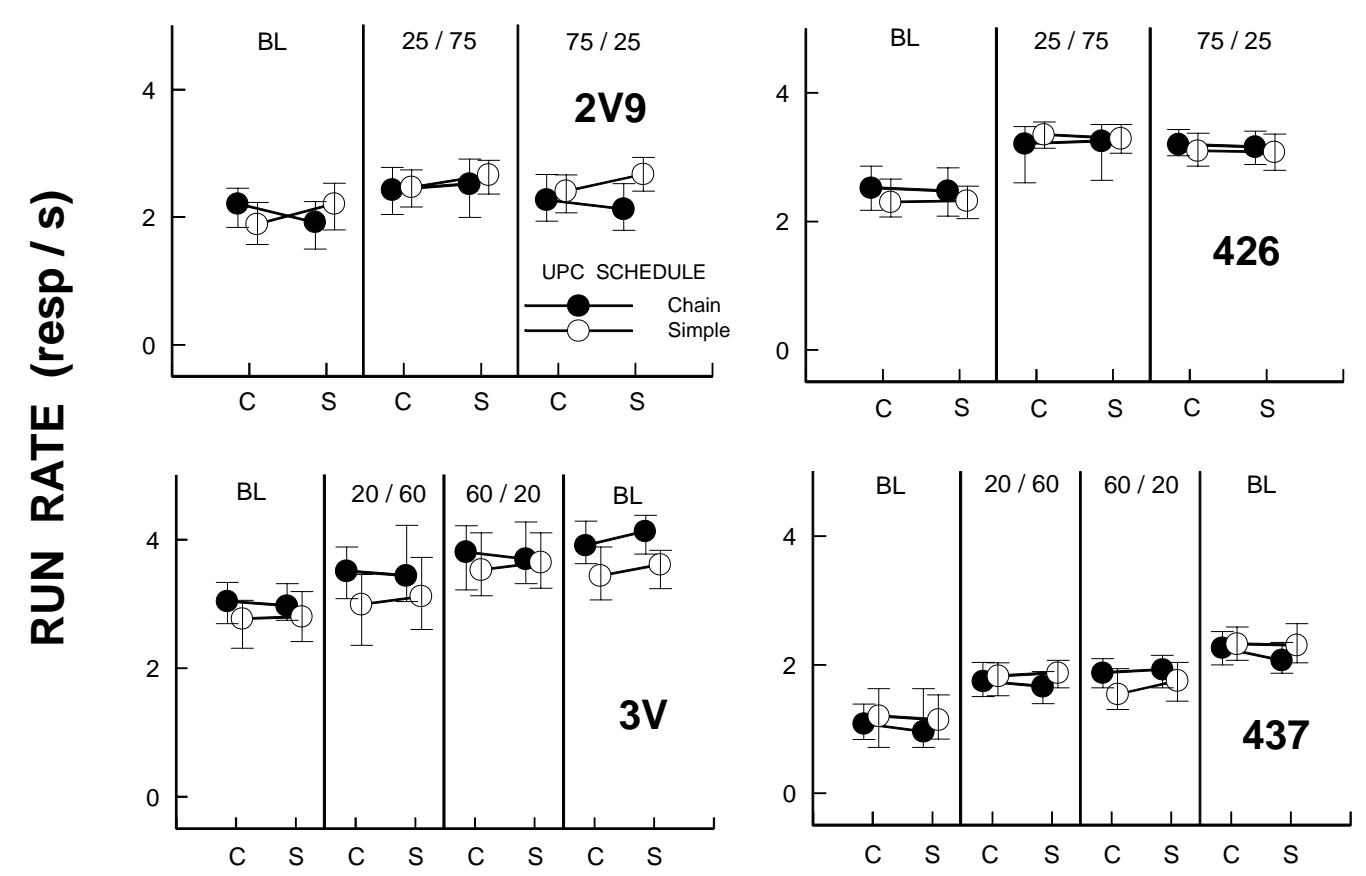

PAST SCHEDULE

Figure 2. Median run rate (responses per second) in the transitions between a simple FR schedule and a chained FR FR schedule calculated over the last 10 sessions of each condition in Experiment 1a. Details are as in Figure 1.

Tables 4 and 5 show run rates in the first and second segment of the chained schedule, respectively, during the experimental conditions. In the case that a chained FR 25 FR 75 schedule operated, the run rate for the first segment was calculated as the number of responses (25) divided by the time between the first response and the response that resulted in the onset of the second segment. The run rate for the second segment was calculated as the number of responses (75) divided by the time between the first and last responses in the second segment. As with pauses, run rates measured during completion of a simple FR schedule (i.e., in the simpleto-simple and chain-to-simple transitions), were calculated as if the schedule was a tandem FR FR. So, in the case that a chain FR 25 FR 75 schedule operated in the chained component, the run rate in the "first segment" of the simple schedule was calculated by dividing 25 by the time 
between the first and $25^{\text {th }}$ response, and the run rate in the "second segment" was calculated by dividing 75 by the time between the $26^{\text {th }}$ response and $100^{\text {th }}$ response.

Table 4. Median run rates (resp/s) in the first segment of the chained FR FR schedule, calculated over the last 10 sessions of each condition in Experiment 1a. Run rates on the simple FR schedules were calculated through what would have been the response to initiate the second segment of a tandem FR FR schedule. The interquartile range is shown in parentheses.

\section{Transition}

\begin{tabular}{|c|c|c|c|c|c|}
\hline Bird & Condition & Chain-Chain & Chain-Simple & Simple-Chain & Simple-Simple \\
\hline \multirow[t]{2}{*}{ 2V9 } & $25 / 75$ & $1.43(0.94-1.89)$ & $1.57(1.18-2.22)$ & $1.56(0.94-2.05)$ & $1.89(1.45-2.33)$ \\
\hline & $75 / 25$ & $2.12(1.73-2.47)$ & $2.19(1.80-2.46)$ & $1.94(1.62-2.32)$ & $2.45(2.17-2.76)$ \\
\hline \multirow[t]{2}{*}{426} & $25 / 75$ & $2.68(1.62-3.20)$ & $2.98(2.39-3.42)$ & $2.74(1.76-3.49)$ & $2.80(2.22-3.34)$ \\
\hline & $75 / 25$ & 3.18 (2.96-3.39) & $3.02(2.79-3.38)$ & $3.14(2.85-3.34)$ & $3.04(2.67-3.35)$ \\
\hline \multirow[t]{2}{*}{$3 \mathbf{V}$} & $20 / 60$ & $2.18(1.71-2.57)$ & $1.80(1.16-2.48)$ & $2.10(1.75-2.55)$ & $2.00(1.37-2.66)$ \\
\hline & $60 / 20$ & $3.37(2.85-3.87)$ & 3.24 (2.79-3.59) & $3.43(2.93-4.02)$ & $3.30(2.93-3.84)$ \\
\hline \multirow[t]{2}{*}{437} & $20 / 60$ & $1.02(0.72-1.31)$ & $1.02(0.77-1.34)$ & $0.89(0.60-1.09)$ & $1.09(0.84-1.40)$ \\
\hline & $60 / 20$ & $1.74(1.43-1.94)$ & $1.41(1.15-1.80)$ & 1.74 (1.48-1.98) & $1.56(1.25-1.85)$ \\
\hline
\end{tabular}

Table 4 shows that, within the first segment, all pigeons responded faster when the stimulus change occurred late as opposed to early in the schedule. In addition, 426, 3V, and 437 responded at higher rates in the chained-schedule components during this condition. Other differences in first-segment run rates were observed as well, but were not consistent across pigeons.

Run rates in the second segment of the schedule, shown in Table 5, were much higher than in the first segment across all transitions. Like the first-segment run rates (and with the exception of 426), second-segment run rates generally were higher when the stimulus change occurred late in the chained schedule. Also, 426 and 437 responded at higher rates on the chained schedule. The latter result suggests that, while the analysis of second-segment pauses indicated 
that all pigeons pecked through the stimulus change, these pigeons showed some sensitivity to the stimulus correlated with the second segment. A different pattern was observed for Pigeons $2 \mathrm{~V} 9$ and $3 \mathrm{~V}$. Both responded at much lower rates during the transition from a simple to a chained schedule and responded at the highest rate in the transition between two simple schedules.

Table 5. Median run rates (resp/s) in the second segment of the chained FR FR schedule, calculated over the last 10 sessions of each condition in Experiment 1a. Run rates on the simple FR schedules were calculated using the time between what would have been the first and last responses in the second segment of a tandem FR FR schedule. The interquartile range is shown in parentheses.

\begin{tabular}{|c|c|c|c|c|c|}
\hline \multirow[b]{2}{*}{ Bird } & \multirow[b]{2}{*}{ Condition } & \multicolumn{4}{|c|}{ Transition } \\
\hline & & Chain-Chain & Chain-Simple & Simple-Chain & Simple-Simple \\
\hline \multirow[t]{2}{*}{ 2V9 } & $25 / 75$ & $3.35(3.07-3.52)$ & $3.16(2.92-3.28)$ & 3.35 (3.17-3.59) & $3.18(3.00-3.41)$ \\
\hline & $75 / 25$ & $3.56(3.04-3.81)$ & $3.59(3.45-3.90)$ & $3.31(2.81-3.64)$ & $3.68(3.54-4.01)$ \\
\hline \multirow[t]{2}{*}{426} & $25 / 75$ & $3.53(3.29-3.67)$ & 3.59 (3.44-3.77) & $3.48(3.13-3.63)$ & $3.57(3.38-3.71)$ \\
\hline & $75 / 25$ & 3.48 (3.23-3.73) & 3.34 (3.15-3.64) & 3.54 (3.24-3.79) & 3.39 (3.23-3.58) \\
\hline \multirow[t]{2}{*}{$3 \mathbf{V}$} & $20 / 60$ & $4.57(4.19-5.15)$ & $4.12(3.55-4.63)$ & $4.44(4.07-4.93)$ & $3.99(3.71-4.48)$ \\
\hline & $60 / 20$ & $5.57(5.15-6.61)$ & $5.52(4.61-6.27)$ & $5.33(4.55-6.21)$ & $5.79(4.61-6.51)$ \\
\hline \multirow[t]{2}{*}{437} & $20 / 60$ & $2.44(2.22-2.70)$ & $2.53(2.29-2.71)$ & $2.52(2.32-2.72)$ & $2.55(2.33-2.73)$ \\
\hline & $60 / 20$ & $2.91(2.53-3.35)$ & $2.62(2.33-3.14)$ & $2.95(2.54-3.45)$ & $2.61(2.26-3.03)$ \\
\hline
\end{tabular}

In summary, while pauses in the simple-to-chain transition did not change consistently across pigeons as a result of the present manipulations (possible reasons for this will be discussed later), some consistent effects were observed when run rates were analyzed in the separate segments across conditions. Specifically, run rates were higher in the second segment than in the first, while run rates in both segments were higher when the stimulus change occurred late in the schedule. The latter result is consistent with the results of Leung and Winton's (1988) 
study, which found that terminal-link response rates increased as the stimulus change occurred closer to the reinforcer. Conditioned reinforcement can be invoked to explain why run rates were higher in the first segment of the chained schedule relative to the simple schedule when segmentation occurred close to the reinforcer. It is likely that the stimulus correlated with the second segment became a stronger conditioned reinforcer, as it signaled a reduction in the delay to reinforcement relative to when the stimulus change occurred early in the schedule. Because completion of the response requirement in the first segment produced the stimulus correlated with the second segment (a relatively strong conditioned reinforcer in this case), higher rates of responding were maintained in the first segment.

The stimulus correlated with the second segment of the chained schedule not only functioned as a conditioned reinforcer, it also possessed discriminative properties that likely resulted in higher run rates in the second segment of the chained schedule relative to the simple schedule, particularly when segmented close to the reinforcer. A discriminative stimulus sets the occasion for a response, or pattern of responding, to occur (Skinner, 1938). When access to the second segment was provided, the stimulus correlated with the second segment signaled that relatively few responses would result in reinforcement (particularly in the case that segmentation occurred close to the reinforcer). This, in turn, established the occasion for rapid responding.

\section{EXPERIMENT 1b}

Fixed-ratio schedules were employed in the current experiment because they typically engender long pauses that, unlike pauses on FI schedules, are necessarily counterproductive in minimizing the time to reinforcement. Research assessing preference between simple and chained schedules of reinforcement, however, has exclusively employed time-based schedules of reinforcement, such as FI and variable-interval (VI) schedules. Therefore, Experiment 1b was a systematic replication of Experiment 1a in which the two components of a multiple schedule consisted of a simple FI schedule and a chained FI FI schedule. The total duration of the FI requirements (1 min) and reinforcer magnitude was held constant across both components. All predictions regarding the results were the same as in Experiment 1a. That is, pauses were expected to be longest in the transition from a simple to a chained schedule relative to the other transitions, particularly when the schedule was chained furthest from the reinforcer. 
Method

\section{Subjects and Apparatus}

The subjects and apparatus were the same as in Experiment 1a.

\section{Procedure}

Table 2 shows a summary of the chained schedules that operated in Experiment 1b. During baseline, an FI 60 s schedule operated in both components of the multiple schedule. For each pigeon, the keycolors remained the same as in Experiment 1a. That is, the keycolor associated with the simple FR schedule in Experiment 1a also was associated with the simple FI schedule in Experiment 1b, and so on (see Table 1). In the experimental conditions, one component remained a simple FI 60-s schedule, while the other component became a chained schedule. While the duration of each segment of the chained schedule varied across conditions (see Table 2), the total duration of the two segments remained at $60 \mathrm{~s}$. In the first experimental condition, the chained component consisted of a chained FI 20-s FI 40-s schedule. The first segment required a single response after $20 \mathrm{~s}$ had elapsed to initiate the second segment. A single response after another $40 \mathrm{~s}$ had elapsed produced a reinforcer. In the next condition, a chained FI 40-s FI 20-s schedule operated, and in the final condition, both components were simple FI schedules as in baseline. The order of the conditions was counterbalanced across pigeons.

The criteria used to judge the stability of behavior were the same as in Experiment 1a with one exception. Only a minimum of 14 sessions had to be completed before stability was assessed during the replication of baseline. This meant that the moving window of the most recent 10 sessions started with the first session. The first median was based on the median pauses obtained in sessions 1 through 10; the second median was based on sessions 2 through 11; and so on. All 5 medians produced were then used in the visual inspection of stability.

\section{Results and Discussion}

Pauses. Figure 3 shows the median pause duration in each transition calculated over the last 10 sessions of each condition. During baseline, when a simple FI schedule operated in both components of the multiple schedule, pauses were about the same length across transitions for Pigeons 426 and 3V, while pauses were slightly longer in the simple component for 2V9 and 437. When the FI schedule in the chained component became a chained FI 20-s FI 40-s schedule, pauses were longer on the chained schedule than on the simple schedule for all pigeons, although the effect shown by $3 \mathrm{~V}$ was small. For Pigeons $2 \mathrm{~V} 9$ and 426, the longest 
pauses occurred in the transition from a simple to a chained schedule in accordance with predictions.
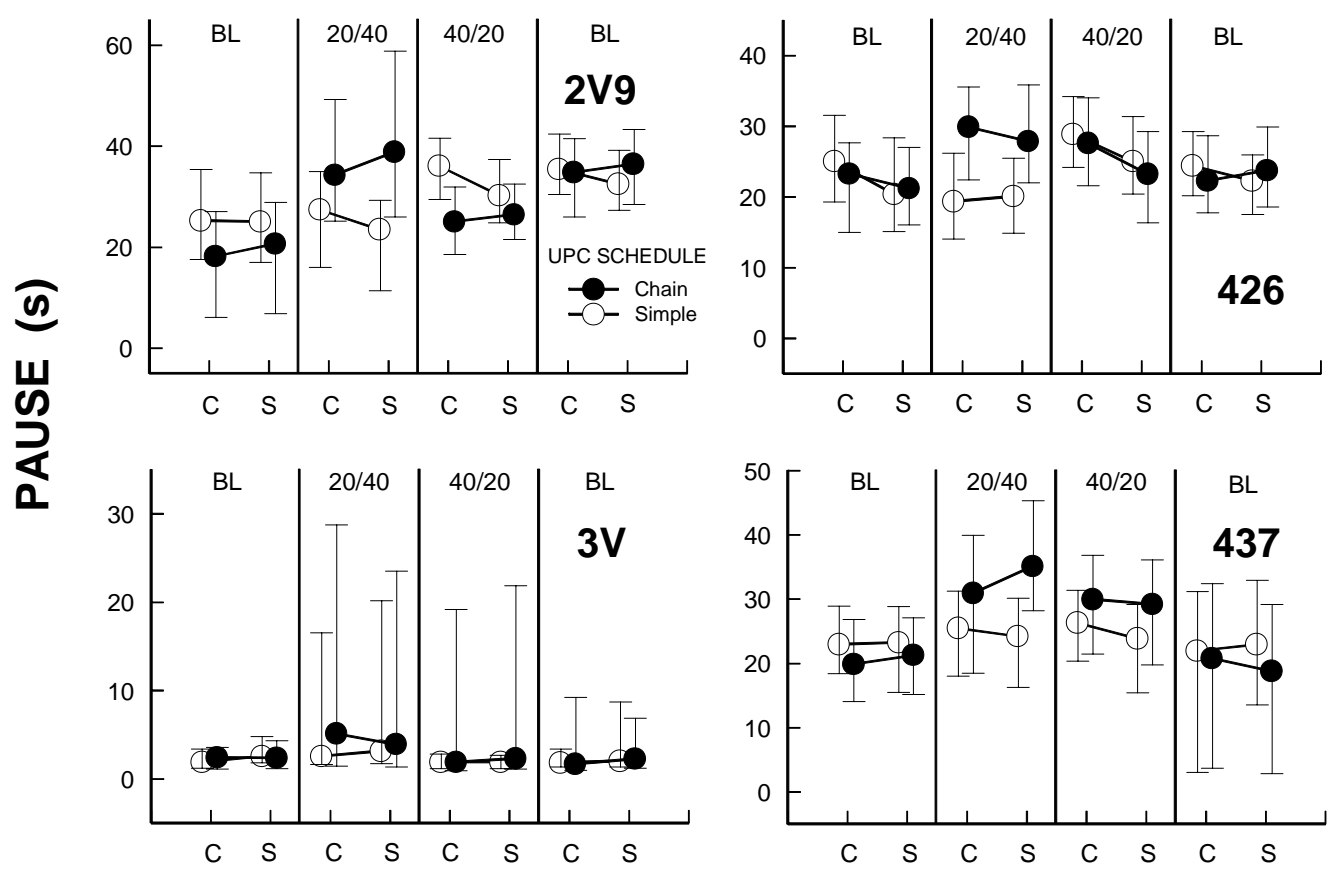

\section{PAST SCHEDULE}

Figure 3. Median pause durations in the transitions between a simple FI schedule and a chained FI FI schedule calculated over the last 10 sessions of each condition in Experiment 1b. Error bars represent the interquartile range. The condition is portrayed at the top of each panel in each graph: Baseline (BL) (note that a simple schedule operated in both the simple and chained components during baseline), when an FI 20-s schedule operated in the first segment of the chained schedule and an FI 40-s schedule in the second (20/40), and when an FI 40-s schedule operated in the first segment of the chained schedule and an FI 20-s schedule in the second (40/20). The abbreviation "UPC" in the legend stands for "upcoming."

When a chained FI 40-s FI 20-s schedule operated in the chained component, pauses in this component decreased relative to the previous condition for all pigeons. Pigeon 2V9 paused for longer durations in the transitions to a simple schedule (particularly in the chain-to-simple transition) and Pigeon 426 paused longer after a chained schedule than after a simple schedule (with no differentiation with respect to the upcoming schedule). Also, while the median pause 
durations emitted by $3 \mathrm{~V}$ were the same across transitions, variability in pauses, as shown by the interquartile range, continued to be large in the transitions to a chained schedule. In the reinstatement of baseline, pauses became undifferentiated across transitions, as they primarily had been in the first exposure to baseline.

Table 6. Median pauses in the second segment of the chained FI FI schedule, calculated over the last 10 sessions of each condition in Experiment $1 \mathrm{~b}$. The interquartile range is shown in parentheses.

\begin{tabular}{|c|c|c|c|c|c|}
\hline \multirow[b]{2}{*}{ Bird } & \multirow[b]{2}{*}{ Condition } & \multicolumn{4}{|c|}{ Transition } \\
\hline & & Chain-Chain & Chain-Simple & Simple-Chain & Simple-Simple \\
\hline \multirow[t]{2}{*}{ 2V9 } & $20 / 40$ & $0.74(0.38-3.31)$ & -- & $0.53(0.34-3.09)$ & -- \\
\hline & $40 / 20$ & $0.29(0.24-0.35)$ & -- & $0.31(0.25-2.11)$ & -- \\
\hline \multirow[t]{2}{*}{426} & $20 / 40$ & $0.34(0.28-0.40)$ & -- & $0.32(0.29-0.37)$ & -- \\
\hline & $40 / 20$ & $0.57(0.28-1.43)$ & -- & $0.78(0.32-1.68)$ & -- \\
\hline \multirow[t]{2}{*}{$3 \mathbf{V}$} & $20 / 40$ & $1.89(0.37-3.22)$ & -- & $1.74(0.38-3.16)$ & -- \\
\hline & $40 / 20$ & $0.37(0.29-1.32)$ & -- & $0.36(0.28-0.71)$ & -- \\
\hline \multirow[t]{2}{*}{437} & $20 / 40$ & $1.99(0.30-5.27)$ & -- & $1.73(0.31-4.08)$ & -- \\
\hline & $40 / 20$ & $0.48(0.22-0.74)$ & -- & $0.46(0.26-0.75)$ & -- \\
\hline
\end{tabular}

Table 6 shows median pauses in the second segment of the chained schedules, calculated over the last 10 sessions of each condition. Recall that in Experiment 1a the simple FR schedules were analyzed as tandem FR FR schedules, because the two schedules operated identically. A simple FI schedule, however, does not operate as a tandem FI FI schedule operates, so this analysis was not conducted in the current experiment. For example, on the simple FI 60-s schedule, a single response after 60 s elapsed was reinforced. On a tandem FI FI schedule (as on a chained FI FI schedule), a single response after the interval in the first segment had elapsed would be required to gain access to the second segment. Then in the second segment, a single 
response after that interval had elapsed would be reinforced. So, the response requirement is not the same across the two schedules as it was across the simple FR and tandem FR FR schedules in the previous experiment. For Pigeons 2V9, 3V, and 437, pauses at the start of the second segment were longer in the condition with an FI 40-s schedule in the second segment. Within this condition, pauses were slightly longer in the chain-to-chain transition than in the simple-tochain transition (this was not the case in the condition with an FI 20-s schedule in the second segment). Second segment pauses in the current experiment were notably longer than those in Experiment 1a, particularly in the condition with an FI 40-s schedule in the second segment. For all pigeons but 426 , the $75^{\text {th }}$ percentile exceeded $3 \mathrm{~s}$, and in one case even exceeded $5 \mathrm{~s}$, indicating that behavior was interrupted to some extent upon entry into the second segment. In Experiment 1a, second-segment pauses were short, indicating that the pigeons had pecked through the stimulus change in chained schedule.

Response rates. Figure 4 shows average response rates in each tenth of the interval, for the simple FI schedules in baseline and in the simple component during experimental conditions, and for each segment of the chained schedule during the experimental conditions. Response rates in each tenth of the interval were averaged across the last 10 sessions of each condition. Specifically, for the baseline and simple schedules, the average response rate was calculated for every 6 s that elapsed in the FI 60-s schedule. When a chained FI 20-s FI 40-s schedule operated, response rates were calculated for every $2 \mathrm{~s}$ that elapsed in the FI 20-s segment and for every $4 \mathrm{~s}$ that elapsed in the FI 40-s segment. This analysis allows for the comparison of the overall pattern of responding across time in the simple schedules and in each segment of the chained schedules.

In baseline, all pigeons showed the typical scalloped pattern of responding engendered by FI schedules; that is, following the pause at the start of the interval, the pigeons started to respond at a relatively slow rate. As the interval elapsed, responding accelerated until the reinforcer was delivered. This pattern was undifferentiated across transitions.

When the first segment of the chain was an FI 20-s schedule, the pattern of responding on the simple schedules was scalloped and undifferentiated across the two transitions to a simple component (the CS and SS transitions in Figure 4). Rates in the first segment of the chained schedule were low throughout the segment, while rates in the second segment were higher than those in both the simple schedules and the first segment of the chained schedule. Although rates in the second segment were higher, the pattern of responding varied across birds. Pigeon 2V9's 
responding was scalloped, while $3 \mathrm{~V}$ and 437 showed a steady, rather than accelerated, increase in responding across the interval. Finally, 426’s responding slowed as the interval progressed.

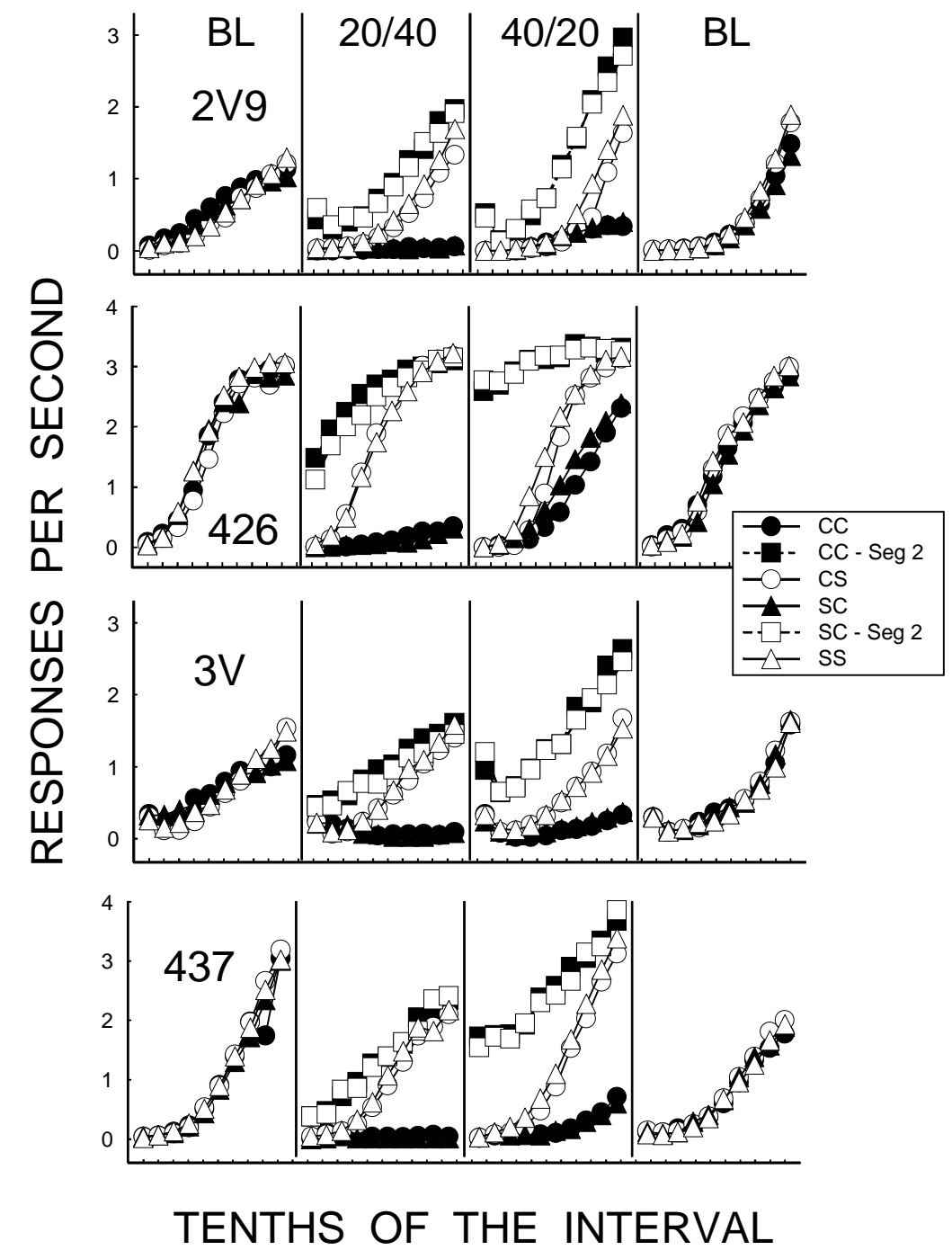

Figure 4. Average response rate (responses per second) in each tenth of the FI schedules employed in Experiment 1b. Rates were calculated over the last 10 sessions of each condition. The condition labels and other details are as in Figure 3.

When the first segment was an FI 40-s schedule, the pattern of responding on the simple schedules stayed similar to baseline. As in the previous condition, rates in the first segment of the 
chained schedules were lower, and rates in the second segment higher, than those in the simple schedule. Unlike the previous condition, however, response rates in the first segment increased to a greater extent as the interval elapsed, particularly for 426 who developed a scalloped pattern of responding. While the pattern of responding emitted by each pigeon in the second segment of the chained schedule was similar to that in the previous condition, rates overall were higher throughout the interval. When baseline was reinstated in the final condition, the scalloped pattern of behavior characteristic of FI schedules was maintained.

In summary, the effects of juxtaposing a simple FI and a chained FI FI schedule in the current experiment did not produce effects on pausing that were more consistent than did the juxtaposition of a simple FR and chained FR FR schedule in Experiment 1a. When the chained FI 20-s FI 40-s schedule was introduced in one component of the multiple schedule pauses became longer in the transitions leading to the chained component for all pigeons, however, only two pigeons paused for an extended period of time in the simple-to-chain transition. Not only did the pigeons pause longer in the chained component, all of them with the exception of $3 \mathrm{~V}$, paused for a duration that was longer than the 20-s interval requirement. This occurred despite the fact that it delayed access to the second segment and subsequently, food. When an FI 40-s FI 20-s schedule operated in the chained component, no consistent changes were observed. These results suggest the possibility that, at least for two subjects, the chained schedule became less favorable than the simple schedule when the stimulus change occurred further from the reinforcer. However, as in Experiment 1a, conclusions cannot be made on the basis of results that occurred for just half of the pigeons.

Possible reasons for the inconsistent results in the present experiment include the schedule parameters employed. For example, a total duration of $60 \mathrm{~s}$ for the simple and chained schedules was employed because this value has been used in previous studies investigating preference between simple FI and chained FI FI schedules with pigeons as subjects (e.g., Fantino, 1983; Leung, 1994; Leung \& Winton, 1985). It is possible that the employment of a total interval requirement longer than 60 s would have caused the chained FI FI schedule to be less favorable relative to the simple schedule (more so than in the current experiment), and as a result, for extended pausing in the simple-to-chain transition to be observed. This possibility is supported by research showing that preference for the simple schedule increases as the total duration of the interval requirements in the simple and chained schedules is increased (Duncan \& 
Fantino, 1972; Leung \& Winton, 1985). This also suggests the possibility that, in Experiment 1a, a larger total ratio requirement could have produced the expected effects of juxtaposing simple FR and chained FR FR schedules on pausing. However, the likelihood of the latter is somewhat negated by the fact that the ratio sizes employed for each pigeon in Experiment 1a were the largest that could sustain reliable responding.

For the most part, response patterns on the simple FI schedules conformed to the scalloped pattern typically observed on FI schedules, in which response rates start out low and then become accelerated as the interval elapses. Very little responding occurred in the first segment of the chained FI FI schedule, particularly when an FI 20-s schedule operated in this segment. In the second segment, response rates were highest overall. In addition, response rates in the second segment were more likely to be scalloped, at least to some extent, than those in the first. This, along with the longer second-segment pauses observed in the current experiment, support the claim that behavior tended to be more sensitive to the onset of the second segment of the chained FI FI schedule than when a chained FR FR schedule was employed in Experiment 1b. This comparison will be discussed further in the general discussion of the results.

\section{EXPERIMENT 1c}

The condition in Experiment 1b that produced the longest pause durations in the simpleto-chain transition was repeated in this experiment, with the addition of a second key that the pigeon could peck to escape from the prevailing schedule conditions. Research has supported the proposition that pausing functions as a form of escape (Carlin, 1998; Cohen \& Campagnoni, 1989; Courtney, 1994; Perone, 2003). Therefore, escape was expected in the simple-to-chain transition to a similar extent that extended pausing occurred in this transition in Experiment $1 \mathrm{~b}$.

Method

\section{Subjects and Apparatus}

The pigeons and apparatus were the same as in Experiments 1a and 1b.

\section{Procedure}

The baseline condition of Experiment 1b (i.e., a multiple FI 60-s FI 60-s schedule) was modified so that, in addition to the illumination of the houselight and center key at the start of each session, the right key was illuminated the same color as that correlated with the schedule in effect on the center key. A single peck on this key (i.e., the escape key) prior to a response on the center (food) key resulted in a timeout signaled by the offset of the houselight, darkening of the 
food key, and dimming of the escape key. During a timeout, pecks on the darkened food key had no consequence, although the time associated with the FI schedule operating on this key continued to elapse. After a timeout was in effect for a minimum of $1 \mathrm{~s}$, a single peck on the escape key reinstated the schedule component; that is, the houselight was turned on, the food key was lit and operative with the color correlated with the aforementioned component, and the escape key was dark and inoperative. A peck on the food key could not be reinforced within $5 \mathrm{~s}$ of the reinstatement of the schedule. This 5-s changeover delay (COD) was implemented to prevent the potential reinforcement of time-in production by immediate food delivery.

If the food key was pecked first (i.e., before a peck on the escape key), the escape key became dark and inoperative. In either case, when the escape key became inoperative, it remained so until the start of the next component. All details regarding the escape key remained the same throughout the conditions of Experiment 1c.

In the next condition, a simple FI 60-s schedule continued to operate in one of the components of the multiple schedule. In the second component was the chained FI FI schedule that produced the most pausing when juxtaposed with the simple schedule in Experiment 1b, particularly in the simple-to-chain transition. In this case, the schedule arranged in the chained component for all pigeons was a chained FI 20-s FI 40-s schedule. An additional COD was employed when a chained schedule operated in one component. In the case that the duration of a timeout exceeded the first segment of the chained schedule, a peck on the food key could not result in access to the second segment within $5 \mathrm{~s}$ of a production of time-in.

In the final condition, the multiple schedule employed during baseline was reinstated.

Behavior was eligible to be assessed for stability after a minimum of 14 sessions. At this point, the frequency of escape in each of the four transitions was examined. Behavior was judged stable by visual inspection when there was no increasing or decreasing trend in these frequencies over the last 5 sessions.

Results and Discussion

Escape. Figure 5 shows the median frequency of escape in each transition over the last 5 sessions of each condition. With a few exceptions, the overall frequency of escape was low. In baseline, 2V9 and 426 escaped more often during the chained component. The frequency of escape was not differentiated across transitions for 3V and 437 (the median frequency was zero in all transitions for 3V). When a chained FI 20-s FI 40-s schedule operated in the chained 
component, changes in the frequency of escape across transitions were inconsistent across pigeons. The frequencies of escape emitted by 426 and 3V appear consistent with the prediction that escape would occur most often in the transition from a simple to a chained schedule, but because the frequency of escape was so low, the effect is negligible. Nonetheless, when baseline was reinstated for these pigeons, escape in the simple-to-chain transition decreased. For the other pigeons, escape frequencies changed when baseline was reinstated but, again, the changes were not consistent.

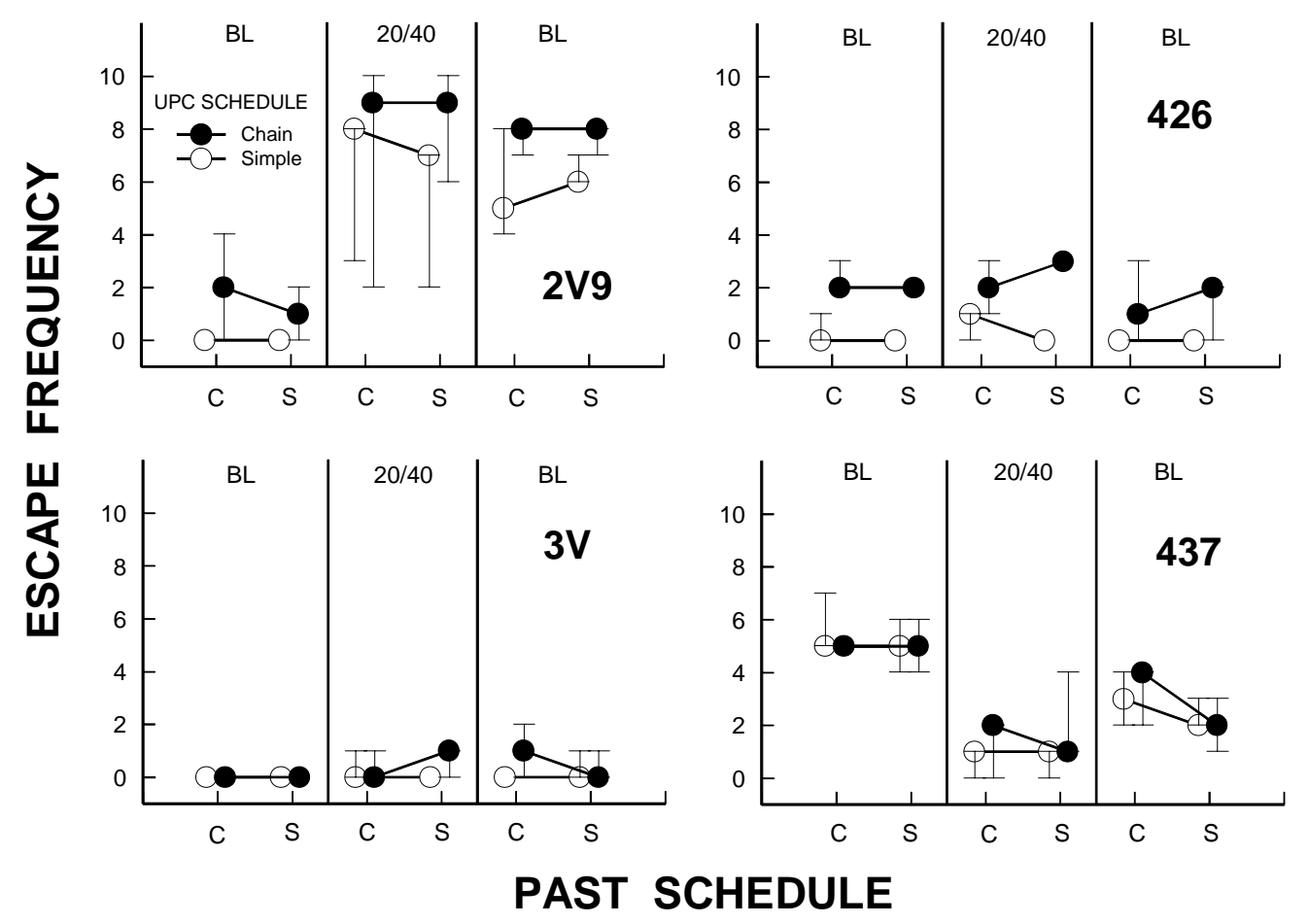

Figure 5. Median escape frequency in the transitions between a simple FI schedule and a chained FI FI schedule calculated over the last 5 session of each condition in Experiment 1c. Error bars represent the interquartile range. The condition labels and other details are as in Figure 3.

Figure 6 shows the median percentage of the session spent in timeout over the last 5 sessions of each condition. These percentages were minimal in most cases. In baseline, all pigeons but $3 \mathrm{~V}$ spent some percentage of the session in timeout, particularly in the chained 
component. When a chained FI 20-s FI 40-s schedule operated in the chained component, changes in the percentage of the session spent in timeout changed inconsistently across pigeons. As with frequencies, the percentage of the session in timeout increased for Pigeon 2V9, especially in the chained component. Timeouts in the simple-to-chain transition constituted a larger percentage of the session than those in the other transitions for 426 , however the overall percentages were too low to represent a noteworthy effect. When baseline was reinstated, the percentage in the simple-to-chain transition decreased for this pigeon. Pauses by the other pigeons remained about the same as in the previous condition when a chained schedule operated in one component.

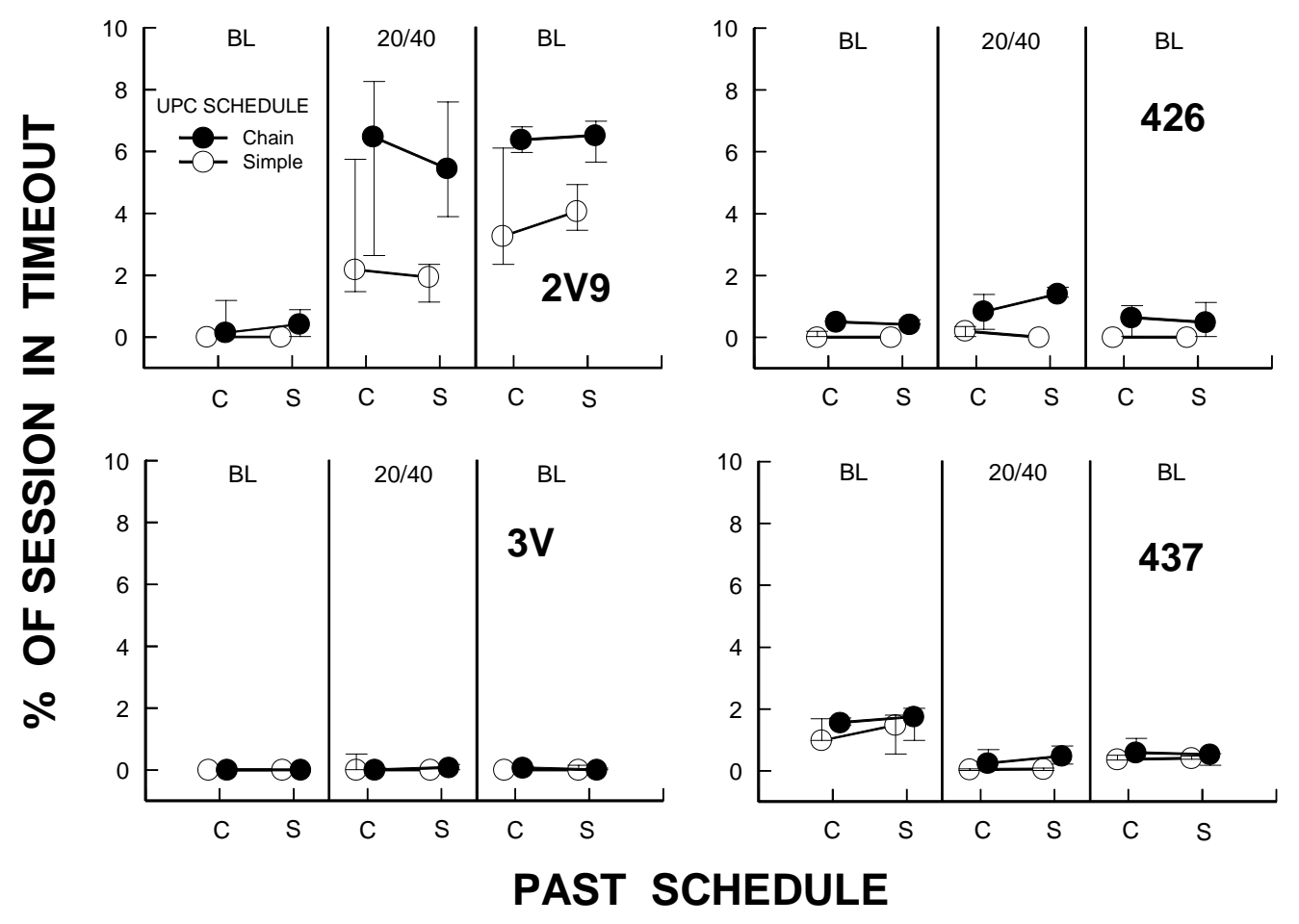

Figure 6. Median percent of the session spent in timeout in the transitions between a simple FI schedule and a chained FI FI schedule. Percentages are based on the last 5 sessions of each condition in Experiment 1c and error bars represent the interquartile range. The condition labels and other details are as in Figure 3. 

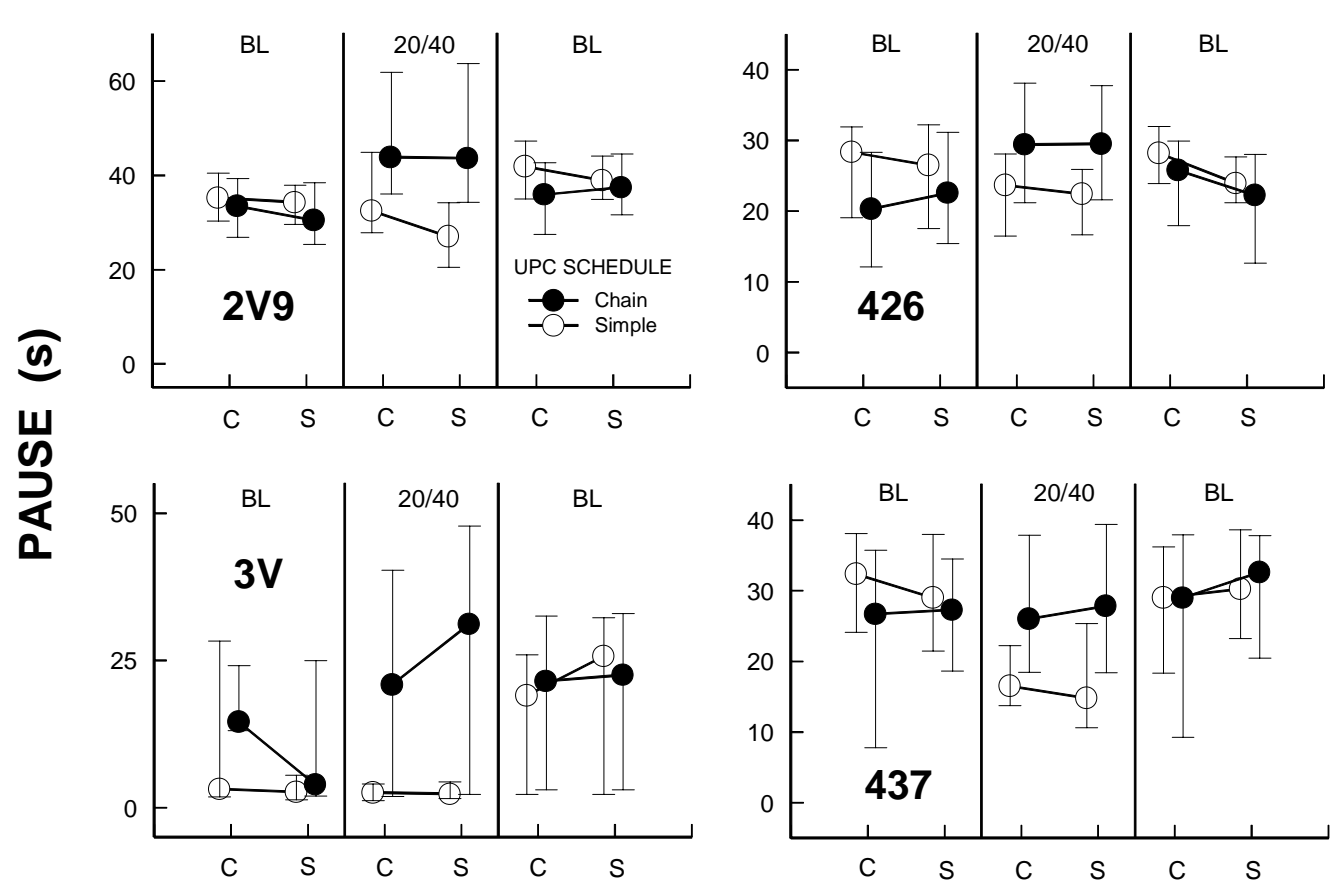

\section{PAST SCHEDULE}

Figure 7. Median pause durations (including any time spent in timeout) in the transitions between a simple FI schedule and a chained FI FI schedule calculated over the last 5 sessions of each condition in Experiment 1c. Error bars represent the interquartile range. The condition labels and other details are as in Figure 3.

Pauses. Figure 7 shows the median pauses in each transition calculated over the last 5 sessions of each condition. Pauses were recorded as the time between the start of a component and the first response on the food key. Therefore, if a pigeon produced a timeout prior to pecking the food key, the duration of this timeout was included in the measurement of the pause. The effect of the present manipulation on pausing replicated those observed in Experiment 1b. The levels of pausing observed during baseline were inconsistent across pigeons; however, when a chained FI 20-s FI 40-s schedule operated in the chained component, pauses became elevated in the transitions to the chained schedule relative to the transitions leading to a simple schedule. 
Only 3V (and possibly 437) paused for a substantially longer time in the simple-to-chain transition, although the variability in pause durations was large.

Table 7. Median pauses in the second segment of the chained FI FI schedule, calculated over the last 5 sessions of the condition in Experiment 1c in which a chained FI 20-s FI 40-s schedule operated in one component. The interquartile range is shown in parentheses.

\begin{tabular}{|c|c|c|c|c|c|}
\hline \multirow[b]{2}{*}{ Bird } & \multirow[b]{2}{*}{ Condition } & \multicolumn{4}{|c|}{ Transition } \\
\hline & & Chain-Chain & Chain-Simple & Simple-Chain & Simple-Simple \\
\hline $2 V 9$ & $20 / 40$ & $3.35(0.34-8.68)$ & -- & $5.68(0.32-15.97)$ & -- \\
\hline 426 & $20 / 40$ & $0.41(0.30-0.89)$ & -- & $0.55(0.30-2.46)$ & -- \\
\hline $3 \mathbf{V}$ & $20 / 40$ & $1.27(0.31-2.42)$ & -- & $0.75(0.30-2.40)$ & -- \\
\hline 437 & $20 / 40$ & $3.42(0.92-7.18)$ & -- & 3.48 (0.95-6.63) & -- \\
\hline
\end{tabular}

Table 7 shows the pauses emitted in the second segment of the chained FI 20-s FI 40-s schedule that operated in the second condition of the current experiment. Pauses were relatively long for Pigeons 2V9 and 437 and short for 426 and 3V. Across the chain-to-chain and simpleto-chain transitions, differences were inconsistent across pigeons. Pigeon 2V9 and 426 emitted longer second-segment pauses in the simple-to-chain transition, while $3 \mathrm{~V}$ emitted longer pauses in the chain-to-chain transition. Pigeon 437 showed no substantial difference in second-segment pauses across the two transitions. 


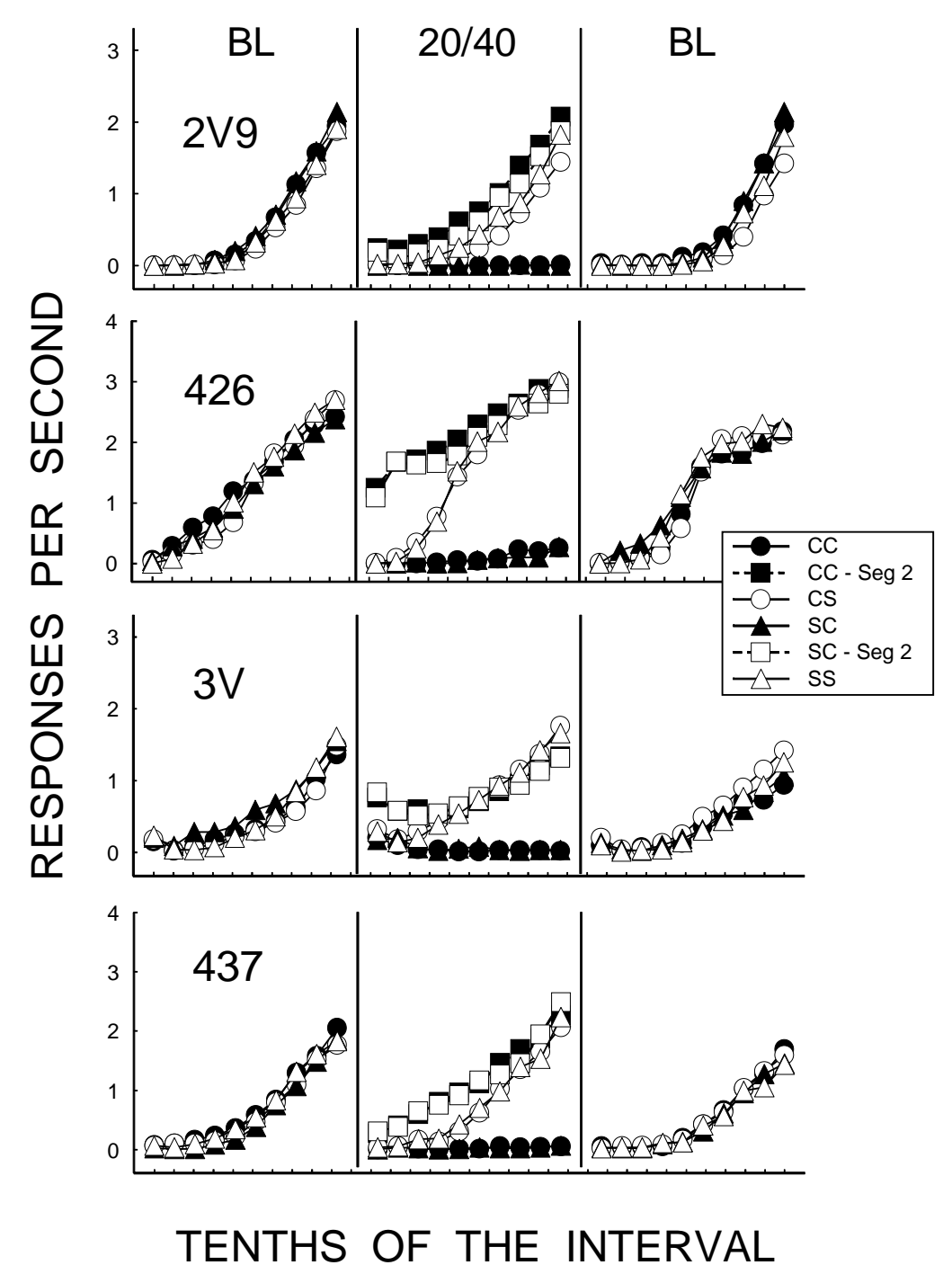

Figure 8. Average response rate (responses per second) in each tenth of the FI schedules employed in Experiment 1c. Rates were calculated over the last 5 sessions of each condition. The condition labels and other details are as in Figure 3.

Response rates. Figure 8 shows average response rates in each tenth of the interval for the simple FI schedules in baseline and in the experimental condition, and for each segment of the chained FI 20-s FI 40-s schedule in the experimental condition. Response rates in each tenth of the interval were averaged across the last 5 sessions of each condition. In baseline, response rates accelerated throughout the FI in all transitions, producing a scalloped pattern of responding. 
When a chained FI 20-s FI 40-s schedule operated in the chained component, response rates remained low in the first segment of the chained schedule, and began to accelerate once the second segment was initiated. With the exception of 426, the scalloped pattern consisted of rates that were the same or slightly higher than in the simple schedule throughout the interval. Pigeon 426 showed a more abrupt transition to a higher rate of responding once the second segment was initiated, and therefore, did not show much of a scalloped response pattern in this segment. When baseline was reinstated, the response patterns and levels observed in the initial exposure to baseline were replicated. One difference across the two exposures to baseline was shown by 426, however, in which the rate of responding tended to level off prior to the reinforcer delivery.

In summary, with a few exceptions, escape did not occur often in the conditions of the current experiment. Because escape was infrequent, one question raised is whether the pigeons paused at levels approximating those in Experiment 1b. If, for example, pause durations in the present experiment were substantially shorter, frequent escape would not be expected. The measurement of pauses revealed that this was not the case. The levels of pausing across the transitions in the current experiment replicated those observed in Experiment 1b. Specifically, pauses were longer in the chained component when a chained FI 20-s FI 40-s schedule operated in one component, with the longest pauses occurring in the simple-to-chain transition for just half the pigeons. Overall, these results suggest that escape is not necessarily going to occur during the time when longer pauses typically occur. Another interpretation is that, although pauses were longer on the chained FI 20-s FI 40-s schedule, this constituted behavior typical of a chained schedule [response rates typically are low in the initial segment(s) of a chained schedule; e.g., Kelleher \& Fry, 1962; Fantino, 1969b] and was not the result of decreased favorability of the schedule as the result of its segmentation. Previous research supports the notion that if the chained schedule was sufficiently less favorable than the simple schedule, pausing would have been substantially longer in the simple-to-chain transition than in the other transitions, including the chain-to-chain transition, and this was not observed consistently across pigeons.

\section{EXPERIMENT 2a}

The first phase of Experiment 2 examined the combined effects of schedule segmentation and reinforcer magnitude on pausing. A two-component multiple schedule operated. Completion of the response requirement in one component (i.e., the lean component) resulted in a small reinforcer and completion of the requirement in the other component (i.e., the rich component) 
resulted in a large reinforcer. Also, in one component (either the rich or lean schedule, depending on the condition), a simple FR schedule operated, and in the other component, the FR schedule was chained.

In baseline, when the components differed only in the magnitude of the reinforcer, extended pausing was expected in the rich-to-lean transition. Pausing in this transition was then expected to increase when the lean component was segmented early in the schedule and decrease when the lean component was segmented late. This prediction was based on the expectation that the lean component would become less favorable in the former case, and more favorable in the latter case, relative to the rich component. When the rich component was segmented early, pausing in the rich-to-lean transition was expected to decrease as the favorability of the rich component decreased relative to the lean component. When the rich component was segmented late, pausing in the rich-to-lean transition was expected to increase as the favorability of the rich component increased.

Method

\section{Subjects and Apparatus}

Four male White Carneau pigeons were used. All pigeons were maintained at $80 \%( \pm$ $2 \%$ ) of their free-feeding weights with the exception of $22 \mathrm{X}$, who was maintained at $75 \%$ ( \pm 2\%). All other details, as well as the apparatus, are the same as in Experiment 1.

\section{Preliminary Training}

The procedures used in preliminary training were the same as those described in Experiment 1a. With respect to determining the existence of color biases, the center key in the chambers used by the pigeons in Experiment 2a was equipped with 4, rather than 3, key colors. This yielded five color combinations that varied across sessions as the FR requirement was increased. Also, because there were 5 combinations, 5 sessions were conducted once terminal FR size was reached so the pigeon could be exposed to each color combination. As in Experiment 1a, the terminal FR size was the highest ratio requirement that could sustain responding with the current schedule parameters and was 100 or 120, depending on the pigeon.

If a particular color was accompanied by extended pausing relative to the other colors, this color was correlated with the rich component. If a particular color was accompanied by minimal pausing relative to the other colors, this color was correlated with the lean component. The key colors correlated with the schedules employed in Experiment 2a are shown in Table 8. 
Table 8. Key colors correlated with the schedules in each component of Experiments $2 a, 2 b$, and $2 c$.

\begin{tabular}{|c|c|c|c|c|}
\hline \multirow[b]{3}{*}{ Pigeon } & \multicolumn{4}{|c|}{ Component } \\
\hline & \multicolumn{2}{|c|}{ Rich } & \multicolumn{2}{|c|}{ Lean } \\
\hline & Segment 1 & Segment 2 & Segment 1 & Segment 2 \\
\hline $20 X$ & White & Green & Blue & Red \\
\hline $21 X$ & Blue & Green & Red & White \\
\hline $22 X$ & Red & Blue & Green & White \\
\hline 231 & White & Red & Green & Blue \\
\hline
\end{tabular}

\section{Experimental Conditions}

Table 9 shows a summary of the conditions in Experiment 2a. During baseline, a simple FR 100 or 120 schedule, depending on the pigeon, operated in both components of a multiple schedule. The lean component ended in a short duration (1- or 2-s, depending on the pigeon) of access to grain (a small reinforcer) and the rich component in a longer duration (6- or 7-s) of access to grain (a large reinforcer).

Across the next 2 conditions, the lean component remained a simple FR schedule. In the rich component, a chained schedule was arranged. As in Experiment 1a, the total number of responses required by the chained schedule was the same as that required by the simple FR schedule (either 100 or 120) and the center key changed colors once the response requirement in the initial segment of the chained schedule was completed (see Table 8). The response requirement in the two segments of the chain schedule varied across conditions. For the pigeons exposed to a total requirement of 100 responses, the requirement in the initial segment of the rich schedule was either 25 or 75, depending on the condition. For the pigeons exposed to a total requirement of 120 responses, the requirement in the initial segment was either 30 or 90, depending on the condition. In the next 2 conditions, the lean component became a chained schedule while a simple FR schedule operated in the rich component. As in the previous conditions, the chained schedule was segmented early or late in the completion of the total response requirement across conditions. 
Table 9. The number of sessions completed by each pigeon in each condition of Experiments 2a, 2b, and 2c. The order of conditions is shown in parentheses.

\begin{tabular}{|c|c|c|c|c|c|}
\hline \multirow[b]{2}{*}{$\begin{array}{c}\text { Rich } \\
\text { Component }\end{array}$} & \multirow[b]{2}{*}{$\begin{array}{c}\text { Lean } \\
\text { Component }\end{array}$} & \multicolumn{4}{|c|}{ Pigeon } \\
\hline & & $20 X$ & $21 X$ & $22 X$ & 231 \\
\hline \multicolumn{6}{|c|}{ Experiment $2 \mathrm{a}$} \\
\hline FR 120 & FR 120 & $37(1)$ & -- & -- & -- \\
\hline Chain FR 30 FR 90 & FR 120 & $21(2)$ & -- & -- & -- \\
\hline Chain FR 90 FR 30 & FR 120 & $24(3)$ & -- & -- & -- \\
\hline FR 120 & Chain FR 30 FR 90 & $22(4)$ & -- & -- & -- \\
\hline FR 120 & Chain FR 90 FR 30 & $0(5)^{a}$ & & & \\
\hline FR 120 & FR 120 & $0(6)^{\mathrm{a}}$ & -- & -- & -- \\
\hline FR 100 & FR 100 & -- & $23(1)$ & $27(1)$ & $24(1)$ \\
\hline Chain FR 25 FR 75 & FR 100 & -- & $36(3)$ & $20(4)$ & $0(5)^{a}$ \\
\hline Chain FR 75 FR 25 & FR 100 & -- & $23(2)$ & $0(5)^{a}$ & $26(4)$ \\
\hline FR 100 & Chain FR 25 FR 75 & -- & $0(5)^{a}$ & $34(2)$ & $20(3)$ \\
\hline FR 100 & Chain FR 75 FR 25 & -- & $0(4)^{a}$ & $24(3)$ & $29(2)$ \\
\hline FR 100 & FR 100 & & $0(6)^{\mathrm{a}}$ & $0(6)^{\mathrm{a}}$ & $0(6)^{\mathrm{a}}$ \\
\hline \multicolumn{6}{|c|}{ Experiment $2 \mathrm{~b}$} \\
\hline FI $60 \mathrm{~s}$ & FI $60 \mathrm{~s}$ & $32(1)$ & $32(1)$ & $34(1)$ & $32(1)$ \\
\hline Chain FI 30 s FI 30 s & FI $60 \mathrm{~s}$ & $20(2)$ & $20(2)$ & $21(3)$ & $22(3)$ \\
\hline FI $60 \mathrm{~s}$ & Chain FI 30 s FI 30 s & $20(3)$ & $26(3)$ & $21(2)$ & $21(2)$ \\
\hline FI $60 \mathrm{~s}$ & FI $60 \mathrm{~s}$ & $14(4)$ & $15(4)$ & $14(4)$ & $16(4)$ \\
\hline \multicolumn{6}{|c|}{ Experiment 2 c } \\
\hline FI $60 \mathrm{~s}$ & FI $60 \mathrm{~s}$ & $14(1)$ & $16(1)$ & $15(1)$ & $14(1)$ \\
\hline FI $60 \mathrm{~s}$ & Chain FI 30 s FI 30 s & $17(2)$ & $14(2)$ & $14(2)$ & $15(2)$ \\
\hline FI $60 \mathrm{~s}$ & FI $60 \mathrm{~s}$ & $14(3)$ & $15(3)$ & $14(3)$ & $14(3)$ \\
\hline
\end{tabular}

Behavior was judged stable according to the same criteria as in Experiment 1a and the order of conditions was counterbalanced across pigeons. Not all pigeons in Experiment 2a were exposed to all of the planned conditions before the experiment was ended (see Table 9). When it became apparent that the effects of the manipulations, particularly on pausing, were for the most part inconsistent, the experiment was terminated in order to proceed with Experiment 2b. 
Results and Discussion

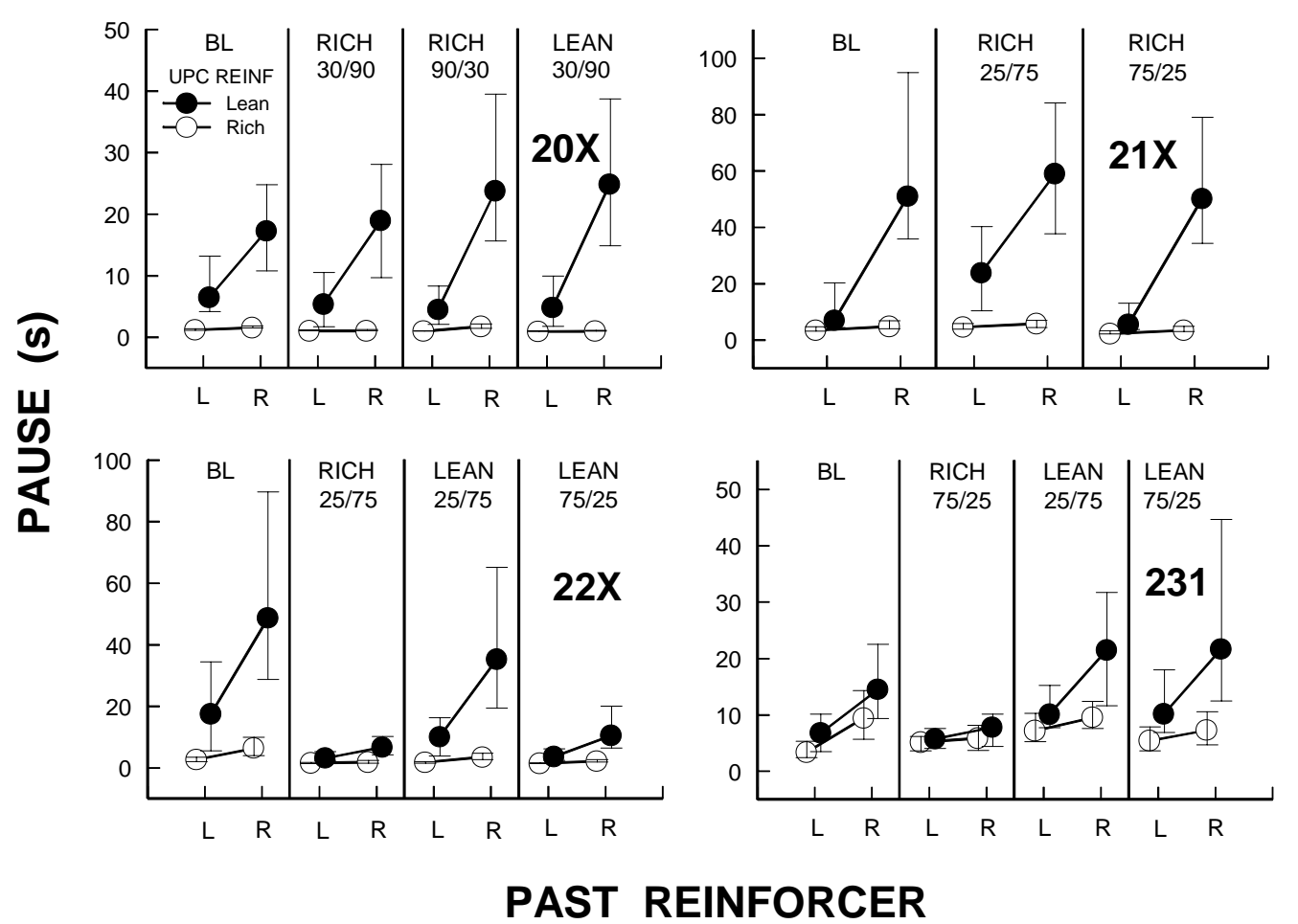

Figure 9. Median pause durations in the transitions between rich and lean FR schedules calculated over the last 10 sessions of each condition in Experiment 2a. Error bars represent the interquartile range. The condition is portrayed at the top of each panel in each graph: Baseline (BL) (note that a simple schedule operated in both the lean and rich components during baseline), when the rich schedule was chained (Rich), and when the lean schedule was chained (Lean). The fraction under the rich and lean labels represents the number of responses required in each segment of the chained schedule. For example, in the "Rich 30/90" condition, the rich schedule was chained, requiring 30 responses in the first segment and 75 in the second. The abbreviations "UPC" and "REINF" in the legend stand for "upcoming” and "reinforcer," respectively.

Pauses. Figure 9 shows the median pause duration in each transition calculated over the last 10 sessions of each condition. During baseline, the components of the multiple schedule differed only in the magnitude of reinforcement obtained by completing each. For three of the four pigeons, the pattern of pausing was consistent with that shown in Perone and Courtney's (1992) study. That is, pauses were longer in the transitions leading to a lean component, and 
were especially extended when the past component had been rich. The one exception was 231 . For this pigeon pauses were longer when the past component was rich, however, pauses in the rich-to-lean transition were not especially extended relative to pauses in the other transitions.

All pigeons but 231 experienced a condition in which the rich component was segmented early in the schedule. Pauses emitted by 20X and 21X did not change from baseline levels. For $22 \mathrm{X}$, pauses in the transition leading to a lean component decreased and became almost as short as in the transitions leading to a rich one. The effect shown by $22 \mathrm{X}$ was consistent with the prediction that pauses in the rich-to-lean transition would decrease as a result of a corresponding decrease in the favorability of the rich schedule relative to the lean schedule.

All pigeons but 22X experienced a condition in which the rich component was segmented late in the schedule. No consistent differences in pauses were observed across these pigeons. Only the effect shown by 20X was consistent with the prediction that rich-to-lean pauses would increase as the result of the increase in the favorability of the rich schedule when the stimulus change occurred closer to the reinforcer.

In the next condition, experienced by all pigeons but $21 \mathrm{X}$, the lean component was chained and the first segment required relatively few responses. Rich-to-lean pauses stayed the same as in the previous condition for $20 \mathrm{X}$ and increased for $22 \mathrm{X}$ and 231. In fact, it was not until this condition, that 231 showed the joint control of pausing by the past and upcoming reinforcer that was sought during baseline. The results shown by $22 \mathrm{X}$ and 231 were consistent with predictions; it was expected that pauses would increase due to the decrease in the favorability of the lean schedule when this schedule was chained and the stimulus change occurred further from the reinforcer.

Finally, when the first segment of the lean component required a large number of responses relative to the second segment, pauses in the rich-to-lean transition were expected to be longer than those observed in all other conditions but the previous one. Only 22X and 231 experienced this condition. For 22X, the rich-to-lean pause decreased substantially, while for 231, this pause increased to the highest levels observed in the experiment.

Table 10 shows median second-segment pauses calculated over the last 10 sessions of each condition. These pauses were calculated in the same manner as in Experiment 1a for both the chained and simple schedules. Unlike Experiment 1a, however, there were no general consistencies in second-segment pauses, either across transitions or across conditions. Only 231 
showed a relatively substantial difference, in which second-segment pauses were longer in the rich schedules when the lean schedule was chained, and particularly so when the first segment of the lean schedule required just 25 responses.

Table 10. Median pauses in the second segment of the chained FR FR schedule, calculated over the last 10 sessions of each condition in Experiment 2a. In the transitions leading to a simple FR schedule, pauses preceding what would have been the first response in the second segment of a tandem FR FR schedule were recorded. The interquartile range is shown in parentheses.

\begin{tabular}{|c|c|c|c|c|c|}
\hline \multirow[b]{2}{*}{ Bird } & \multirow[b]{2}{*}{ Condition } & \multicolumn{4}{|c|}{ Transition } \\
\hline & & Lean-Lean & Lean-Rich & Rich-Lean & Rich-Rich \\
\hline \multirow[t]{3}{*}{$20 X$} & Rich 30/90 & $0.35(0.31-0.38)$ & $0.30(0.27-0.34)$ & $0.34(0.31-0.38)$ & $0.31(0.28-0.34)$ \\
\hline & Rich 90/30 & $0.36(0.34-0.43)$ & $0.40(0.36-0.46)$ & $0.36(0.33-0.44)$ & $0.39(0.36-0.46)$ \\
\hline & Lean 30/90 & $0.28(0.23-0.33)$ & $0.31(0.28-0.38)$ & $0.28(0.24-0.32)$ & $0.32(0.28-0.38)$ \\
\hline \multirow[t]{2}{*}{$21 X$} & Rich 25/75 & $0.37(0.29-0.44)$ & $0.34(0.28-0.38)$ & $0.35(0.30-0.44)$ & $0.32(0.27-0.35)$ \\
\hline & Rich 75/25 & $0.32(0.13-0.39)$ & $0.32(0.20-0.38)$ & $0.33(0.17-0.39)$ & $0.32(0.29-0.36)$ \\
\hline \multirow[t]{3}{*}{$22 X$} & Rich 25/75 & $0.12(0.11-0.20)$ & $0.20(0.12-0.25)$ & $0.14(0.11-0.31)$ & $0.16(0.12-0.27)$ \\
\hline & Lean 25/75 & $0.29(0.22-0.34)$ & $0.27(0.19-0.34)$ & $0.27(0.16-0.33)$ & $0.27(0.16-0.36)$ \\
\hline & Lean 75/25 & $0.14(0.12-0.33)$ & $0.13(0.11-0.24)$ & $0.19(0.11-0.33)$ & $0.14(0.11-0.22)$ \\
\hline \multirow[t]{3}{*}{231} & Rich 75/25 & $0.19(0.12-0.26)$ & $0.20(0.17-0.28)$ & $0.21(0.12-0.29)$ & $0.20(0.16-0.29)$ \\
\hline & Lean 25/75 & $0.24(0.14-0.39)$ & $0.43(0.13-0.59)$ & $0.26(0.16-0.38)$ & $0.41(0.22-0.61)$ \\
\hline & Lean 75/25 & $0.31(0.25-0.40)$ & $0.37(0.19-0.59)$ & $0.29(0.22-0.37)$ & $0.38(0.20-0.51)$ \\
\hline
\end{tabular}

One observation regarding second-segment pauses is consistent with Experiment 1a. These pauses were short (none of the medians exceeded $0.5 \mathrm{~s}$ ) across all transitions, indicating that once the pigeons started responding toward completing the total FR requirement, they 
continued to peck without interruption (i.e., through the stimulus change in the case of the chained schedules) until the delivery of the next reinforcer.

Run rates. Figure 10 shows the median run rate in each transition, calculated over the last 10 sessions of each condition. During baseline, only $21 \mathrm{X}$ showed an effect of transition on run rates; run rates were higher on the rich schedule. The lack of an effect of the different magnitudes of reinforcement in the two components on run rates is consistent with the results obtained by Perone and Courtney (1992).

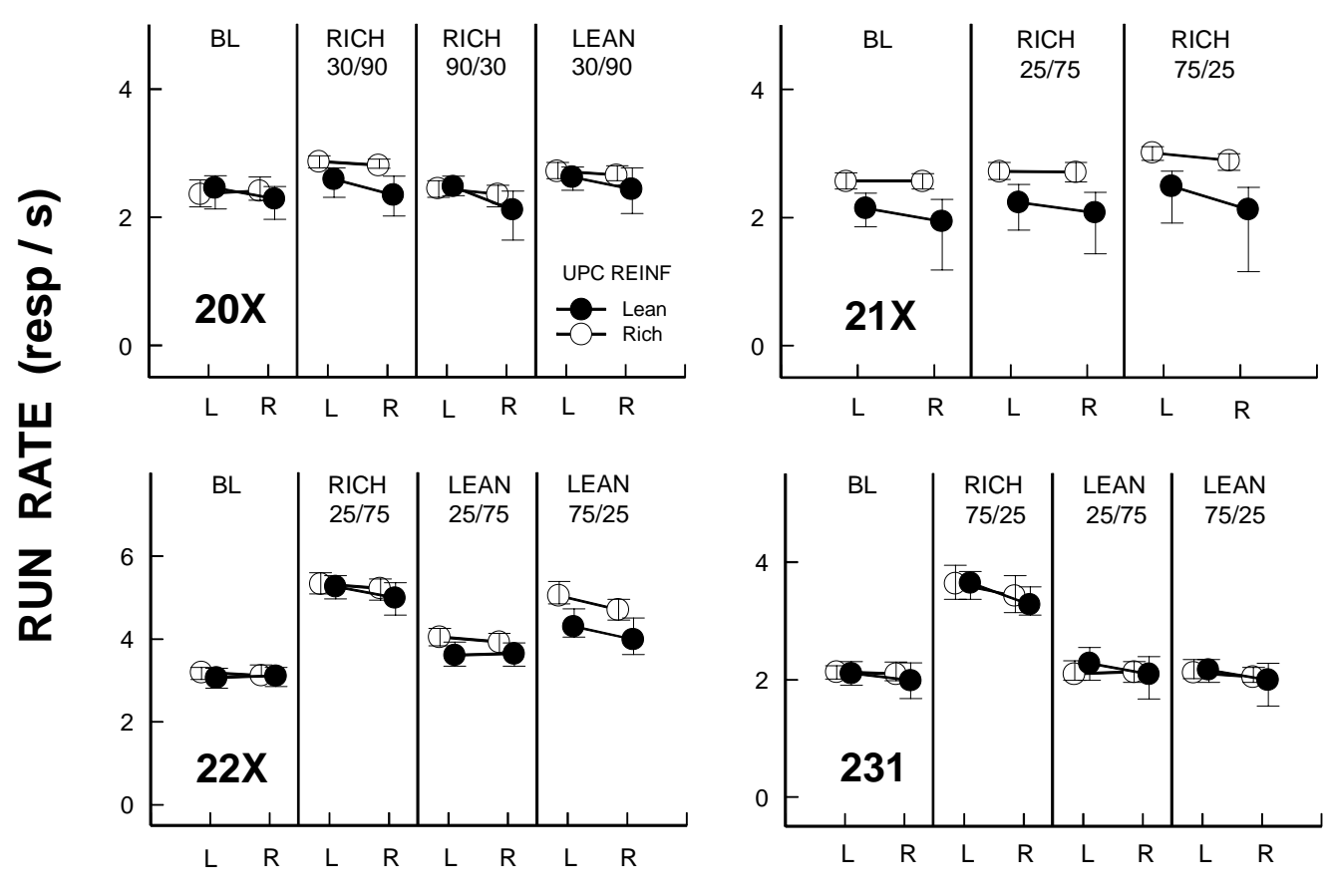

PAST REINFORCER

Figure 10. Median run rate (responses per second) in the transitions between rich and lean FR schedules calculated over the last 10 sessions of each condition in Experiment 2a. Details are as in Figure 9.

Across the experimental conditions, changes in run rates were inconsistent across pigeons. When the first segment of the rich component was short, run rates emitted by $21 \mathrm{X}$ stayed the same as in baseline, while the other pigeons exposed to this condition, 20X and 22X, 
responded faster overall. In addition, Pigeon 20X began to respond slightly faster in the rich component. Run rates returned to baseline levels when the stimulus change occurred late in the rich component. Run rates emitted by $21 \mathrm{X}$ and 231 (the other pigeons exposed to this condition) increased slightly overall and this increase occurred predominately in the transitions to a rich component for $21 \mathrm{X}$.

When the first segment of the lean component required relatively few responses, run rates emitted by 20X were roughly the same as in baseline. Pigeons 22X and 231 responded slower overall relative to the previous condition, in which the rich schedule had been chained. For 231, run rates were at baseline levels and remained there throughout the next condition, in which the first segment of the lean component was long. When, in the lean component, the stimulus change occurred close to the reinforcer, run rates emitted by $22 \mathrm{X}$ increased, particularly in the rich component. Pigeons 231 and 22X were the only subjects exposed to this condition.

Table 11 shows the median first-segment run rate in the final 10 sessions of each condition, calculated in the same manner as in Experiment 1a for both the simple and chained schedules. Regardless of whether the rich or lean schedule was chained, all pigeons responded the slowest in the rich-to-lean transition, and the fastest in the lean-to-rich transition. The second fastest run rates were obtained in the rich-to-rich transition. This suggests that reinforcer magnitude, and not the segmentation of the schedules, primarily controlled run rates early in the completion of the schedule. One observation suggests some role of the segmentation of the lean schedule in controlling run rates, however. Pigeons 22X and 231 responded at lower rates when the first segment of the lean component was short. This was the case for $20 \mathrm{X}$ as well, but only in the lean-to-lean and rich-to-lean transitions. 
Table 11. Median run rates (resp/s) in the first segment of the chained FR FR schedule, calculated over the last 10 sessions of each condition in Experiment 2a. Run rates on the simple FR schedules were calculated through what would have been the response to initiate the second segment of a tandem FR FR schedule. The interquartile range is shown in parentheses.

\begin{tabular}{|c|c|c|c|c|c|}
\hline \multirow[b]{2}{*}{ Bird } & \multirow[b]{2}{*}{ Condition } & \multicolumn{4}{|c|}{ Transition } \\
\hline & & Lean-Lean & Lean-Rich & Rich-Lean & Rich-Rich \\
\hline \multirow[t]{3}{*}{$20 X$} & Rich 30/90 & $2.42(1.70-2.92)$ & 3.26 (3.09-3.39) & $1.87(1.15-2.45)$ & $2.80(2.62-2.90)$ \\
\hline & Rich 90/30 & $2.61(2.45-2.79)$ & $2.69(2.58-2.79)$ & $2.07(1.51-2.39)$ & $2.59(2.43-2.70)$ \\
\hline & Lean 30/90 & $2.21(1.71-2.70)$ & $3.14(3.01-3.26)$ & $1.88(1.19-2.60)$ & $2.91(2.72-3.05)$ \\
\hline \multirow[t]{2}{*}{$21 X$} & Rich 25/75 & $1.64(1.00-2.26)$ & $2.65(2.40-2.96)$ & $1.47(0.67-1.98)$ & $2.45(2.16-2.84)$ \\
\hline & Rich 75/25 & $2.31(1.66-2.58)$ & $2.89(2.78-3.02)$ & $1.90(0.94-2.25)$ & $2.77(2.58-2.88)$ \\
\hline \multirow[t]{3}{*}{$22 X$} & Rich 25/75 & $4.31(3.88-4.78)$ & $4.53(4.21-4.75)$ & $3.84(3.22-4.42)$ & $4.04(3.69-4.33)$ \\
\hline & Lean 25/75 & $3.19(2.51-3.71)$ & $3.52(3.21-3.84)$ & $3.29(2.62-3.70)$ & $3.08(2.77-3.28)$ \\
\hline & Lean 75/25 & $4.04(3.74-4.43)$ & $5.01(4.68-5.42)$ & 3.73 (3.30-4.19) & $4.52(4.29-4.88)$ \\
\hline \multirow[t]{3}{*}{231} & Rich 75/25 & 3.57 (3.28-3.88) & $3.72(3.39-4.03)$ & $3.19(2.89-3.55)$ & $3.34(3.05-3.73)$ \\
\hline & Lean 25/75 & $1.69(1.19-2.23)$ & $1.86(1.52-2.14)$ & $1.38(0.86-2.01)$ & $1.66(1.44-2.00)$ \\
\hline & Lean 75/25 & $2.03(1.85-2.20)$ & $2.09(1.93-2.26)$ & $1.86(1.35-2.25)$ & $1.97(1.85-2.14)$ \\
\hline
\end{tabular}

Table 12 shows the median second-segment run rate in the final 10 sessions of each condition, calculated in the same manner as in Experiment 1a for both the simple and chained schedules. Consistent with the results of Experiment 1a, run rates during the second segment were higher than in the first. In addition, 22X and 231 responded at lower rates when the first segment of the lean component had a small ratio requirement. For 231, low rates were obtained also when the first segment of the lean schedule was long, although these rates were not as low as in the aforementioned case. 
Table 12. Median run rates (resp/s) in the second segment of the chained FR FR schedule, calculated over the last 10 sessions of each condition in Experiment 2a. Run rates on the simple FR schedules were calculated using the time between what would have been the first and last responses in the second segment of a tandem FR FR schedule. The interquartile range is shown in parentheses.

\begin{tabular}{|c|c|c|c|c|c|}
\hline \multirow[b]{2}{*}{ Bird } & \multirow[b]{2}{*}{ Condition } & \multicolumn{4}{|c|}{ Transition } \\
\hline & & Lean-Lean & Lean-Rich & Rich-Lean & Rich-Rich \\
\hline \multirow[t]{3}{*}{$20 \mathrm{X}$} & Rich 30/90 & $2.74(2.61-2.85)$ & $2.76(2.70-2.89)$ & $2.71(2.58-2.83)$ & $2.87(2.79-2.95)$ \\
\hline & Rich 90/30 & $2.24(2.03-2.44)$ & $1.94(1.70-2.25)$ & $2.34(2.13-2.58)$ & $1.90(1.62-2.29)$ \\
\hline & Lean 30/90 & $2.83(2.71-2.97)$ & $2.62(2.48-2.78)$ & $2.84(2.72-2.98)$ & $2.66(2.54-2.77)$ \\
\hline \multirow[t]{2}{*}{$21 X$} & Rich 25/75 & $2.63(2.46-2.83)$ & $2.81(2.69-2.93)$ & $2.55(2.40-2.73)$ & $2.83(2.73-2.95)$ \\
\hline & Rich 75/25 & $3.50(3.26-3.66)$ & $3.50(3.34-3.67)$ & 3.39 (3.22-3.59) & 3.52 (3.39-3.67) \\
\hline \multirow[t]{3}{*}{$22 X$} & Rich 25/75 & $5.81(5.44-6.20)$ & $5.85(5.54-6.22)$ & $5.85(5.40-6.09)$ & $5.93(5.65-6.18)$ \\
\hline & Lean 25/75 & $4.03(3.75-4.25)$ & $4.34(4.14-4.59)$ & $3.91(3.71-4.19)$ & $4.45(4.11-4.77)$ \\
\hline & Lean 75/25 & $5.82(5.21-6.31)$ & $5.61(5.13-6.00)$ & $5.75(4.98-6.24)$ & $5.54(5.16-6.10)$ \\
\hline \multirow[t]{3}{*}{231} & Rich 75/25 & $4.00(3.54-4.42)$ & $3.74(3.27-4.21)$ & $4.00(3.51-4.55)$ & $3.90(3.42-4.31)$ \\
\hline & Lean 25/75 & $2.69(2.38-2.97)$ & $2.35(2.17-2.56)$ & $2.57(2.39-2.86)$ & $2.39(2.23-2.55)$ \\
\hline & Lean 75/25 & $2.76(2.49-3.02)$ & $2.55(2.14-2.83)$ & $2.73(2.48-3.11)$ & $2.48(2.21-2.68)$ \\
\hline
\end{tabular}

In summary, the current experiment obtained results that were similar to those reported by Perone and Courtney (1992). During baseline, extended pauses were observed in the rich-tolean transition relative to the other transitions between components. The effects of segmenting the rich and lean components at various points in the schedule produced inconsistent effects on pausing. As for run rates, a few consistencies were observed, but only when rates were analyzed within segments. Reinforcer magnitude appeared to be the primary variable controlling run rates, particularly in the first segment of the schedules. This result was not maintained in the second 
segment, where the only consistency across pigeons was that run rates were lower when the first segment of the lean schedule required just a few responses.

\section{EXPERIMENT 2b}

As previously discussed, FR schedules were employed in the previous experiment because they typically engender long pauses that are counterproductive in minimizing the time to reinforcement, even though research assessing preference between simple and chained schedules has exclusively employed time-based schedules. The current experiment was a systematic replication of Experiment 2a, using FI instead of FR schedules. Across conditions, either the rich or lean schedule was chained in one component, while a simple FI 1-min schedule operated in the other. Unlike the previous experiment, the schedule requirement in the segments of the chained schedule was not manipulated; a chained FI 30-s FI 30-s schedule operated in the chained component, whether it was the rich or lean component. This aspect of the procedure was eliminated to simplify the segmentation manipulation and because the manipulation of the size of the two segments did not yield consistent results in the previous experiment. Predictions regarding the results were similar to those in Experiment 2a. Pausing was expected to increase in the rich-to-lean transition when the lean component was chained and decrease in the same transition when the rich component was chained.

\section{Method}

\section{Subjects and Apparatus}

The subjects and apparatus were the same as in Experiment 2a, with one exception. Because of problems maintaining Pigeon 20X at $80 \%$ of his free-feeding weight throughout Experiment 2a, his target weight was adjusted to $85 \%$ ( $\pm 2 \%)$ for the remainder of the study. Procedure

Table 9 shows a summary of the chained schedules that operated in Experiment 2b. During baseline, an FI 60-s schedule operated in both components of the multiple schedule. As in Experiment 2a, the lean component ended in a small reinforcer and the rich in a large reinforcer. The reinforcer magnitudes associated with each component remained the same as in Experiment 2a with one exception. In an attempt to establish extended pausing in the rich-to-lean transition, the reinforcer magnitudes for Pigeon 231 were changed from 2- and 6-s access to grain to 1- and 7-s access to grain in the lean and rich components, respectively. The keycolors associated with the schedules remained the same as in Experiment 2a (see Table 8). 
In the experimental conditions, one component remained a simple FI 60-s schedule and the other component became a chained FI 30-s FI 30-s schedule. Across conditions, either the rich or lean component was chained (see Table 9). The order of conditions was reversed across pigeons.

The stability criterion used to judge the stability of behavior was the same as in Experiment 1b.

Results and Discussion
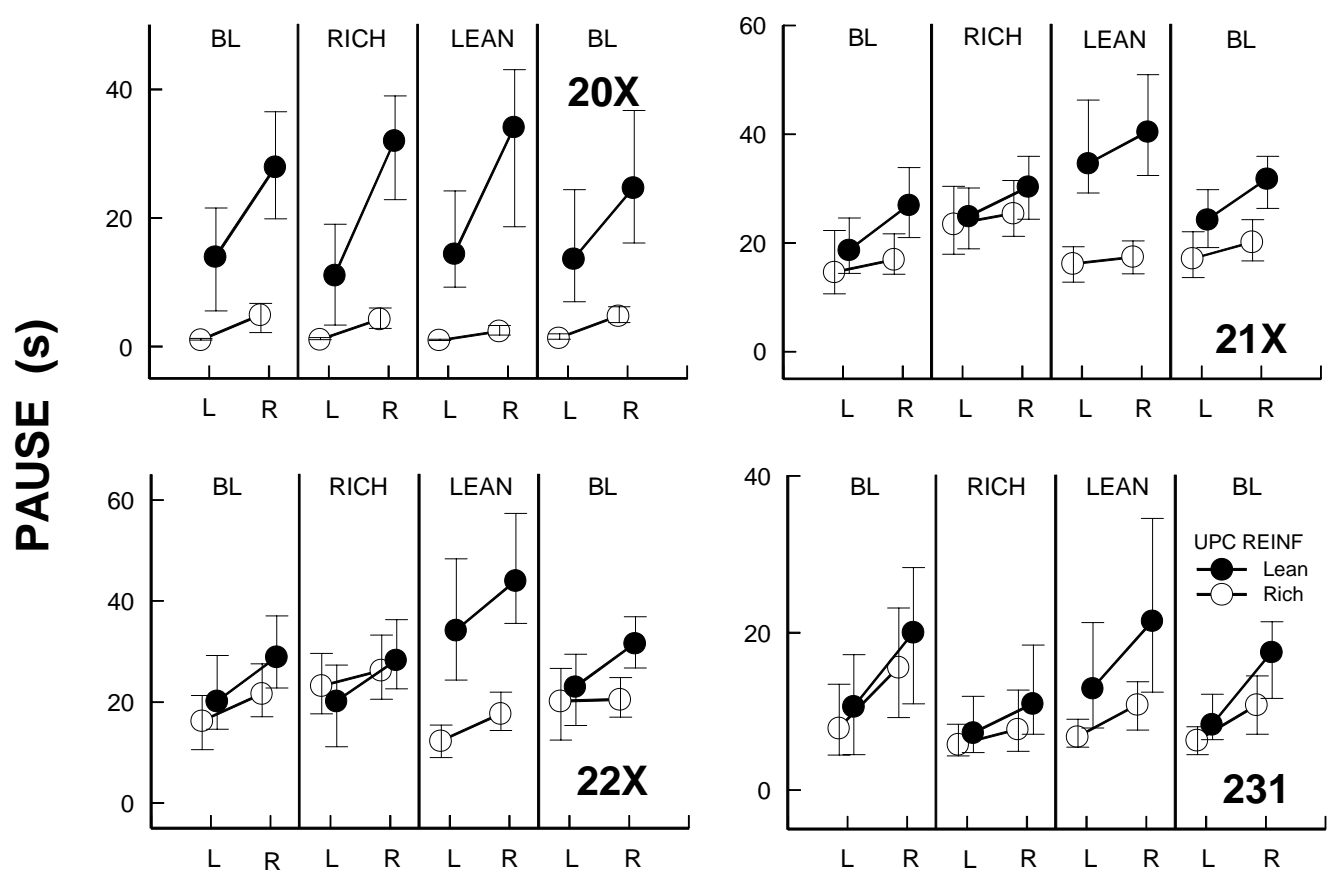

PAST REINFORCER

Figure 11. Median pause durations in the transitions between rich and lean FI schedules calculated over the last 10 sessions of each condition in Experiment 2b. Error bars represent the interquartile range. The condition is portrayed at the top of each panel in each graph: Baseline (BL) (note that a simple schedule operated in both the lean and rich components during baseline), when the rich schedule was chained (Rich) and when the lean schedule was chained (Lean). (An FI 30-s schedule operated in both segments of the schedule that was chained.) The abbreviations "UPC" and "REINF" in the legend stand for "upcoming” and "reinforcer," respectively. 
Pauses. Figure 11 shows the median pause duration in each transition calculated over the last 10 sessions of each condition. During baseline, when the components differed only in the magnitude of the reinforcer, pauses generally were longer when the upcoming component was lean. All pigeons, with the exception of 231, showed the anticipated effect and paused for extended durations in the transition from a rich to a lean component. Pigeon 231 paused longer after a rich reinforcer than after a small one, regardless of the upcoming reinforcer.

When the rich component became chained, pauses in the rich-to-lean transition were no longer extended relative to the other transitions, with the exception of $20 \mathrm{X}$ who continued to show a pattern of pausing similar to baseline. For Pigeon 231, all pauses decreased, although the rich-to-lean pause remained slightly longer than in the other transitions. For $21 \mathrm{X}$ and $22 \mathrm{X}$, pauses in the transitions to a rich component increased to about the same length as those in the transitions to a lean component. It was predicted that chaining the rich schedule would decrease favorability of this schedule and, as a result, decrease pause durations in the rich-to-lean transition relative to baseline. It is clear that 231 showed this effect. For $21 \mathrm{X}$ and $22 \mathrm{X}$, pauses in the rich-to-lean transition stayed about the same while pauses in the other transitions increased to a similar level as the rich-to-lean pauses. Therefore, although pause durations in the rich-to-lean transition were unchanged, these pauses no longer were extended relative to pauses in the other transitions. Table 13 shows pauses in each transition expressed as the percentage of the total time spent pausing. For Pigeons 21X and 22X, the percentage of the total pause time spent pausing in the rich-to-lean transition decreased relative to baseline when the rich schedule was chained, although the effect was small.

When the lean schedule became chained, pauses increased rather dramatically in the lean component relative to the rich component for all Pigeons but 20X. In addition, pauses in the richto-lean transition were heightened, to a much greater extent than in baseline, relative to pauses in the other transitions. This effect was observed regardless of whether pauses were expressed as medians or as the percentage of total pause time (see Table 13). The median pause duration emitted by $20 \mathrm{X}$ and its associated variability was slightly longer than in baseline and when the rich component was chained, but the effect was small. When baseline was reinstated, pause durations observed across the transitions returned to levels similar to those observed during the first exposure to baseline. Overall, the effects shown in this condition were consistent with the 
prediction that chaining either the lean or rich schedule would further decrease the relative favorability of the schedule.

Table 13. Pausing in each transition expressed as the percentage of total time spent pausing in Experiment $2 b$.

\begin{tabular}{lcccc}
\hline & \multicolumn{4}{c}{ Transition } \\
\cline { 2 - 5 } Condition & LL & LR & RL & RR \\
\hline \multicolumn{4}{c}{ Pigeon 20X } \\
\hline Baseline & 30.93 & 2.92 & 55.18 & 10.97 \\
Rich & 25.25 & 3.29 & 60.43 & 11.03 \\
Lean & 33.87 & 2.04 & 59.12 & 4.96 \\
\hline \multicolumn{5}{c}{ Pigeon 21X } \\
\hline Baseline & 25.49 & 19.45 & 33.18 \\
Rich & 23.13 & 22.83 & 30.02 & 21.88 \\
Lean & 33.17 & 14.15 & 37.21 & 15.47 \\
\hline \multicolumn{5}{c}{ Pigeon 22X } \\
Baseline & 23.38 & 20.34 \\
Rich & 19.52 & 24.24 & 32.82 \\
Lean & 32.76 & 10.80 & 29.22 & 27.47 \\
\hline \multicolumn{4}{c}{ Pigeon 231 } \\
\hline Baseline & 21.95 & 15.55 & 36.03 \\
Rich & 23.17 & 17.00 & 36.10 \\
Lean & 27.09 & 12.42 & 41.63 \\
\hline
\end{tabular}

Note. Baseline percentages were calculated using the total time spent pausing in both baseline conditions.

Table 14 shows median pauses in the second segment of the chained schedules, calculated over the last 10 sessions of each condition. As discussed in Experiment 1b, the simple schedules were not analyzed as tandem schedules, as was the case with the simple FR schedules in Experiments 1a and 2a. The only consistent observation was that, for Pigeons 21X and 22X, second-segment pauses were longer when the lean schedule was chained than when the rich schedule was chained. The $75^{\text {th }}$ percentile for these pauses ranged from $1.49 \mathrm{~s}$ to $2.28 \mathrm{~s}$. Thus, many of the second-segment pauses in the current experiment were longer than those in the chained FR FR schedules in Experiments 1a and 2a, but not quite as long as those emitted when the stimulus change occurred early in the schedule in Experiment 1b. It is likely that the longer second-segment pauses observed when the lean component was chained was the result of the relatively weak behavior maintained by the small reinforcer. This is consistent with the observation in Experiment 2a that responding across the rich and lean components was 
controlled primarily by the magnitude of the reinforcer, regardless of which schedule was chained. Specifically, run rates were higher in the rich component than in the lean component.

Table 14. Median pauses in the second segment of the chained FI FI schedule, calculated over the last 10 sessions of each condition in Experiment $2 b$. The interquartile range is shown in parentheses.

\begin{tabular}{|c|c|c|c|c|c|}
\hline \multirow[b]{2}{*}{ Bird } & \multirow[b]{2}{*}{ Condition } & \multicolumn{4}{|c|}{ Transition } \\
\hline & & Lean-Lean & Lean-Rich & Rich-Lean & Rich-Rich \\
\hline \multirow[t]{2}{*}{$20 X$} & Rich & -- & $0.35(0.31-0.40)$ & -- & $0.36(0.31-0.41)$ \\
\hline & Lean & $0.32(0.25-0.37)$ & -- & $0.36(0.29-0.39)$ & -- \\
\hline \multirow[t]{2}{*}{$21 X$} & Rich & -- & $0.37(0.34-0.47)$ & -- & $0.36(0.32-0.45)$ \\
\hline & Lean & $0.68(0.37-2.28)$ & -- & $0.48(0.36-1.49)$ & -- \\
\hline \multirow[t]{2}{*}{$22 X$} & Rich & -- & $0.37(0.30-0.71)$ & -- & $0.37(0.29-1.35)$ \\
\hline & Lean & $0.83(0.32-1.82)$ & -- & $1.08(0.34-2.28)$ & -- \\
\hline \multirow[t]{2}{*}{231} & Rich & -- & $0.24(0.16-0.38)$ & -- & $0.31(0.19-0.44)$ \\
\hline & Lean & $0.39(0.17-0.52)$ & -- & $0.31(0.14-0.49)$ & -- \\
\hline
\end{tabular}

Response rates. Figure 12 is similar to Figures 4 and 10 from Experiments $1 \mathrm{~b}$ and $1 \mathrm{c}$, respectively. Response rates, averaged over the last 10 sessions of each condition, were calculated across tenths of the interval for simple schedules and each segment of the chained schedules. In baseline, all pigeons responded at the lowest rates throughout the interval in the rich-to-lean transition, and at the highest rates in the rich component, regardless of the past reinforcer. Only the response rates of 231were controlled by the past and upcoming component, such that rates were highest in the lean-to-rich component. The response rates emitted by Pigeons 21X and 22X were scalloped throughout the interval in all transitions, while those of 20X and 231 deviated somewhat from this pattern. Pigeon 20X's responding tended to decelerate toward the end of the interval, while 231's responding increased steadily throughout the interval rather than being scalloped. 


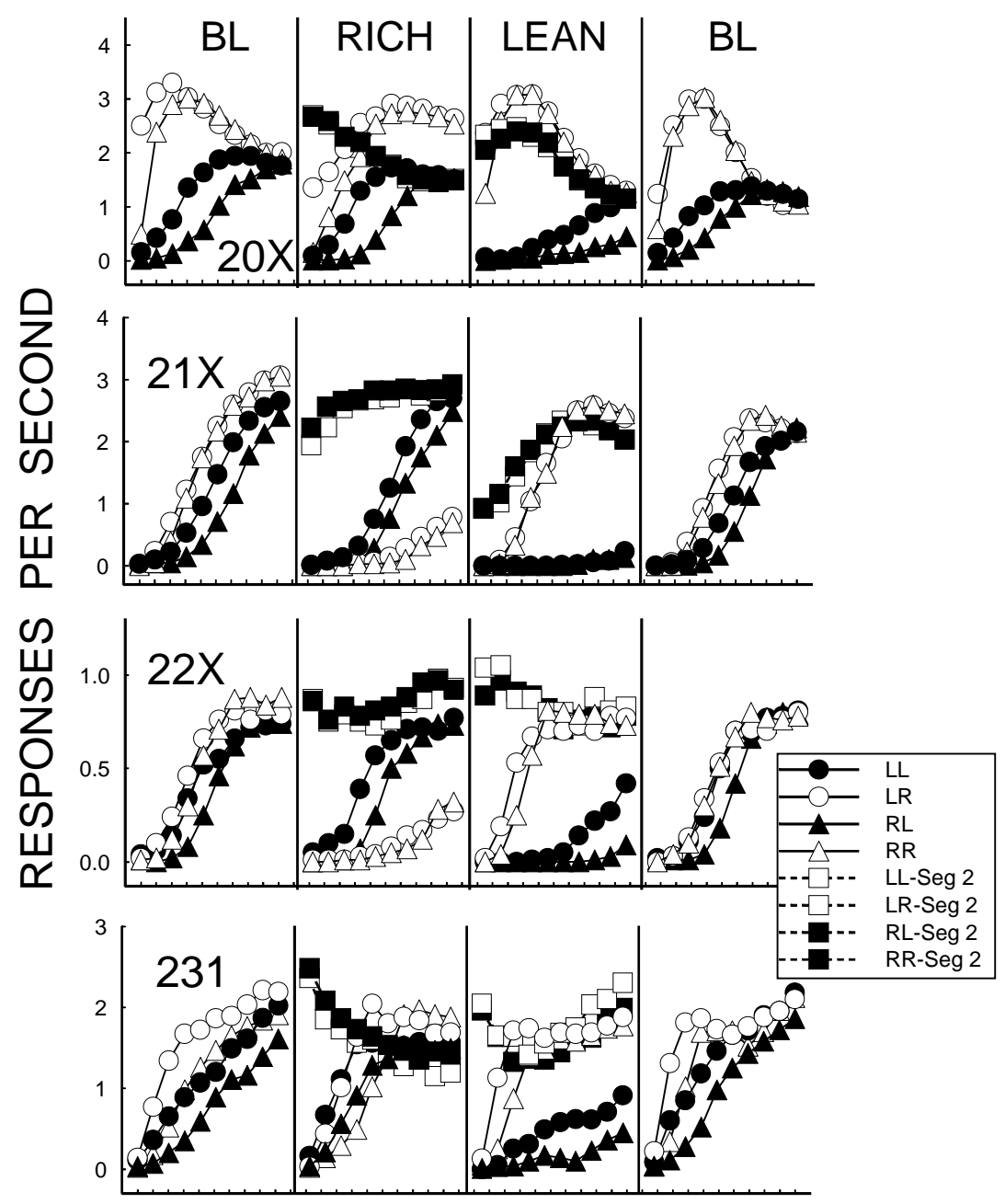

TENTHS OF THE INTERVAL

Figure 12. Average response rate (responses per second) in each tenth of the FI schedules employed in Experiment 2b. Rates were calculated over the last 10 sessions of each condition. The condition labels and other details are as in Figure 11.

When the rich component was chained, the pattern of responding in the lean (unchained) component was similar to baseline. Pigeons $21 \mathrm{X}$ and $22 \mathrm{X}$ responded at low rates throughout the first segment of the rich (chained) component and at high rates throughout the second component. Pigeons 20X and 231 showed a different pattern of responding in the rich component. Rates in the first segment increased and then leveled off as the interval elapsed. In 
the second segment, rates started out high, decelerated, and then leveled off prior to the reinforcer delivery.

When the lean component was chained, response rates in the rich (unchained) component were somewhat scalloped for Pigeons 21X, 22X, and 231, although rates tended to level off prior to the reinforcer. Pigeon 20X responded at relatively high rates early in the simple component, but then slowed down substantially as the interval progressed. For all pigeons, rates in the first segment of the lean (chained) schedule tended to be low and accelerated somewhat later in the interval, particularly in the lean-to-lean component. The pattern of responding in the second segment varied across birds, but these rates were as high as or higher than rates in the rich (unchained) component. When baseline was reinstated, the pattern and level of response rates in all transitions approximated those observed in the initial exposure to baseline.

In summary, the effects of chaining either the lean or rich component in the current experiment produced the predicted effects. First of all, the pattern of pausing obtained in baseline when a lean component was juxtaposed with a rich component was consistent with that reported by Perone and Courtney (1992). That is, pauses were longest in the transition from a rich to a lean component. When the rich component was chained, pauses in the rich-to-lean transition decreased relative to baseline or became less extended relative to pauses in the other transitions. When the lean component was chained, pauses increased in the transitions leading to the lean component, with the longest pauses observed in the rich-to-lean transition. These changes were consistent with the predicted decrease in the favorability of both schedules as the result of segmenting them. These observations support the proposition that the effects observed in Experiment 2a were the result of a relatively lesser difference in the favorability of the simple and chained schedules. Recall that pauses were long when the upcoming component was chained, however, pauses were especially extended in the simple-to-chain transition for just 2 pigeons. In the current experiment, when the favorability of one component was decreased both by segmentation and its correlation with a small reinforcer, pauses in the rich-to-lean transition were more extended than when the components differed only by the reinforcer magnitude.

Consistent with the run rates observed in Experiment 2a, response rates in the current experiment tended to vary according to past and upcoming reinforcer magnitudes. Overall rates on the simple schedules were lowest in the rich-to-lean transition and highest in the transitions to a rich component, regardless of which component was chained. In the chained schedules, 
response rates in the second segment were higher than in the first, but the pattern of responding did not vary as a function of whether the rich or lean component was chained. Response rates in the first segment, however, accelerated to a greater extent when the rich component was chained.

As in Experiment 1b, pauses in the second segment of the chained FI FI schedule were longer than those in the chained FR FR schedule employed in Experiments 1a and 2a. This was particularly the case when the lean schedule was chained.

\section{EXPERIMENT 2c}

The condition in Experiment $2 \mathrm{~b}$ that produced the longest pause durations in the rich-tolean transition was repeated in this experiment, with the addition of a second key that the pigeon could peck to escape from the prevailing schedule conditions. As in Experiment 1c, this manipulation was conducted to test the functional similarity of pausing and escape. It was expected that escape would be greater in the rich-to-lean transition than in the other transitions when the components differed only in the reinforcer magnitude. When the condition from Experiment 2b that engendered the longest rich-to-lean pauses was replicated, escape was expected to increase in the rich-to-lean transition to a similar extent that extended pausing occurred in this transition in Experiment 2b.

\section{Method}

\section{Subjects and Apparatus}

The pigeons and apparatus was the same as in Experiments 2a and $2 \mathrm{~b}$.

\section{Procedure}

The baseline condition of Experiment 2c was the same as that in Experiment 2b (i.e. a multiple FI 60-s FI 60-s schedule, with a lean component and a rich component). In addition, the option to escape was made available at the start of each component according to the same procedure as that employed in Experiment 1c.

In the next condition, the rich component remained a simple FI 60-s schedule, while a chained FI 30-s FI 30-s schedule operated in the lean component. This condition was employed because it was the combination of components that produced the most pausing, particularly in the rich-to-lean transition, in Experiment 2b.

The remaining condition consisted of a return to baseline and throughout all conditions, behavior was judged stable according to the same criterion as in Experiment 1c. 
Results and Discussion.

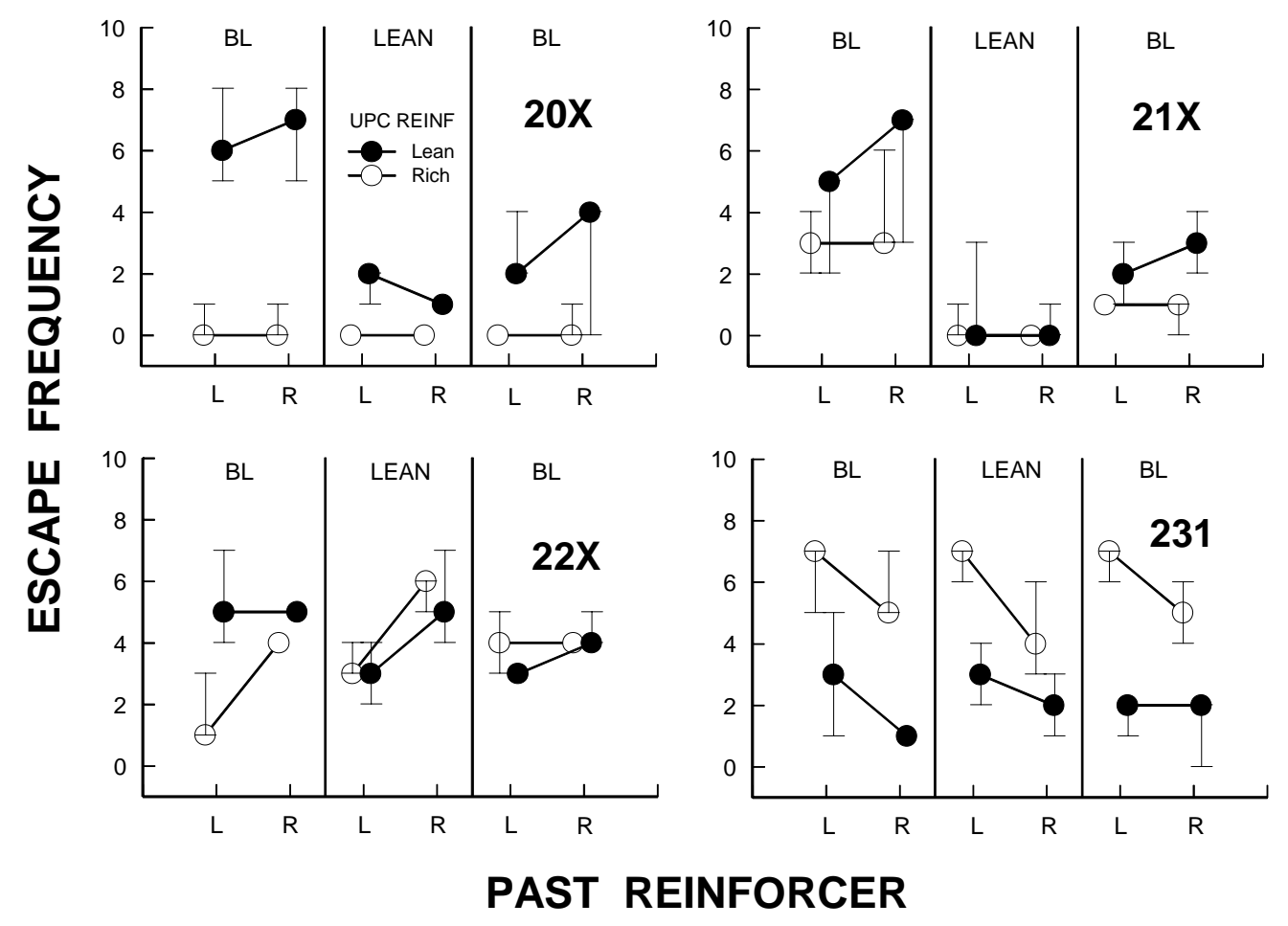

Figure 13. Median escape frequency in the transitions between rich and lean FI schedules calculated over the last 5 sessions of each condition in Experiment 2c. Error bars represent the interquartile range. The condition labels and other details are as in Figure 11.

Escape. Figure 13 shows the median frequency of escape in each transition over the last 5 sessions of each condition. In baseline, escape was more frequent in the lean component for three of the four pigeons (231 was the exception), and for $20 \mathrm{X}$ and $21 \mathrm{X}$, the frequencies were highest in the rich-to-lean transition. When the lean component was chained, none of the pigeons behaved according to the prediction that escape would increase in the rich-to-lean transition relative to baseline. In fact, escape decreased in the lean component for $20 \mathrm{X}$ (for this pigeon, escape rarely occurred in the rich component, and this was unchanged across the remainder of the experiment) and in all transitions for $21 \mathrm{X}$. Pigeon $22 \mathrm{X}$ began to escape more frequently following a rich reinforcer, while the pattern of escape for 231 remained unchanged. When 
baseline was reinstated, the frequencies of escape emitted by $20 \mathrm{X}$ and $21 \mathrm{X}$ returned to the same pattern shown by these pigeons in baseline, but remained lower. Finally, escape following a rich reinforcer decreased slightly for $22 \mathrm{X}$, while the frequencies of escape across transitions continued to remain about the same for 231.

Figure 14 shows the median percentage of the session spent in timeout over the last 5 sessions of each condition. In baseline, a larger percentage of the session was spent in timeout in the lean component, with the exception of 231 who spent larger percentages of the session in timeout in the rich component. Only $21 \mathrm{X}$ showed the highest percentage in the rich-to-lean transition. When the lean component was chained, the only consistent change was that the percentage of the session in timeout in the lean component decreased for $20 \mathrm{X}$ and $21 \mathrm{X}$. For 22X, the percentage decreased in the lean-to-lean transition and increased in the rich-to-lean transition relative to baseline. For 231, the percentage decreased in the rich-to-lean transition. When baseline was reinstated, percentages increased in the lean component for 20X and 21X. The relatively large percentage observed in the rich-to-lean transition decreased for $22 \mathrm{X}$, while percentages stayed about the same as in the previous condition for 231. 

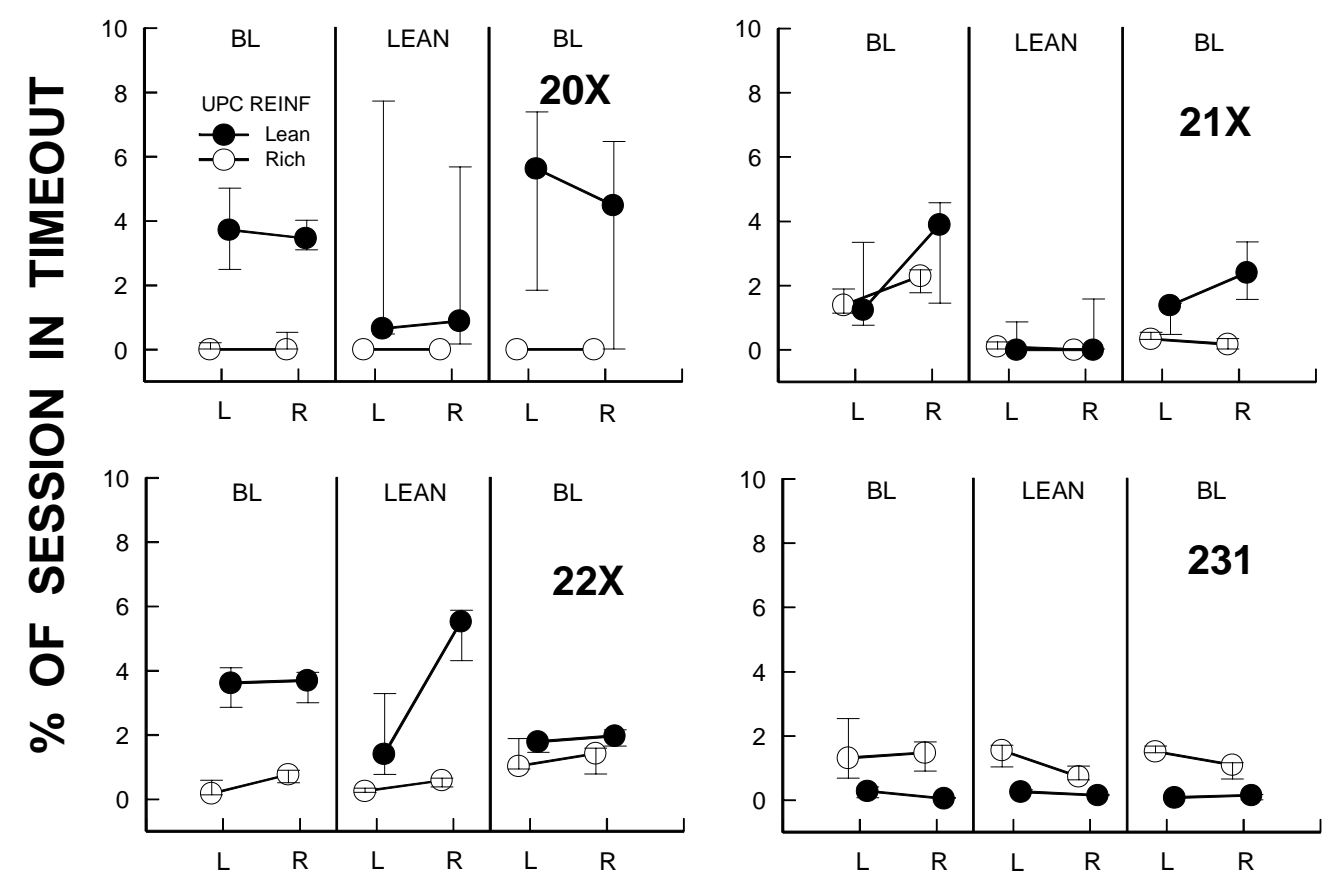

\section{PAST REINFORCER}

Figure 14. Median percent of the session spent in timeout in the transitions between rich and lean FI schedules. Percentages are based on the last 5 sessions of each condition in Experiment 2c and error bars represent the interquartile range. The condition labels and other details are as in Figure 11.

Pauses. Figure 15 shows median pauses in each transition calculated over the last 5 sessions of each condition. As in Experiment 1c (Figure 7), pauses were measured as the time between the start of a component and the first response on the food key, and therefore included any time spent in timeout. In baseline, pausing was elevated in the rich-to-lean transition for $20 \mathrm{X}$ and 231 only. The other pigeons paused longer in the lean component than in the rich component but the rich-to-lean pause was not especially extended relative to the others. When the lean component became chained, however, three pigeons (the exception was 21X) paused substantially longer in the rich-to-lean transition. When baseline was reinstated pausing by these pigeons reverted to levels similar to those observed during baseline. 


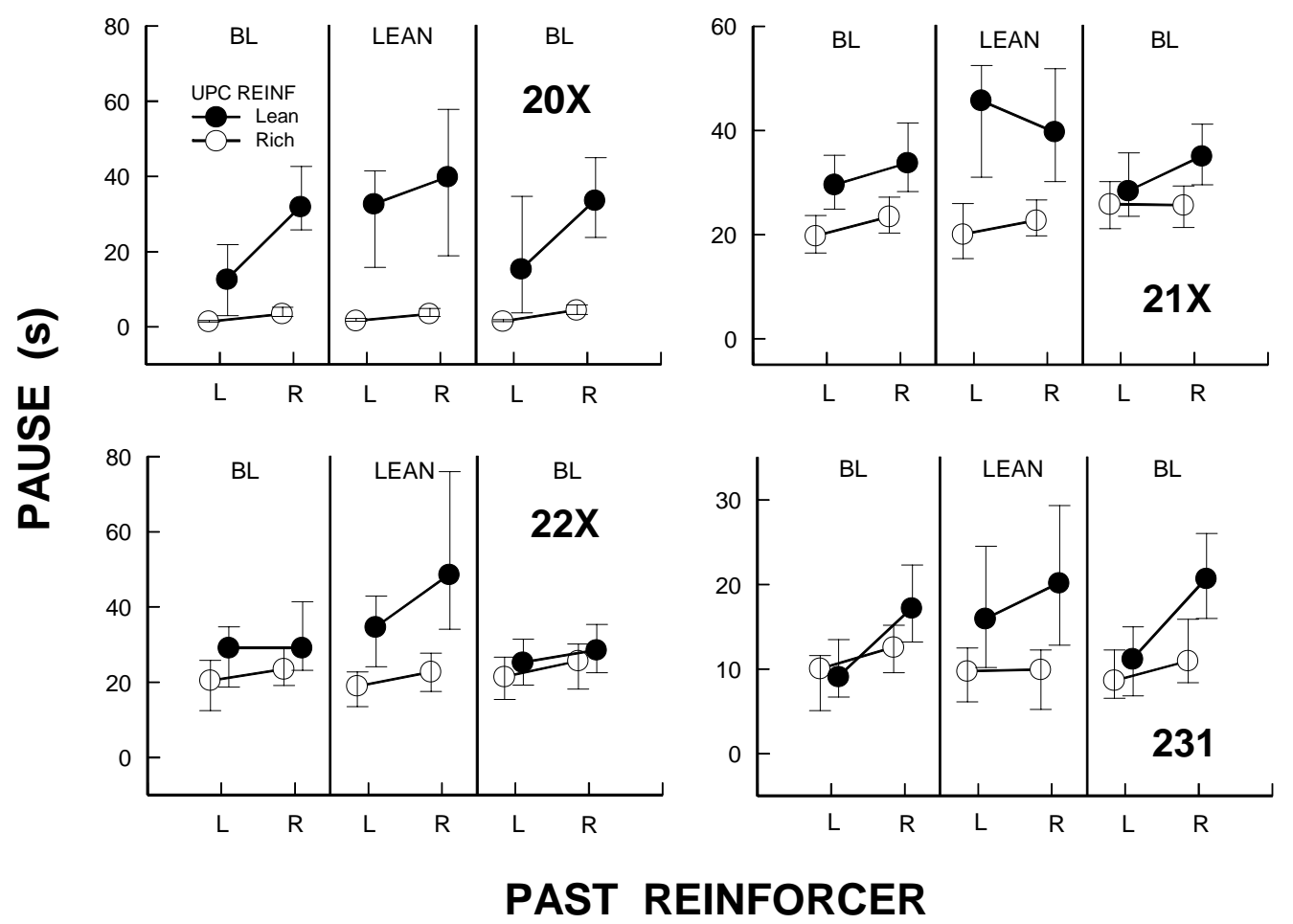

Figure 15. Median pause durations (including any time spent in timeout) in the transitions between rich and lean FI schedules calculated over the last 5 sessions of each condition in Experiment 2c. Error bars represent the interquartile range. The condition labels and other details are as in Figure 11.

Table 15 shows the pauses emitted in the second segment of the chained FI 30-s FI 30-s schedule that operated in the lean component in the second condition of the experiment. Across the chain-to-chain and simple-to-chain transitions, the only difference was that 21X emitted longer second-segment pauses in the lean-to-lean transition than in the rich-to-lean transition. The differences shown by the other pigeons across these transitions were inconsequential. 
Table 15. Median pauses in the second segment of the chained FI FI schedule, calculated over the last 5 sessions of the condition in Experiment 2c in which a chained FI 30-s FI 30-s schedule operated in the lean component. The interquartile range is shown in parentheses.

\begin{tabular}{|c|c|c|c|c|c|}
\hline \multirow[b]{2}{*}{ Bird } & \multirow[b]{2}{*}{ Condition } & \multicolumn{4}{|c|}{ Transition } \\
\hline & & Lean-Lean & Lean-Rich & Rich-Lean & Rich-Rich \\
\hline $20 X$ & Lean & $0.34(0.29-0.39)$ & -- & $0.37(0.32-0.79)$ & -- \\
\hline $21 X$ & Lean & $1.35(0.39-3.34)$ & -- & $0.82(0.35-2.83)$ & -- \\
\hline $22 X$ & Lean & $1.71(0.42-2.93)$ & -- & $1.69(0.73-3.25)$ & -- \\
\hline 231 & Lean & $0.23(0.16-0.41)$ & -- & $0.31(0.18-0.44)$ & -- \\
\hline
\end{tabular}

Response rates. Figure 16 shows average response rates in each tenth of the interval, for the simple FI schedules in both baseline and in the experimental condition, and for each segment of the chained FI 20-s FI 40-s schedule in the experimental condition. Response rates in each tenth of the interval were averaged across the last 5 sessions of each condition. In baseline, all pigeons except 231 responded at higher rates in the rich component throughout the interval. For all pigeons except 22X, behavior deviated in some manner from the scalloped pattern typically produced by FI schedules. For example, 20X's response rates in the rich component accelerated rather dramatically at the start of the interval, and then decelerated as the reinforcer approached. Likewise, the response rates emitted by $21 \mathrm{X}$ decelerated prior to the reinforcer, whereas rates leveled off rather early in the interval for 231. When a chained schedule operated in the lean component, the pattern of responding in the simple component stayed about the same as in baseline. Pigeons $21 \mathrm{X}$ and $22 \mathrm{X}$ responded at low rates in the first segment of the chained schedule, while the other pigeons' rates accelerated throughout the first segment, particularly those in the rich-to-lean transition for 20X. Response rates in the second segment were scalloped only for $21 \mathrm{X}$, whereas they remained relatively high throughout the interval and conformed to various patterns, for the other pigeons. When baseline was reinstated, the pattern of behavior observed in the initial exposure to baseline was reestablished for the most part. 


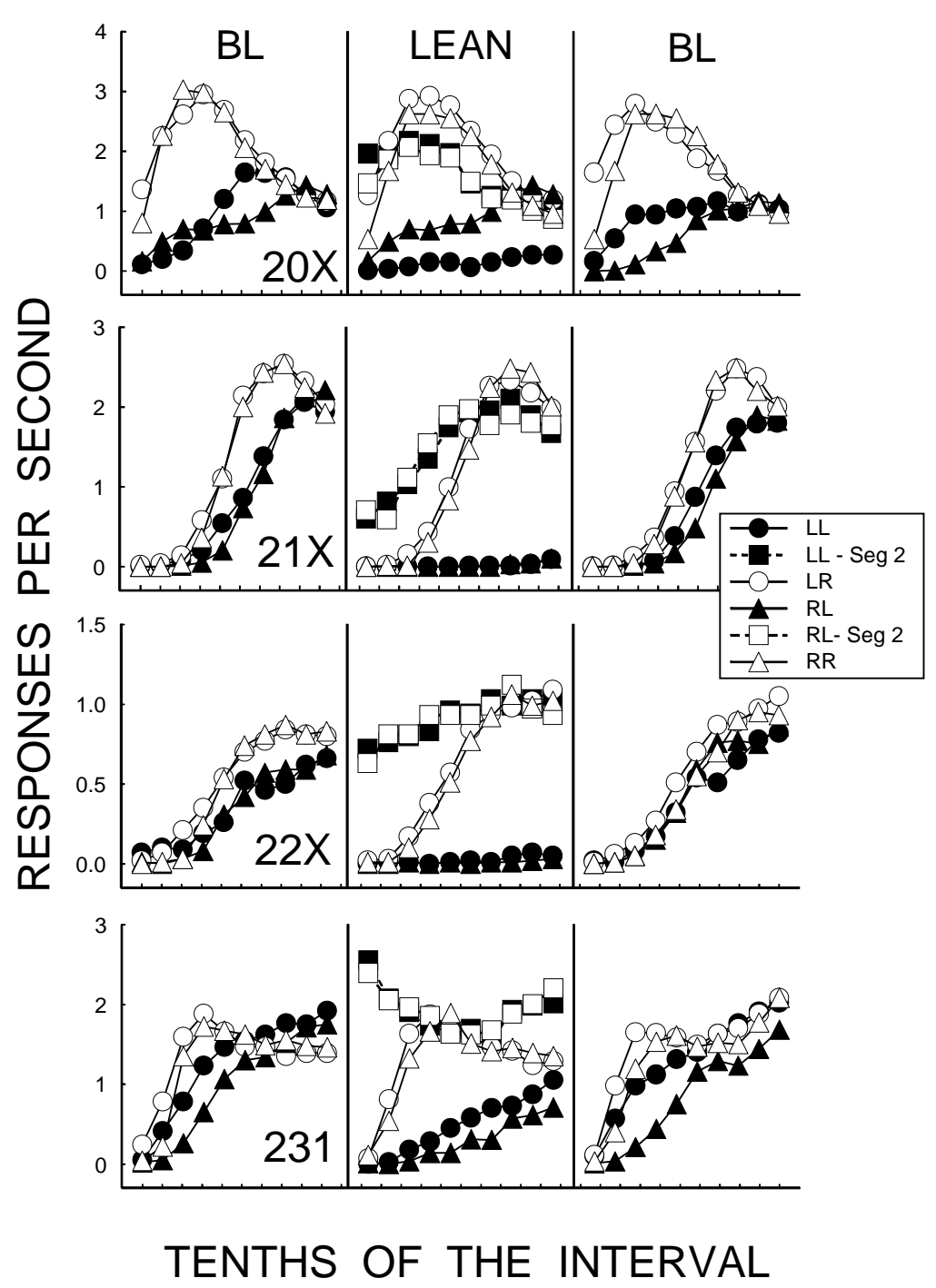

Figure 16. Average response rate (responses per second) in each tenth of the FI schedules employed in Experiment 2c. Rates were calculated over the last 5 sessions of each condition. The condition labels and other details are as in Figure 11.

Overall, the pigeons in the current experiment escaped to a greater extent than those in Experiment 1c. However, as in Experiment 1c, the effects of the present manipulation on escape were inconsistent across pigeons. In baseline, escape was more pronounced in the rich-to-lean transition for just half the pigeons. Pigeon 231 showed a different effect completely; this pigeon escaped more often in the rich component, particularly in the lean-to-rich transition. When the 
lean component became chained, changes in measures of escape varied across pigeons. Only one pigeon showed an effect consistent with predictions; that is, the largest percentage of the session was spent in timeout in the rich-to-lean component when the lean component was chained. As with Experiment 1c, the failure to obtain consistent results cannot be explained by the failure to replicate the effect that segmenting the lean schedule had on pausing in Experiment 2b. In general, that effect was replicated in the current experiment.

\section{General Discussion}

\section{Summary of Findings}

The current study was designed to integrate two research findings. First, research has shown that when a subject (human or nonhuman) is given a choice between a simple schedule and a segmented schedule of equal duration, the simple schedule is reliably preferred (Duncan \& Fantino, 1972; Fantino, 1983; Leung, 1989, 1993). In addition, preference for the simple schedule becomes more extreme as the first segment of the chained schedule is shortened (Leung \& Winton, 1986, 1988). Second, when a relatively favorable schedule is juxtaposed with a relatively unfavorable schedule, behavior becomes disrupted in the transitions from favorable to unfavorable schedule conditions relative to behavior in the other transitions (Bejarano, et al., 2003; Carlin, 1998; Courtney, 1994; Perone \& Courtney, 1992; Wade-Galuska, et al., 2004). The current research attempted to extend the favorable and unfavorable conditions that disrupt behavior to simple and segmented schedules, respectively. This was accomplished by arranging a multiple schedule in which a simple schedule operated in one component and a chained schedule operated in the other. Experiment 1a compared FR and chained FR FR schedules in which the response requirement in the first segment varied across conditions. Although a couple of the subjects behaved in accordance with the prediction that pauses would be extended in the transition from a simple schedule to a chained schedule, particularly when the first segment was short, this result was not shown consistently across all of the pigeons. In Experiment 1b, FI schedules were studied instead of FR schedules. The results were similar to those of Experiment 1a; pauses were extended in the transition from a simple FI to a chained FI FI schedule in which the first segment was short, but the effect was unreliable, appearing in only half the subjects. Experiment 1c replicated the conditions in Experiment 1b that produced the most consistent result (i.e., the simple FI schedule and chained FI FI schedule with a short initial segment) and added an escape contingency: The pigeons could peck an additional response key to initiate a 
timeout in which the schedule-correlated stimuli were turned off. While there was some tendency for the pigeons to escape from the simple-to-chained transition, the effect was inconsistent.

In Experiment 2a, simple FR and chained FR FR schedules were compared as in Experiment 1a. In this case, the schedules differed also in the magnitude of the reinforcer. Across conditions, either the rich component (ending in a large reinforcer) or the lean component (ending in small reinforcer) was chained and the length of the first component of the chained schedule varied. When the lean schedule was least favorable relative to the rich schedule (i.e., when it was chained and the first segment was short), pausing in the rich-to-lean transition was expected to be longest. When the lean schedule was more favorable relative to the rich schedule (i.e., when the rich schedule was chained and the first segment was short), pausing was expected to be shortest. The results did not conform to predictions and no consistent changes in pausing as the result of the aforementioned manipulations were observed. In Experiment 2b, FI schedules were employed and the length of the first segment of the chained schedule was not varied. In this experiment, the predicted effects were obtained. When the lean schedule was chained, pauses in the rich-to-lean transition were longer than in baseline. When the rich schedule was chained, rich-to-lean pauses did not change relative to baseline, but did become less extended relative to pauses in the other transitions. In Experiment 2c, pigeons could escape from the prevailing schedule conditions. Although there was a tendency for pigeons to escape from the rich-to-lean transition in baseline, only one pigeon escaped at a higher rate when the lean schedule was chained.

In summary, the results of Experiment 2b showed that, while the segmentation of the schedule alone was not sufficient to produce extended pauses in the transitions from simple to chained schedules, this manipulation combined with the manipulation of reinforcer magnitude did produce the anticipated effects. Specifically, segmenting the rich and lean schedules appeared to modulate the disruption in behavior produced by manipulating reinforcer magnitude alone. A couple of questions are raised by these results. First, why was behavior not disrupted as the result of schedule segmentation alone? Second, why did the combination of reinforcer magnitude and schedule segmentation produce effects with FI schedules, but not FR schedules? In the sections below, the relative favorability of the components will be discussed as a critical variable in answering the first question. In answering the second question, differences in behavior maintained by FI and FR schedules will be discussed with relation to how these 
distinctions may have played a role in the attainment of the present results. In the last sections, the contribution of the present research to the determination of a relation between pausing and escape and the prospective applied implications of the present research will be considered. Relative Favorability of the Components

One explanation for the present results focuses on the overall degree of favorability across the two components of the multiple schedule. Recall that in Experiments 1a and 1b, inconsistent results were obtained when a simple schedule was juxtaposed with a chained schedule. Perhaps the degree to which the simple schedule was favored over the chained schedule was insufficient to produce the disruption in behavior typically observed in the transition from favorable conditions (in this case, the simple schedule) to unfavorable conditions (in this case, the chained schedule) of reinforcement. In fact, studies have been mixed with respect to the degree to which pigeons prefer a simple schedule to a chained schedule. For example, pigeons in Duncan and Fantino's (1972) study almost exclusively preferred an FI 30-s schedule to a chained FI 15-s FI 15-s schedule, while pigeons in Fantino’s (1983) study showed just a weak preference for a simple FI 30-s schedule over a chained FI 15-s FI 15-s schedule. Perone and Courtney (1992) reported data that illustrate how an increase in favorability across the schedules being compared may be required to produce a disruption in behavior in the simpleto-chain transition. They exposed one pigeon to a multiple FR FR schedule in which one component ended in 2-s access to grain and the other in 6-s access to grain. Under these circumstances, one of their pigeons paused at minimal levels and without differentiation across transitions. After changing the reinforcer magnitudes from 2-s and 6-s to 1-s and 7-s access to grain, however, the rich-to-lean pause increased to approximately $30 \mathrm{~s}$ while pauses in the other transitions remained brief.

One way to increase the discrepancy in favorability between the simple and chained schedules in Experiments $1 \mathrm{a}$ and $1 \mathrm{~b}$ is to increase the total schedule requirement (the total number of responses in the case of FR schedules or the interval lengths in the case of FI schedules) of the simple and chained schedules. Previous studies have shown that increasing the total duration of the simple and chained schedules results in more extreme preference for the simple schedule (Duncan \& Fantino, 1972; Leung \& Winton, 1985). As mentioned previously, the response requirement of the FR and chained FR FR schedules in Experiment 1a was the maximum response requirement that could maintain responding during pretraining. So, 
increasing the total response requirement was not a feasible option. On the other hand, the total duration of the simple FI and chained FI FI schedules in Experiment 1b was 1 min. This duration was chosen because it has produced appreciable levels of choice for the simple schedule over a chained schedule in previous studies (Fantino, 1983; Leung, 1994; Leung \& Winton, 1985). It does not follow from this, however, that the levels of preference obtained in the previous studies were sufficient to produce extended pauses in the transition from simple to chained schedules as studied in the present research. To date, no study has systematically investigated the relation between preference among various conditions of reinforcement and the degree of pausing obtained when these conditions are irregularly alternated in the components of a multiple schedule.

Another way to increase the difference in favorability across the simple and chained schedules is to implement an additional manipulation that would further increase or decrease the favorability of these schedules, respectively. This is what was done in Experiments 2a and 2b. In these experiments, both reinforcer magnitude and schedule segmentation were studied. In Experiment $2 \mathrm{~b}$ pauses in the rich-to-lean transition increased when the lean schedule (ending in a small reinforcer) was chained and decreased when the rich schedule (ending in a large reinforcer) was chained. This is consistent with the idea that an increase in the difference in the favorability across simple and chained schedules may be required to produce appreciable disruptions, or extended pauses, in behavior in the transitions from simple to chained schedules. Additional support comes from a study conducted by Bejarano, et al. (2003). To disrupt behavior in a richto-lean transition in a human subject, the authors had to juxtapose a high response requirement with a low reinforcer magnitude in one component of a multiple schedule with a low response requirement and a high reinforcer magnitude in the other.

FR versus FI schedules

Combining the manipulation of reinforcer magnitude with the segmentation of the schedule produced an effect only in Experiment 2b when FI schedules were employed (inconsistent results were obtained in Experiment 2a when these parameters were varied across FR schedule components). This raises questions about differences in behavior maintained by FR and FI schedules. When FR schedules were used in Experiments 1a and 2a, results were inconsistent. In light of this, FI schedules were used in similar manipulations in Experiments 1b and $2 \mathrm{~b}$. The reason was that the majority of studies assessing preference between simple and 
chained schedules used time-based schedules. No studies were found that assessed preference between simple FR and chained FR FR schedules. As previously stated, FR schedules initially were used in the present study because they tend to produce long and counterproductive pauses in behavior. FI schedules produce long pauses as well, but on these schedules, pauses may constitute efficient (rather than counterproductive) behavior. Because a certain amount of time must elapse before a response can be reinforced on an FI schedule, pauses in responding that do not exceed the interval are considered efficient because fewer responses are emitted per reinforcer. That being said, when a chained FI 20-s FI 40-s schedule was employed in Experiment 1b, pauses on the chained schedule were elevated relative to those on the simple schedule. More importantly, these pauses often exceeded the interval requirement (i.e., 20 s), unnecessarily delaying access to the second segment of the schedule and the food that results from completing the response requirement in that segment. Therefore, extended pausing on chained FI FI schedules potentially can be counterproductive, as on FR schedules.

One reason why the use of FI schedules, but not FR schedules, may have produced the intended effects in the current study involves the response pattern engendered by each. Recall that the simple FR schedule operated no differently from the chained FR FR schedule and that the pigeons tended to peck through the stimulus change that occurred at the onset of the second segment (shown by the consistently short second-segment pauses). Research has shown, in fact, that responses allocated toward completing the ratio requirement of an FR schedule tend to occur as a unit that is not easily disrupted once responding begins (Skinner, 1938). This behavior pattern may have resulted in decreased sensitivity to the independent response requirements of the segments of the chained schedule. Under these circumstances, the simple schedule would not be expected to differ in favorability from the chained schedule.

Another difference between FR and FI schedules that could have contributed to the current results is the correlation between the rate of responding on an FR schedule and the time to reinforcement, a correlation that does not exist on an FI schedule. That is, the faster a subject responds on an FR schedule, the sooner the reinforcer will be delivered. On an FI schedule, a response will not be reinforced until the interval has elapsed, no matter what the subject does, and this may make the chained FI FI schedule more aversive relative to the simple FI schedule than the chained FR FR schedule is relative to a simple FR schedule. 
A couple of the reasons posed for why a simple FI schedule is preferred to a chained FI FI schedule comprises another potential explanation for the effect observed with FI schedules, but not FR schedules, in the current study. First, a chained FI FI schedule requires additional work (i.e., the response required to gain access to the second segment) that is not required by its simple schedule counterpart. Second, this “extra work” is required during a discriminable period in which reinforcement is unavailable. As discussed earlier, there is mixed support for the interpretation that the extra work requirement is responsible for preference for a simple FI schedule over a chained FI FI schedule. However, while the chained FR FR schedule also requires responding during a discriminable period of nonreinforcement, this schedule does not require additional work relative to the simple FR schedule. Perhaps this (alone or in addition to the aforementioned possibilities) resulted in the functional similarity of the simple FR and chained FR FR schedule and in the lack of an effect of the juxtaposition of these schedules on pausing, with or without the manipulation of reinforcer magnitude across the components. Escape

The effects of the manipulations on escape in Experiments 1c and 2c did not conform to predictions. In Experiment 1c, just half the pigeons escaped more frequently in the transition from a simple to a chained schedule, but the conclusion that this constituted an effect was precluded by the fact that escape was so infrequent. Nonetheless, if the possibility of an effect were entertained for these pigeons, the mixed finding would be consistent with the fact that the results (with respect to pausing) of Experiments $1 \mathrm{~b}$ and 1c also were mixed.

The effects of juxtaposing rich and lean FIs on escape in the baseline condition of Experiment 2c were consistent with predictions for three of the four pigeons (when both the escape frequency and the percentage of the session spent in timeout are considered) and replicate previous findings. For example, Perone (2003) reported the results of an experiment that employed Perone and Courtney's (1992) general procedure with the addition of the opportunity to escape in half of the exposures to each type of transition between rich and lean FR schedules. Across conditions, pausing and escape were measured across conditions as the FR size was increased. Consistent with Perone and Courtney’s (1992) results, when the FR size reached 60, pauses became extended in the rich-to-lean transition. This effect intensified as the FR size was increased further. In addition, a corresponding increase in the frequency of escape with the 
increases in FR size was observed, indicating that both phenomena may function similarly to reduce contact with the stimuli associated with reinforcement.

When the lean schedule was chained in Experiment 2c, escape did not increase in the simple-to-chain transition relative to baseline as predicted, although pauses were consistent with those observed in Experiment 2b. This does not support the congruency between the levels of pausing and escape reported by previous studies. In fact, in many cases and for reasons unknown, escape decreased in this condition relative to baseline.

\section{Applied Significance}

Shifts from favorable to unfavorable conditions of reinforcement have been shown to result in pronounced disruptions in behavior. The generality of this phenomenon transcends species boundaries, having been shown in rats, pigeons, and most recently, a human subject. In addition, the conditions of reinforcement that can be varied along a continuum of favorability to produce this effect have been extended to several parameters of reinforcement as well as combinations of parameters. The next logical step is to develop a bridge between the basic research findings and the applied setting. Bejarano, et al. (2003) discuss the need for such a bridge as a way for basic research to translate its findings to application and vice-versa. In the remainder of this section, the manifestation of negative incentive shifts in applied populations will be discussed, as well as a way for basic research to contribute to solutions to these problems.

The disruption in behavior observed in the transitions between favorable and unfavorable conditions in the pigeon chamber take the form of pauses and key pecks that reduce contact with or turn off stimuli correlated with the upcoming conditions of reinforcement. Aberrant behaviors emitted by persons with developmental disabilities and mental retardation (e.g., aggression, destruction, tantrums) may also function as a form of escape from having to engage in relatively unfavorable behavior such as compliance with a request or completion of a demanding task (Carr, 1994; Iwata, et al., 1994). One type of environment that may engender escape or other offtask behaviors is the aversive transition from favorable to unfavorable activities, settings, rewards, or other conditions (Bejarano, et al., 2003). In fact, Carr (1994) suggested that a next step in determining the functions of problem behavior is to examine the context in which the behavior occurs, including the sequencing of tasks and activities. If this assessment is accurate, basic research in the experimental analysis of behavior may contribute to the application of treatments aimed at decreasing the aversiveness of these incentive shifts. For example, some 
studies have suggested ways in which the disruption in behavior in the transitions from a rich to a lean schedule may be reduced. Perone (2003) presented data showing that the removal of the stimuli associated with upcoming reinforcement conditions (i.e., employing a mixed rather than a multiple schedule) resulted in decreased pausing and escape in the critical rich-to-lean transition. Similarly, Galuska (2003) found that by increasing the number of rich components in a session (and thereby decreasing the number of rich-to-lean transitions in a session), pausing in the richto-lean transitions could be attenuated. In Experiment 2b of the current study, pauses in the richto-lean transition were decreased relative to pauses in the other transitions by segmenting the rich schedule.

While the aforementioned manipulations can be conducted rather easily to reduce pausing and escape in the laboratory, the development of an applied intervention based on these manipulations is surely more challenging. It was cited that the elimination of signals correlated with the upcoming reinforcer magnitude decreased pausing and escape in the transition from rich to lean schedules. How feasible, however, would it be to conduct such a manipulation in an applied setting? To answer this, a distinction must be made between an institutional setting in which some intervention is being conducted to reduce problem behavior in a person with developmental disabilities, mental retardation, or other disorder, and the everyday environment in which control over stimuli correlated with conditions of reinforcement is more limited. In the former case, stimuli might be removed so that the magnitude or quality of the reinforcer to be delivered following each task or aspect of the treatment is unknown by the participant. This potentially could eliminate problem behaviors that otherwise would occur in the transitions from a favorable to an unfavorable aspect of the program. In an everyday environment, removing such stimuli is more difficult. For example, when going to work on a Monday morning, it is impossible to remove all stimuli signaling the day of the week. Likewise, children may become disruptive in math class, particularly when the previous activity of the day was recess. Again, the stimuli correlated with math class are inherent in the situation and cannot be removed. Nonetheless, if the transition from one set of circumstances to another can be identified as the primary variable responsible for problem behavior, it may be possible to attenuate such behavior by decreasing the difference in favorability across the conditions. For example, perhaps the "richness" of recess could be decreased if supervision was in place, students had to engage in more subdued activities, or if there was a cool-down period following play and prior to 
commencing with afternoon classes. On the other hand, increasing the amount of reinforcement available in the classroom would accomplish the same objective by making a relatively unfavorable part of the day more favorable.

Another potential method for decreasing disruptive behavior in a favorable-tounfavorable transition is to apply a principle of reinforcement known as Premack's principle (Mazur, 2002). According to this principle, a less probable behavior will increase in frequency (i.e., be reinforced) if it is followed by a more probable behavior (Premack, 1959, 1961). For example, the probability of a child doing homework after school would be expected to increase if, following completion of homework, the child is permitted to play video games. In this case, the act of playing video games (the more probable behavior) reinforces doing homework (the less probable behavior). Such an arrangement may serve to reduce the aversiveness of a transition from favorable-to-unfavorable conditions of reinforcement; that is, if playing video games was not contingent upon doing homework, the child may find the transition between coming home from school and doing homework rather aversive and may exhibit problem behavior as a result. Because homework results in the ability to play video games, however, the aversiveness of the transition between coming home from school and doing homework would be expected to decrease (resulting in a corresponding decrease in disruptive behaviors that may otherwise occur).

In summary, basic research findings may help not only to identify the environmental variables controlling disruptive and off-task behavior, but also to develop interventions to reduce such behavior. Practical considerations limit the likelihood that every basic finding will be translated directly to an application; however, basic research may still provide a general processoriented framework for the development of realistic treatments.

\section{Conclusions}

The results of the present study replicated the finding that discriminable shifts from relatively favorable to relatively unfavorable conditions of reinforcement can engender disruptions in behavior in the forms of extended pausing and escape. However, the results suggest the possibility that an appreciable difference in favorability across these conditions is needed to produce this effect. The relation between the degree of preference for one context over another and the extent to which behavior is disrupted in the transitions between these contexts should be examined more closely. Another notable result of the present research is the finding 
that the relative favorability of reinforcement conditions can be altered by manipulating more than one parameter. This supports the contention that disruptive or off-task behaviors in the favorable-to-unfavorable transitions (whether it is in the laboratory or applied setting) may be engendered by multiple aspects of the overall context of reinforcement. 


\section{References}

Baron, A., \& Herpolsheimer, L.R. (1999). Averaging effects in the study of fixed-ratio response patterns. Journal of the Experimental Analysis of Behavior, 71, 145-153.

Baron, A., Mikorski, J., \& Schlund, M. (1992). Reinforcement magnitude and pausing on progressive-ratio schedules. Journal of the Experimental Analysis of Behavior, 58, 377388.

Bejarano, R., Williams, D.C., \& Perone, M. (2003). Pausing on multiple schedules: Toward a laboratory model of escape-motivated behavior. Experimental Analysis of Human Behavior Bulletin, 21, 18-20.

Belke, T.W., Pierce, D.W., \& Powell, R.A. (1989). Determinants of choice for pigeons and humans on concurrent-chains schedules of reinforcement. Journal of the Experimental Analysis of Behavior, 52(2), 97-109.

Carlin, L.A. (1998). Pausing and escape on fixed-interval schedules: Effects of stimuli correlated with different reinforcer magnitudes and different reinforcement rates. Unpublished doctoral dissertation, West Virginia University.

Carr, E.G. (1994). Emerging themes in the functional analysis of problem behavior. Journal of Applied Behavior Analysis, 27, 393-399.

Cohen, P.S., \& Campagnoni, F.R. (1989). The nature and determinants of spatial retreat in the pigeon between periodic grain presentations. Animal Learning and Behavior, 17, 39-48.

Courtney, K. (1994). Pausing on fixed-ratio and fixed-interval schedules of food reinforcement: Tests of the escape hypothesis. Unpublished doctoral dissertation, West Virginia University.

Duncan, B., \& Fantino, E. (1972). The psychological distance to reward. Journal of the Experimental Analysis of Behavior, 18, 23-34.

Fantino, E. (1969a). Choice and rate of reinforcement. Journal of the Experimental Analysis of Behavior, 12(5), 723-730.

Fantino, E. (1969b). Conditioned reinforcement, choice, and the psychological distance to reward. In D.P. Hendry (Ed.), Conditioned reinforcement (pp. 163-191). Homewood, IL: Dorsey Press.

Fantino, E. (1983). On the cause of preference for unsegmented over segmented reinforcement schedules. Behaviour Analysis Letters, 3, 27-33. 
Ferster, C.B., \& Skinner, B.F. (1957). Schedules of reinforcement. New York: AppletonCentury-Crofts.

Galuska, C. (2003). Reducing pausing during rich-to-lean schedule transitions: Effects of reinforcer context and cue accuracy. Unpublished doctoral dissertation, West Virginia University.

Iwata, B.A., Pace, G.M., Dorsey, M.F., Zarcone, J.R., Vollmer, T.R., Smith, R.G., Rodgers, T.A., Lerman, D.C., Shore, B.A., \& Mazalesk, J.L. (1994). The functions of selfinjurious behavior: an experimental-epidemiological analysis. Journal of Applied Behavior Analysis, 27, 215-240.

Kelleher, R.T., and Fry, W.T. (1962). Stimulus functions in chained fixed-interval schedules. Journal of the Experimental Analysis of Behavior, 5, 167-173.

Lattal, K.A. (1991). Scheduling positive reinforcers. In I.H. Iversen (Ed.) \& K.A. Lattal (Ed.), Experimental analysis of behavior, Parts 1 \& 2: Techniques in the behavioral and neural sciences, Vol. 6 (pp. 87-134). New York, NY: Elsevier Science.

Leung, J.P. (1987). Preference for less segmented over more segmented reinforcement schedules: Stimulus and response factors. Behavioural Processes, 15(2-3), 305-313.

Leung, J.P. (1989). Psychological distance to reward: A human replication. Journal of the Experimental Analysis of Behavior, 51(3), 343-352.

Leung, J.P. (1993). Psychological distance to reward: Segmentation of aperiodic schedules of reinforcement. Journal of the Experimental Analysis of Behavior, 59(2), 401-410.

Leung, J.P. (1994). Psychological distance to reward: The aversiveness of the first component stimulus in a chain. Behavioural Processes, 32(1), 67-77.

Leung, J.P. \& Winton, A.S. (1985). Preference for unsegmented interreinforcement intervals in concurrent chains. Journal of the Experimental Analysis of Behavior, 44(1), 89-101.

Leung, J.P. \& Winton, A.S. (1986). Preference for less segmented fixed-time components in concurrent-chains schedules of reinforcement. Journal of the Experimental Analysis of Behavior, 46(2), 175-183.

Leung, J.P. \& Winton, A.S. (1988). Preference for simple interval schedules of reinforcement in concurrent-chains: Effect of segmentation ratio. Journal of the Experimental Analysis of Behavior, 49, 9-20. 
Mazur, J.E. (2000). Two- versus three- alternative concurrent-chains schedules: A test of three models. Journal of Experimental Psychology: Animal Behavior Processes, 26(3), 286293.

Mazur, J. (2002). Learning and Behavior (5 ${ }^{\text {th }}$ ed.). New Jersey: Prentice Hall.

Moore, J., \& Fantino, E. (1975). Choice and response contingencies. Journal of the Experimental Analysis of Behavior, 23(3), 339-347.

Neuringer, A. (1969). Delayed reinforcement versus reinforcement after a fixed interval. Journal of the Experimental Analysis of Behavior, 12, 375-383.

Perone, M. (2003). Negative effects of positive reinforcement. The Behavior Analyst, 26, 1-14.

Perone, M., \& Courtney, K. (1992). Fixed-ratio pausing: Joint effects of past reinforcer magnitude and stimuli correlated with upcoming magnitude. Journal of the Experimental Analysis of Behavior, 57, 33-46.

Premack, D. (1959). Toward empirical behavior laws: I. Positive reinforcement. Psychological Review, 66, 29-31.

Premack, D. (1961). Predicting instrumental performance from the independent rate of the contingent response. Journal of experimental psychology, 61, 163-171.

Schneider, J.W. (1972). Choice between two-component chained and tandem schedules. Journal of the Experimental Analysis of Behavior, 18(1), 45-60.

Skinner, B.F. (1938). The Behavior of Organisms. New York: Appleton-Century-Crofts.

Takahashi, M. (1993). Psychological distance to reward in monkeys. Behavioural Processes, 30(3), 299-308.

Wade-Galuska, T., Perone, M., \& Wirth, O. (2004). Effects of past and upcoming response-force requirements on fixed-ratio pausing. Manuscript submitted for publication. 